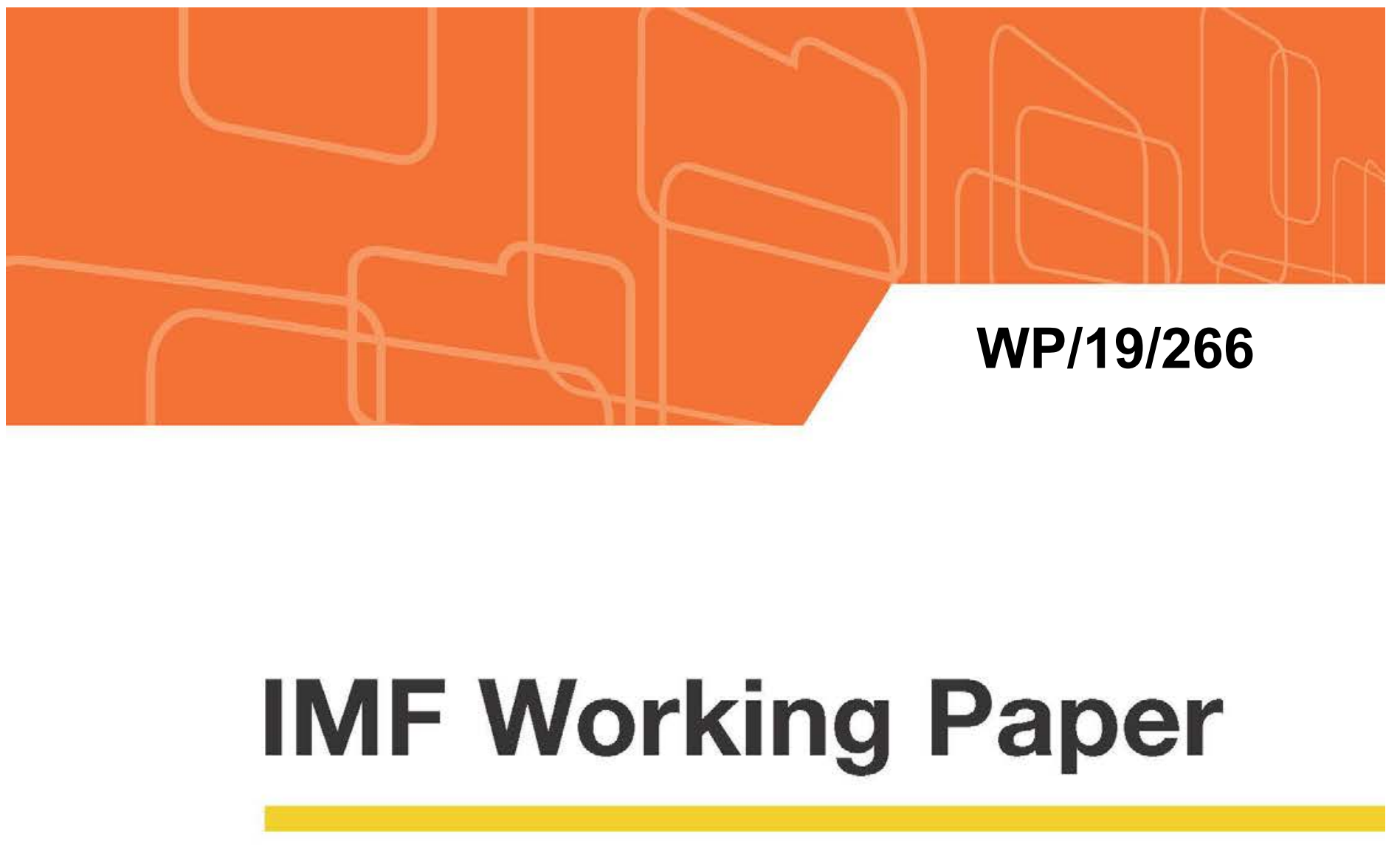

\title{
Sovereign Risk in Macroprudential Solvency Stress Testing
}

by Andreas A. Jobst and Hiroko Oura

IMF Working Papers describe research in progress by the author(s) and are published to elicit comments and to encourage debate. The views expressed in IMF Working Papers are those of the author(s) and do not necessarily represent the views of the IMF, its Executive Board, or IMF management. 


\title{
IMF Working Paper
}

Monetary and Capital Market Department

\author{
Sovereign Risk in Macroprudential Solvency Stress Testing \\ Prepared by Andreas A. Jobst and Hiroko Oura \\ Authorized for distribution by Martin Čihák
}

December 2019

IMF Working Papers describe research in progress by the author(s) and are published to elicit comments and to encourage debate. The views expressed in IMF Working Papers are those of the author(s) and do not necessarily represent the views of the IMF, its Executive Board, or IMF management.

\begin{abstract}
This paper explains the treatment of sovereign risk in macroprudential solvency stress testing, based on the experiences in the Financial Sector Assessment Program (FSAP). We discuss four essential steps in assessing the system-wide impact of sovereign risk: scope, loss estimation, shock calibration, and capital impact calculation. Most importantly, a market-consistent valuation approach lies at the heart of assessing the resilience of the financial sector in a tail risk scenario with sovereign distress. We present a flexible, closed-form approach to calibrating haircuts based on changes in expected sovereign defaults affecting bank solvency during adverse macroeconomic conditions. This paper demonstrates the effectiveness of using extreme value theory (EVT) in this context, with empirical examples from past FSAPs.
\end{abstract}

JEL Classification Codes: G12, G21, G28

Keywords: FSAP, macroprudential, sovereign risk, stress testing, valuation haircut Authors’ E-Mail Addresses: ajobst@imf.org; houra@imf.org 


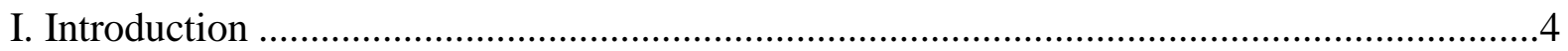

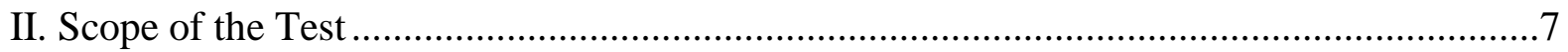

III. Method to Estimate Potential Losses .............................................................................11

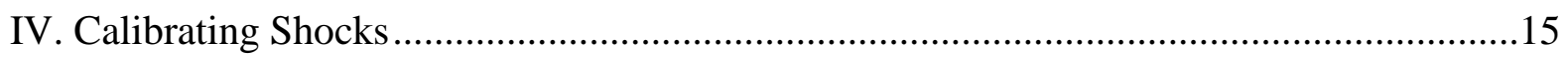

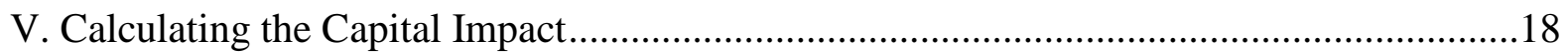

VI. Empirical Application: Examples from Stress Tests in FSAPs for Selected European

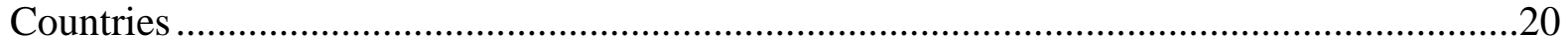

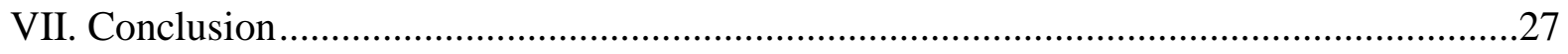

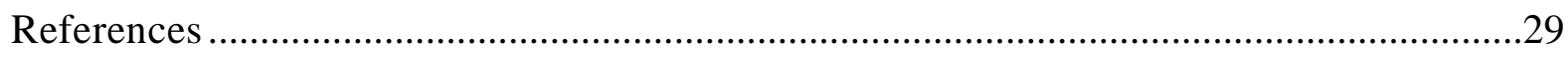

Figures

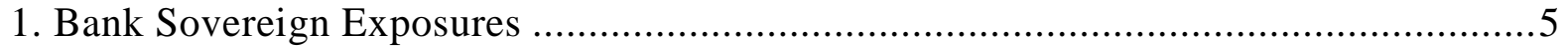

2. Conceptual Difference between Expected and Unexpected Losses .............................11

Tables

1.Treatment of Sovereign Exposures in Mandatory IMF FSAPs and European

System-wide Stress Tests...........................................................................................

2. Treatment of Sovereign Exposures in IMF FSAPs for Non-European Union S-29

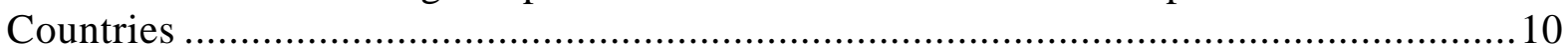

3. Asset Valuation Rules........................................................................................ 12

4. Comparison of Sovereign Valuation Haircut Methods in IMF FSAP and EU

System-wide Stress Tests...................................................................................2

5. Comparison of Sovereign Valuation Haircuts in European Stress Tests (2010-2011)

and Results in IMF Stress Testing (Percent) ................................................................26

Appendices

I. Interaction and Feedback between the Sovereign and Financial .................................34

II. Estimating Valuation Haircuts for Sovereign Risk ....................................................... 36

III. Moments of the GEV Distribution and Estimation of the Shape Parameter Using the

Linear Combination of Ratios of Spacings (LRS) Method ..............................................5 54

IV. Credit Risk-Based Approach to Estimating Expected Losses of HtM Sovereign

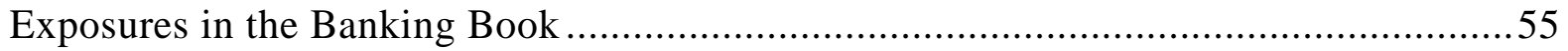

V. Detailed Estimation Results: Valuation Haircuts....................................................56

VI. Causes for High Sovereign Exposures in the Banking Sector .................................58 


\section{INTRODUCTION ${ }^{1}$}

1. Sovereign distress has been a significant source of systemic financial risk in many countries where banks hold large exposures to the public sector. In advanced economies (AEs), bank claims on domestic government debt range from a few percents of bank assets (e.g., Sweden and Switzerland) to more than 10 percent of assets (e.g., Italy, Japan, and Spain; see Figure 1). In many emerging market and developing economies (EMDEs), sovereign exposures are twice as high as in advanced economies (AEs) on average and particularly large in Argentina, Brazil, China, Egypt, Hungary, India, and Mexico. A broader definition of sovereign exposures (see Box 1), which includes sub-national governments, lending (i.e., loans and receivables), and sovereign guarantees, more than doubles these amounts. ${ }^{2}$

2. In addition to the sheer size of exposures, sovereign risk could affect banks' solvency through a wide range of transmission channels with potentially complex feedback effects. Unlike private-sector debt, where individual default is frequent (but the effects are diversified among many counterparties), sovereign default occurs rarely but has wide-ranging consequences. Sovereign risk also results in many hard-to-assess spillover effects across sectors and countries, which can further amplify the bank-sovereign nexus. Sovereign distress can take many forms, including (i) outright default or restructuring, (ii) a technical default (e.g., missing payments if there is no fundamental debt sustainability problem), (iii) currency redenomination, (iv) hyperinflation (and currency crisis), and (v) default by quasi-sovereign entities (BCBS 2017a; Ams and others 2018). These severe forms of distress have been more frequently observed in EMDEs and affect banks through direct (e.g., losses from direct exposures) as well as indirect (e.g., the impact on economic growth, inflation, and exchange rates) transmission channels. The episode of such explicit sovereign distress is rare among AEs in the post-World War II period. During the European sovereign debt crisis, for instance, the key channels included valuation losses of sovereign securities and their impact on bank funding costs as well as the feedback effects to sovereigns through potential bank support measures (Enria and others 2016).

\section{The paper shows how to assess banks' vulnerability to sovereign risk in}

macroprudential stress testing. We discuss four aspects of the tests: scope of exposures and transmission channels, loss estimation methods, shock calibration, and calculation of capital impact. Our discussion is largely based on the experiences with stress testing of banks in the IMF’s Financial Sector Assessment Program (FSAP) over the past decade. The same loss-

\footnotetext{
${ }^{1}$ Andreas (Andy) Jobst is Senior Economist in the Front Office of the IMF’s European Department (and was Adviser to the Managing Director and CFO of the World Bank Group when this paper was completed). Hiroko Oura is a Deputy Division Chief in the Financial Sector Assessment and Policy Division in the MCM Department. We are grateful to Martin Čihák, Udaibir Das, Ehsan Ebrahimy, Caio Ferreira, Jad Khallouf, Raphael Lam, James Morsink, Erlend Nier, Luc Riedweg, and Mustafa Saiyid as well as staff from the national authorities of Germany, Italy, Mexico, Spain, and Saudi-Arabia for their helpful comments and suggestions. The views expressed in this paper do not represent those of the authors' current employers. We thank Carlos Caceres (IMF) for his contribution to Appendix IV, as well as Pavel Lukyantsau and Xiaodan Ding for their excellent data assistance.

${ }^{2}$ Various factors could encourage banks to hold sovereign exposures that strengthen sovereign-bank linkages, including regulatory incentives (e.g., low risk weights for sovereign securities), risk-taking incentives (e.g., banks invest in higher-risk sovereign to earn attractive spreads over their funding costs), and economic cyclical factors (e.g., countercyclical fiscal policies). See Annex V for a comprehensive overview of these factors.
} 
estimation and calibration approach is, in principle, applicable to not only banks but also other types of financial institutions, such as insurance companies, pension funds, and asset managers.

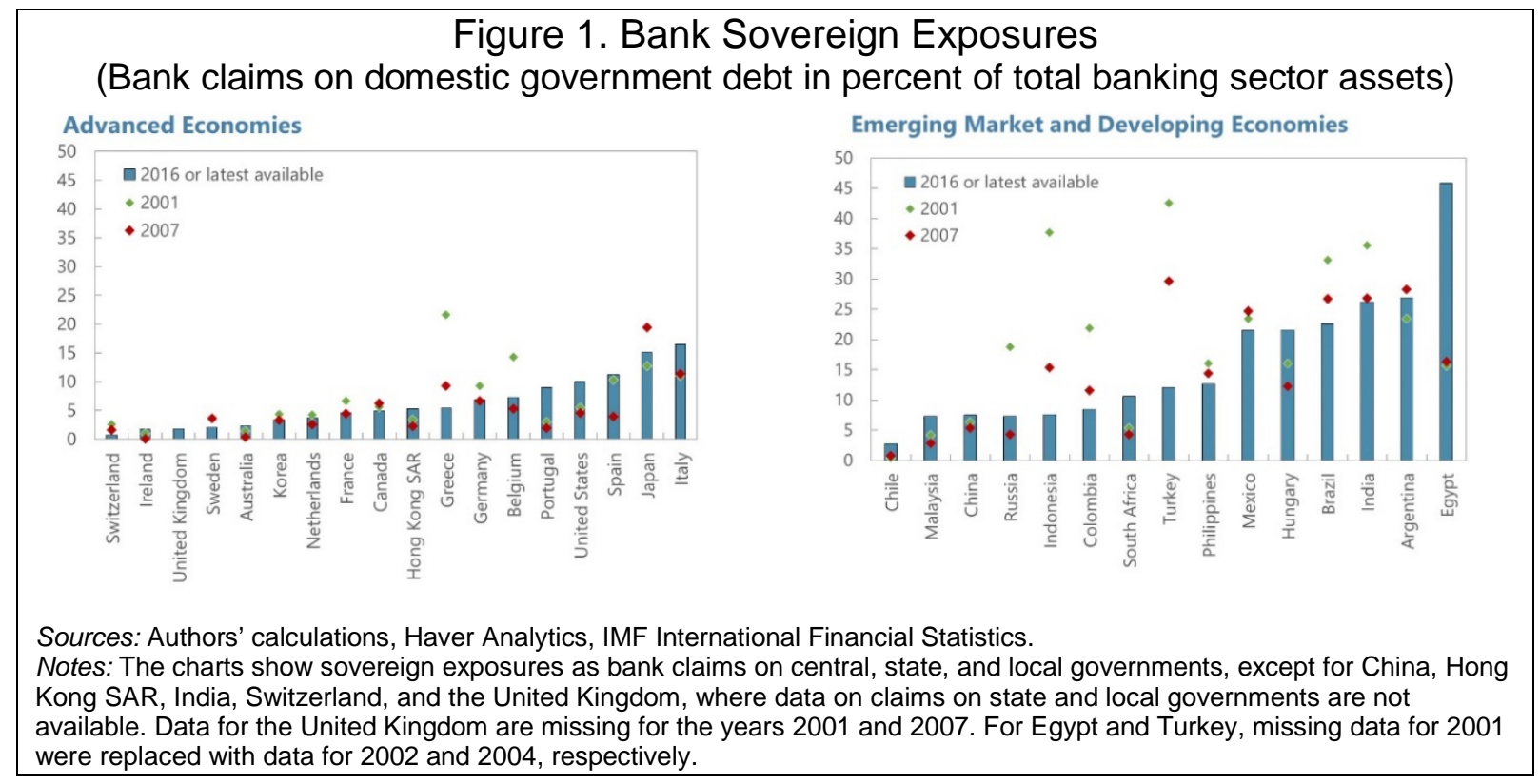

4. The potential scope for sovereign risk varies across countries. So far, FSAPs have focused on the direct impact through security holdings, but a more comprehensive coverage of exposures and channels seems appropriate in some cases (IMF 2015). This is partly because the European sovereign debt crisis, which motivated the integration of sovereign risk in stress tests, took place in countries where most sovereign exposures were securities (and, thus, banks' solvency situation was significantly influenced by the market valuation of their security holdings). However, such an approach may miss essential transmission channels in other countries where the primary bank-sovereign direct linkages stem from loans to the general government and its deposits. If a country has a relatively frequent history of sovereign defaultincluding payment delays, restructuring, hyperinflation - then the test may need to incorporate these channels explicitly. Indeed, the Basel III monitoring exercises (BCBS 2018a and 2018b) confirms that exposures other than securities (i.e., banking book exposures) are a large part of overall sovereign exposures.

\footnotetext{
Box 1. Definition of Bank Sovereign Exposures: Basel III Monitoring Exercise

As part of the semi-annual Basel III Monitoring Exercise, the Basel Committee on Banking Supervision (BCBS, 2018a and 2018b) monitors the exposures of major banks across all member jurisdictions. Sovereign exposures ${ }^{1}$ are one of the key elements of this exercise and are defined as:

- $\quad$ Direct sovereign exposures are exposures to sovereigns (as immediate counterparts). They include both banking book (e.g., loans and receivables) and trading book assets (securities and financial instruments, including derivatives assets and valuation margins). For the monitoring of Basel III liquidity ratios, liabilities from sovereigns are also monitored, including deposits, secured borrowings, derivatives liabilities, and valuation margins among others.

- $\quad$ Indirect exposures are exposures to counterparties other than the sovereign itself, which are (i) protected (guaranteed) by a sovereign entity, and (ii) collateralized by instruments issued by sovereign entities and not subject to haircuts. An example of the latter is a reverse repo transaction, where a bank swaps an asset for government bond as collateral. Another example is a credit default swap (CDS) on sovereign securities.

Note: 1/ "Sovereign" includes a central bank, a central government, multilateral development banks and some international organizations, subnational governments, and public sector entities (PSEs).
} 
5. The method to estimate potential losses from a sovereign distress scenario in FSAPs has been broadly following the Basel III framework with some modifications desirable for a macroprudential perspective. The outputs of FSAP stress tests are not expected to result in immediate supervisory actions — unlike those of microprudential stress tests—but may inform discussions on the robustness of systemic crisis preparedness and the use of possible macroprudential policy measures. As a result, they focus on assessing the potential capital impact of systemic risk as fully and transparently as possible, mainly by applying market-implied estimates of expected sovereign default to all types of sovereign exposures. In contrast, microprudential rules smooth out short-term cyclical volatility to avoid introducing excessive procyclicality to capital ratios.

6. The main FSAP approach for stress testing sovereign risk has been to measure valuation effects on traded government debt caused by changes in expected default rather than actual default during adverse macroeconomic conditions. ${ }^{3}$ A sovereign risk shock is calibrated as the market-consistent haircut implied by the estimated (and not realized) decline in the fair value of government bonds (“market valuation approach") using their price or yield volatility (i.e., standard deviation). For each country, the haircut reflects the observable cost of protecting the value of government bond against rising default risk perceived in markets and is applied to most sovereign security holdings to determine the capital impact of the sovereign risk shock.

7. In this paper, we advance the existing approach towards a tractable method for the calibration of sovereign risk shocks as tail events. For instance, if a shock is defined relative to the historical average, the shape of the distribution function is fundamental the calibration process. For instance, a two-standard-deviation shock drawn from a standard normal distribution is much smaller than if the shock were drawn from a distribution with a fat tail. The size of the haircut could differ substantially depending on the method to account for tail risks. For instance, a one standard deviation valuation shock from a distribution with a fat tail is far more sizeable than the shock drawn from a standard normal distribution. Therefore, we fit a generalized extreme value (GEV) distribution to the historical spread dynamics of spot and forward sovereign credit default swaps (CDS). This approach allows us to derive the density forecast of severe, non-linear changes in the credit risk premium consistent with the tail risk nature of sovereign distress within a flexible functional form. Once a level of credit risk premium under stress is chosen, we can derive market-consistent valuation haircuts using standard bond pricing models. Compared to the approaches using changes in government bond yields, sovereign CDS spreads, when available, provide a "pure” measure of maturity-consistent default risk without potential contamination from varying security characteristics and policy measures influencing government bond prices (Box 2).

8. As part of this approach, the determination of a market-implied valuation haircut provides the conceptual foundation for incorporating broader bank-sovereign linkages. A higher sovereign risk may also imply a lower probability as well as diminished capacity of

\footnotetext{
${ }^{3}$ See Jobst, Ong and Schmieder $(2013,2017)$ for a broader review of macroprudential solvency and liquidity stress testing in major FSAPs.
} 
governments to bail out banks in a systemic event. These indirect effects may have additional costs ex-ante (e.g., higher funding costs, especially if the sovereign risk is originally triggered by deteriorating bank solvency) and ex-post (e.g., a higher probability of bank failure and lower recovery rates). The effects are usually covered as contingent liabilities in the public debt sustainability analysis of the IMF's Article IV surveillance. When sovereign loan exposures are sizeable, credit risk parameters that are consistent with the market valuation haircut could be more useful to model tail risk when the actual history of the credit risk parameters do not include extreme events.

9. The paper is structured as follows. The next four sections describe the key steps of stress testing sovereign risk, which inform the specification of our approach, followed by its empirical application during the European sovereign debt crisis. The final section concludes the paper by summarizing the key aspects of measuring sovereign risk in bank stress tests and providing suggestions for incorporating sovereign risk within integrated stress testing frameworks that model dynamic and systemic effects from the interaction of credit, market and liquidity risks.

\section{SCOPE OF THE TEST}

\section{A. Exposures and Transmission Channels}

\section{The relevant forms of sovereign distress, types of exposures, and channels of} transmission differ substantially across countries. For instance, AEs have rarely experienced "crude forms" of sovereign distress such as restructuring and (hyper) inflation in the post-World War II period, while such incidents have been more frequent among EMDEs (BCBS 2017a). Banks' sovereign exposures are largely securities in countries with developed sovereign bond markets (AEs and major emerging market (EM) countries). When financial markets are underdeveloped (many EMDEs), loans and other types of exposures become more important. It is important to adjust the scope and the design of sovereign risk stress tests according to the ecosystem of each financial system.

\section{Economies with Developed Financial Markets with Low Outright Sovereign Default Risk}

\section{In these systems, sovereign distress propagates through the valuation shock to} sovereign bonds with significant indirect effects. Then, a test could focus on securities exposures and apply a valuation haircut to them. This approach implicitly defines sovereign default as a market risk, rather than a credit risk.

\section{A severe indirect channel could stem from the interaction of bank solvency and}

liquidity. The resulting decline of bank solvency ratio could increase the counterparty risk of the affected banks, raising their funding costs, especially when they rely on wholesale funding that is more sensitive to counterparty risk than deposits. Banks could struggle to satisfy liquidity requirements, as the value of liquid asset buffer that includes sovereign securities diminishes. Such liquidity stress could eventually lead to higher overall funding costs. 
Economies with Underdeveloped Financial Markets with Higher Outright Sovereign Default Risk

13. These economies face higher chances of sovereign distress with various forms of default. Delayed interest payments or unilateral debt restructuring — which often constitute “credit events” for CDS contracts (see Appendix II, Box A2)—could occur frequently. Such "defaults" could also manifest as the monetization of public deficits and lead to hyperinflation, which would reduce public debt in real terms and weaken the exchange rate (potentially resulting in a currency crisis).

14. Sovereign distress could be closely related to external vulnerabilities, raising the role of global investors and macro-financial conditions. Sovereign risk in many EMDEs tends to be more influenced by external factors than those of AEs. Especially small open economies are susceptible to global demand shocks. Also external and public sector balances of commodity exporters could experience large swings along the commodity price cycle. In countries where governments, banks, and non-financial corporates depend on external finance, global market selloff events could reduce or reverse capital outflows, resulting in potentially extreme exchange rate and asset valuation shocks in line with a high "beta" of EMDE securities found in empirical studies (IMF 2014a).

\section{Broader types of sovereign exposures become relevant, given the considerable role} of the state. The prevalence of state-owned banks could create strong cyclical linkages between bank performance and public finance (as well as contingent liabilities). These linkages manifest in interest rate controls, directed credit, or financial repression, which may force banks to take on higher credit risk. They may also raise the resolution cost of failed banks

\section{B. Determining the Scope}

\section{A comprehensive assessment includes all types of relevant sovereign exposures,} beyond the valuation of traded exposures during times of stress (see Box 1). ${ }^{4}$ In most FSAPs for AEs, solvency stress was mostly driven by the market valuation losses from government debt securities, and cash balances at central banks as well as repurchase agreements (repos) or asset swaps were often excluded. Loan exposures are included, but they tend to be a small part of bank assets, and the estimated losses are usually negligible given the limited history of outright sovereign default in most AEs (see the following section on loss estimation for details). However, in macroprudential stress testing exercise for the economies with higher outright default risk and underdeveloped capital markets, it will be essential to think beyond the market risk aspect, securities exposures, and central government debt, since a larger share of losses are likely to come from loan or loan guarantee exposures to broader government (including stateowned enterprises). Where needed, a reliable test may require additional data collection to supplement standard reporting.

\footnotetext{
${ }^{4}$ Given the empirical application of our approach for mostly European countries, it is important to note that many European FSAPs covered all relevant exposures to match the coverage used in EU-wide exercises, which provided the basis for the current BCBS definition (see Tables 1 and 2). These exercises are the 2011 capital exercise and subsequent tests (EBA 2011a, 2011b, 2012), which covered both direct and indirect exposures similar to the BCBS definition in Box 1.
} 
Table 1. Treatment of Sovereign Exposures in Mandatory FSAPs in European Union and European System-wide Stress Tests

\begin{tabular}{|c|c|c|c|c|c|c|c|c|}
\hline & \multirow{2}{*}{$\begin{array}{c}\text { Year } \\
\text { (w/ link } \\
\text { to } \\
\text { paper) }\end{array}$} & \multicolumn{3}{|c|}{$\begin{array}{l}\text { Scope of Sovereign } \\
\text { Exposure }\end{array}$} & \multirow{2}{*}{$\begin{array}{c}\text { Different } \\
\text { Treatment for } \\
\text { Domestic } \\
\text { Debt? }(\mathrm{Y} / \mathrm{N})\end{array}$} & \multirow{2}{*}{$\begin{array}{c}\text { Scenarios: } \\
\text { baseline (B), } \\
\text { adverse (A) }\end{array}$} & \multirow{2}{*}{$\begin{array}{l}\text { Timing of Shock: } \\
\text { all front-loaded }(\mathrm{F}) \\
\text { or } \\
\text { over time }(\mathrm{T})\end{array}$} & \multirow{2}{*}{ Valuation Method } \\
\hline & & $\mathrm{HtM}$ & AfS & $\mathrm{HfT}$ & & & & \\
\hline \multicolumn{9}{|c|}{$\begin{array}{c}\text { IMF FSAP } \\
\text { European Union S-29 Countries (IMF 2014b) }\end{array}$} \\
\hline \multicolumn{9}{|c|}{ First FSAP (since 2010) } \\
\hline United Kingdom & $\underline{2011}$ & $\mathrm{Y}$ & $\mathrm{Y}$ & $\mathrm{Y}$ & $\mathrm{Y} 3 /$ & $A, B$ & $\mathrm{~T}$ & Zero coupon pricing with cash/forward CDS spreads for country-specific shock $1 /$ \\
\hline Germany & $\underline{2011}$ & Y 21 & Y 21 & Y & $\mathrm{N}$ & $A, B$ & $\mathrm{~T}$ & Zero coupon pricing with cash/forward CDS spreads for country-specific shock 1 / \\
\hline France & $\underline{2013}$ & $\mathrm{~N}$ & $\mathrm{Y}$ & Y & Y $4 /$ & $A, B$ & $\mathrm{~F}$ & Discounted cash flow pricing with cash CDS spreads for country-specific shock \\
\hline Italy & $\underline{2013}$ & Y 21 & Y 21 & $\mathrm{Y}$ & Y 5/ & $A, B$ & $\mathrm{~T}$ & Discounted cash flow pricing with cash CDS spreads for country-specific shock \\
\hline Netherlands & $\underline{2011}$ & $\mathrm{Y}$ & $\mathrm{Y}$ & $\mathrm{Y}$ & $\mathrm{N}$ & $A, B$ & $\mathrm{~T}$ & Discounted cash flow pricing with cash CDS spreads for country-specific shock \\
\hline Spain & $\underline{2012}$ & $\mathrm{~N}$ & $\mathrm{Y}$ & $\mathrm{Y}$ & $\mathrm{N}$ & A & $\mathrm{T}$ & Zero coupon pricing with cash/forward CDS spreads for country-specific shock 1 / \\
\hline Belgium & $\underline{2013}$ & $\mathrm{Y}$ & $\mathrm{Y}$ & $\mathrm{Y}$ & $\mathrm{N}$ & $A, B$ & $\mathrm{~T}$ & Zero coupon pricing with cash/forward CDS spreads for country-specific shock 1 / \\
\hline Ireland & $\underline{2016}$ & $\mathrm{~N}$ & Y & Y & Y $5 /$ & $A, B$ & $\mathrm{~T}$ & Discounted cash flow pricing with country-specific shock to bond yield \\
\hline Austria & $\underline{2013}$ & Y $9 /$ & $\mathrm{Y}$ & $\mathrm{Y}$ & $\mathrm{N}$ & A & $\mathrm{T}$ & Discounted cash flow pricing with country-specific shock to bond yield \\
\hline Luxembourg & $\underline{2011}$ & $\mathrm{Y}$ & $\mathrm{Y}$ & $\mathrm{Y}$ & $\mathrm{N}$ & A & $\mathrm{T}$ & Discounted cash flow pricing with country-specific shock to bond yield \\
\hline Sweden & $\underline{2011}$ & $\mathrm{Y}$ & $\mathrm{Y}$ & $\mathrm{Y}$ & $\mathrm{N}$ & $A, B$ & $\mathrm{~T}$ & Discounted cash flow pricing with cash CDS spreads for country-specific shock $1 /$ \\
\hline Denmark & $\underline{2014}$ & Y & Y & Y & $\mathrm{N}$ & A & $\mathrm{F} 8 /$ & Discounted cash flow pricing with country-specific shock to bond yield \\
\hline Finland & $\underline{2016}$ & Y & $\mathrm{Y}$ & $\mathrm{Y}$ & Y $5 /$ & A & $\mathrm{F}$ & Expected losses based on three-notch downgrade using historical PD and LGD \\
\hline Norway & 2015 & $\mathrm{~N}$ & $\mathrm{Y}$ & $\mathrm{Y}$ & $\mathrm{N}$ & $A, B$ & $\mathrm{~T}$ & Discounted cash flow pricing with country-specific shock to bond yield \\
\hline Poland & $\underline{2013}$ & $\mathrm{~N}$ & $\mathrm{~N}$ & $\mathrm{~N}$ & - & - & - & - \\
\hline $\begin{array}{c}\text { European Union (no stress } \\
\text { test) }\end{array}$ & $\underline{2013}$ & $\mathrm{~N}$ & $\mathrm{~N}$ & $\mathrm{~N}$ & - & - & - & - \\
\hline \multicolumn{9}{|c|}{ Second FSAP (since 2010)* } \\
\hline United Kingdom & 2016 & $\mathrm{Y}$ & $\mathrm{Y}$ & $\mathrm{Y}$ & $\mathrm{N}$ & A & $T$ & Discounted cash flow pricing with country-specific shock to bond yield 9/ \\
\hline Germany & $\underline{2016}$ & $\mathrm{~N}$ & $\mathrm{Y}$ & $\mathrm{Y}$ & $\mathrm{N}$ & A & $\mathrm{F}$ & Discounted cash flow pricing with country-specific shock to bond yield \\
\hline Netherlands & $\underline{2017}$ & $\mathrm{~N}$ & $\mathrm{Y}$ & $\mathrm{Y}$ & $\mathrm{N}$ & A & $\mathrm{T}$ & Discounted cash flow pricing with country-specific shock to bond yield \\
\hline Spain & $\underline{2017}$ & $\mathrm{~N}$ & $\mathrm{Y}$ & Y & $\mathrm{N}$ & A & $\mathrm{T}$ & Discounted cash flow pricing with country-specific shock to bond yield \\
\hline Belgium & $\underline{2018}$ & $\mathrm{~N}$ & $\mathrm{Y}$ & $\mathrm{Y}$ & $\mathrm{N}$ & $A, B$ & $\mathrm{~T}$ & Discounted cash flow pricing with country-specific shock to bond yield \\
\hline Luxembourg & $\underline{2017}$ & $\mathrm{Y}$ & Y & $\mathrm{Y}$ & $\mathrm{N}$ & A & $\mathrm{T}$ & Discounted cash flow pricing with country-specific shock to bond yield \\
\hline Sweden & $\underline{2017}$ & $\mathrm{~N}$ & $\mathrm{Y}$ & $\mathrm{Y}$ & $\mathrm{N}$ & A & $\mathrm{F}$ & Discounted cash flow pricing with country-specific shock to bond yield \\
\hline Poland $d^{\star *}$ & $\underline{2019}$ & $\mathrm{Y}$ & $\mathrm{Y}$ & $\mathrm{Y}$ & $\mathrm{N}$ & A & $\mathrm{F}$ & Discounted cash flow pricing with country-specific shock to bond yield \\
\hline Euro Area Policies & 2018 & $\mathrm{Y}$ & $\mathrm{Y}$ & $\mathrm{Y}$ & $\mathrm{N}$ & A & $\mathrm{T}$ & Discounted cash flow pricing with country-specific shock to bond yield \\
\hline \multicolumn{9}{|c|}{ European Authorities (CEBS-EBA-ECB) } \\
\hline EU Capital Exercise & 2011 & $\mathrm{~N} 6 /$ & Y 6/ & $\mathrm{Y}$ & $\mathrm{N}$ & A & $\mathrm{F}$ & Discounted cash flow pricing with cash CDS spreads for country-specific shock \\
\hline EU System-wide Stress Test & $\underline{2010}$ & $\mathrm{~N}$ & $\mathrm{~N}$ & $\mathrm{Y}$ & $\mathrm{N}$ & $A, B$ & $\mathrm{~T}$ & Discounted cash flow pricing with cash CDS spreads for country-specific shock \\
\hline EU System-wide Stress Test & $\underline{2014}$ & $\mathrm{~N}$ & $\mathrm{Y}$ & $Y 71$ & $\mathrm{~N}$ & A & $\mathrm{T}$ & Discounted cash flow pricing with country-specific shock to bond yield \\
\hline EU System-wide Stress Test & 2016 & $\mathrm{~N}$ & $\mathrm{Y}$ & Y 71 & $\mathrm{~N}$ & A & $\mathrm{F}$ & Discounted cash flow pricing with country-specific shock to bond yield \\
\hline EU System-wide Stress Test & $\underline{2018}$ & $\mathrm{~N}$ & $\mathrm{Y}$ & Y $7 /$ & $\mathrm{N}$ & A & $\mathrm{F}$ & Discounted cash flow pricing with country-specific shock to bond yield \\
\hline
\end{tabular}

Sources: Authors, EBA (2010, 2011a, 2014, 2016 and 2018), ECB (2011), and IMF FSAP country reports.

Notes: $\mathrm{Y}=\mathrm{yes}, \mathrm{N}=$ no; $\mathrm{n} . \mathrm{a}=\mathrm{=not}$ available.

1/ The haircut model in this paper (Appendix II) was applied in the FSAPs for Belgium (2013), Germany (2011), Hong Kong SAR (2014), Spain (2012), Sweden (2011), and the United Kingdom (2011); other FSAPs followed similar approaches-with an empirically derived sovereign credit spread shock, using either (i) the historical volatility of CDS spreads, such as in the case of France (2013), Italy (2013), Netherlands (2011), Singapore (2013), and Sweden (2011), or (ii) the historical volatility of bond yields, such as in the case of Argentina (2016), Austria (2014), Denmark (2014), Indonesia (2017), Ireland (2016), Japan (2012), Mexico (2016), Norway (2015), South Africa (2015), and Korea (2015) as well as most European countries in the

2/ In the FSAPS for Germany (2011), Japan (2012), and Italy (2013), MtM is applied to HtM securities only in separate sensitivity analysis (unlike UK FSAP's bottom-up test in 2011); 3/ HtM exposures tend to be assessed using the credit risk approach; 4/ Haircuts are applied only to non-"AAA"-rated debt, and French sovereign exposures ("AAA"-rated) were not subject to a valuation haircut; 5/ Only domestic sovereign exposures were stressed; 6/ MtM is applied to HtM sovereign exposures, and the AfS filter was removed; $7 /$ Including only direct exposures (indirect exposures were covered in the market risk impact); 8/ A part of the overall sensitivity analysis of the capital impact of credit risk; 9/ Following Longstaff and others (2011). 
Table 2. Treatment of Sovereign Exposures in Mandatory FSAPs (Excluding European Union Countries)

\begin{tabular}{|c|c|c|c|c|c|c|c|c|}
\hline & \multirow{2}{*}{$\begin{array}{l}\text { Year } \\
\text { (w/ link } \\
\text { to } \\
\text { paper) }\end{array}$} & \multicolumn{3}{|c|}{$\begin{array}{c}\text { Scope of Sovereign } \\
\text { Exposure }\end{array}$} & \multirow{2}{*}{$\begin{array}{c}\text { Different } \\
\text { Treatment for } \\
\text { Domestic Debt? } \\
(\mathrm{Y} / \mathrm{N})\end{array}$} & \multirow{2}{*}{$\begin{array}{l}\text { Scenarios: } \\
\text { baseline }(B), \\
\text { adverse }(A)\end{array}$} & \multirow{2}{*}{$\begin{array}{l}\text { Timing of } \\
\text { Shock: } \\
\text { all front-loaded } \\
(\mathrm{F}) \text { or over time } \\
(\mathrm{T})\end{array}$} & \multirow[b]{2}{*}{ Valuation Method } \\
\hline & & $\mathrm{HtM}$ & AfS & HfT & & & & \\
\hline \multicolumn{9}{|c|}{ IMF FSAP } \\
\hline \multicolumn{9}{|c|}{ Other Non-EU S-29 and G-20 Countries } \\
\hline \multicolumn{9}{|c|}{ First FSAP (since 2010)* } \\
\hline United States & 2010 & $\mathrm{~N}$ & $\mathrm{~N}$ & $\mathrm{~N}$ & $\mathrm{Y} 21$ & A & $\mathrm{T}$ & Distress dependence with emerging market sovereigns $3 /$ \\
\hline Japan & $\overline{2012}$ & $\mathrm{~N}$ & $\mathrm{Y}$ & $\mathrm{Y}$ & $\mathrm{N}$ & A & n.a. & Discounted cash flow pricing with country-specific shock to bond yield \\
\hline Canada & $\overline{2014}$ & $\mathrm{Y}$ & $\mathrm{Y}$ & $\mathrm{Y}$ & $\mathrm{N}$ & Single factor & $\mathrm{F}$ & Discounted cash flow pricing with country-specific shock to bond yield \\
\hline Switzerland & $\underline{2014}$ & $\mathrm{Y}$ & $\mathrm{Y}$ & $\mathrm{Y}$ & Y $4 /$ & A & $\mathrm{T}$ & No special test for own sovereign (safe haven); the general increase in credit and market risks \\
\hline China & $\underline{2010}$ & $\mathrm{~N}$ & $\mathrm{~N}$ & $\mathrm{~N}$ & - & - & - & - \\
\hline Australia & $\underline{2012}$ & $\mathrm{Y}$ & $\mathrm{Y}$ & $\mathrm{Y}$ & Y $4 /$ & A & $\mathrm{T}$ & No special test for own sovereign (general increase in credit and market risks) \\
\hline India & $\overline{2013}$ & $\mathrm{~N}$ & $\mathrm{~N}$ & $\mathrm{~N}$ & - & - & - & - \\
\hline Hong Kong SAR & $\underline{2014}$ & $\mathrm{Y}$ & $\mathrm{Y}$ & $\mathrm{Y}$ & $\mathrm{N}$ & $A, B$ & T & Zero coupon pricing with cash/forward CDS spreads for country-specific shock 1/ \\
\hline Brazil & $\underline{2012}$ & $\mathrm{~N}$ & $\mathrm{Y}$ & $\mathrm{Y}$ & $\mathrm{N}$ & Single factor & $\mathrm{F}$ & Valuation losses from sovereign yield changes \\
\hline Russia & $\underline{2011}$ & $\mathrm{~N}$ & $\mathrm{~N}$ & $\mathrm{~N}$ & - & - & - & - \\
\hline Korea & $\underline{2015}$ & $\mathrm{~N}$ & $\mathrm{Y}$ & $\mathrm{Y}$ & $\mathrm{N}$ & A & $\mathrm{T}$ & Discounted cash flow pricing with country-specific shock to bond yield \\
\hline Singapore & $\underline{\underline{2013}}$ & $\mathrm{~N}$ & Y & $\mathrm{Y}$ & $\mathrm{N}$ & A & $\mathrm{F}$ & Discounted cash flow pricing with cash CDS spreads for country-specific shock \\
\hline Turkey & $\underline{2012}$ & $\mathrm{~N}$ & $\mathrm{Y}$ & $\mathrm{Y}$ & $\mathrm{N}$ & A, single factor & $\mathrm{T}$ & Expected losses from valuation changes (market risk) due to higher sovereign risk \\
\hline Mexico & $\underline{2012}$ & $\mathrm{~N}$ & $\mathrm{~N}$ & $\mathrm{~N}$ & - & - & - & - \\
\hline Norway & $\underline{2015}$ & $\mathrm{Y}$ & $\mathrm{Y}$ & $\mathrm{Y}$ & $\mathrm{N}$ & $A, B$ & $\mathrm{~T}$ & Discounted cash flow pricing with country-specific shock to bond yield \\
\hline Argentina & $\underline{2016}$ & $\mathrm{Y}$ & $\mathrm{Y}$ & $\mathrm{Y}$ & $\mathrm{N}$ & A & $\mathrm{F}$ & Discounted cash flow pricing with country-specific shock to bond yield \\
\hline Indonesia & $\underline{2010}$ & $\mathrm{~N}$ & $\mathrm{~N}$ & $\mathrm{~N}$ & - & - & - & - \\
\hline Saudi Arabia & $\underline{\underline{2012}}$ & $\mathrm{~N}$ & $\mathrm{~N}$ & $\mathrm{~N}$ & - & - & - & - \\
\hline South Africa & $\underline{2015}$ & $\mathrm{Y}$ & $\mathrm{Y}$ & $\mathrm{Y}$ & Y $5 /$ & A & $\mathrm{F}$ & Discounted cash flow pricing with country-specific shock to bond yield \\
\hline \multicolumn{9}{|c|}{ Second FSAP (since 2010)* } \\
\hline United States & $\underline{2015}$ & $\mathrm{~N}$ & $\mathrm{~N}$ & $\mathrm{Y}$ & $\mathrm{Y}$ & Single factor & $\mathrm{F}$ & MtM losses from market price and rate moves \\
\hline Japan & $\underline{2017}$ & $\mathrm{Y}$ & $\mathrm{Y}$ & $\mathrm{Y}$ & $\mathrm{Y}$ & A & $\mathrm{T}$ & Haircuts for HfT and AfS of exposures to own sovereign; credit risk approach for $\mathrm{HtM}$ securities \\
\hline China & $\underline{2017}$ & $\mathrm{~N}$ & $\mathrm{~N}$ & $\mathrm{~N}$ & - & - & - & - \\
\hline India & $\underline{2017}$ & $\mathrm{Y}$ & $\mathrm{Y}$ & $\mathrm{Y}$ & Y 5/ & A & $\mathrm{F}$ & Discounted cash flow pricing with country-specific shock to bond yield \\
\hline Brazil & $\underline{2018}$ & $\mathrm{Y}$ & Y & $\mathrm{Y}$ & $\mathrm{N}$ & A & T & Valuation losses from sovereign yield changes \\
\hline Russia & $\underline{2016}$ & $\mathrm{~N}$ & $\mathrm{~N}$ & $\mathrm{~N}$ & - & - & - & Data constraints prevented a full analysis $6 /$ \\
\hline Turkey & $\underline{2017}$ & $\mathrm{Y}$ & $\mathrm{N}$ & $\mathrm{N}$ & $\mathrm{N}$ & A & $\mathrm{T}$ & Credit risk approach $6 /$ \\
\hline Mexico & 2016 & $\mathrm{Y}$ & $\mathrm{Y}$ & $\mathrm{Y}$ & $\mathrm{N}$ & A & $\mathrm{T}$ & Discounted cash flow pricing with country-specific shock to bond yield \\
\hline Indonesia & $\underline{2017}$ & $\mathrm{~N}$ & $\mathrm{Y}$ & $\mathrm{Y}$ & $\mathrm{N}$ & A & $\mathrm{T}$ & Discounted cash flow pricing with country-specific shock to bond yield \\
\hline Saudi Arabia & $\underline{2017}$ & Y & $\mathrm{Y}$ & $\mathrm{Y}$ & $\mathrm{N}$ & Single factor, $\mathrm{A}$ & $\mathrm{T}$ & No emphasis on sovereign risk; single factor interest rate test on bond valuation/credit risk test \\
\hline
\end{tabular}

Sources: Authors and IMF FSAP country reports.

Notes: $\mathrm{Y}=\mathrm{yes}, \mathrm{N}=$ no; $\mathrm{n} \cdot \mathrm{a} .=$ not available.

1/ The haircut model in this paper (Appendix II) was applied in the FSAPs for Belgium (2013), Germany (2011), Hong Kong SAR (2014), Spain (2012), Sweden (2011), and the United Kingdom (2011); other FSAPs followed similar approaches - with an empirically derived sovereign credit spread shock, using either (i) the historical volatility of CDS spreads, such as in the case of France (2013), Italy (2013), Netherlands (2011), Singapore (2013), and Sweden (2011), or (ii) the historical volatility of bond yields, such as in the case of Argentina (2016), Austria (2014), Denmark (2014), Indonesia (2017), Ireland (2016), Japan (2012), Korea (2015), Mexico (2016), Norway (2015), and South Africa (2015), as well as most European countries in the

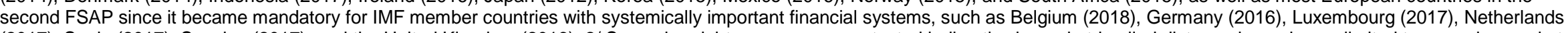

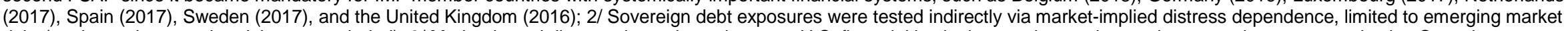
debt (so domestic sovereign debt was excluded); 3/ Market-based distress dependence between U.S. financial institutions and emerging market sovereigns measured using Segoviano (2006); 4/ Sovereign risk was not tested explicitly, but a general increase of credit risk from higher expected losses due to European sovereign debt exposures; $5 /$ Only domestic sovereign exposures were stressed; 6/ Credit risks from SOEs were considered more important than market risk. 


\section{Method to Estimate Potential Losses}

\section{A. Benchmark Approach}

17. Like any other risk factors, sovereign risks generate both expected and unexpected losses impacting bank solvency (see Figure 2). Expected losses represent average losses that are likely to materialize in the future based on current information. These losses affect the capital adequacy ratio (CAR) (i.e., capital divided by risk-weighted-assets, RWA) through its numerator-either as a direct hit to capital or through profit and losses (P\&L), depending on the types of exposures (e.g., securities held for trading, HfT, available for sale, AfS, and held to maturity, HtM). In contrast, unexpected losses are extreme losses that tend to occur with a very low probability — say once in 1,000 years shown as the Value-at-Risk (VaR) at $99.9^{\text {th }}$ percentile in the figure. These tail risks affect the CAR though its denominator by increasing the capital intensity of assets (i.e., risk weights).

Figure 2. Conceptual Difference between Expected and Unexpected Losses (Example for loan exposures) ${ }^{1}$

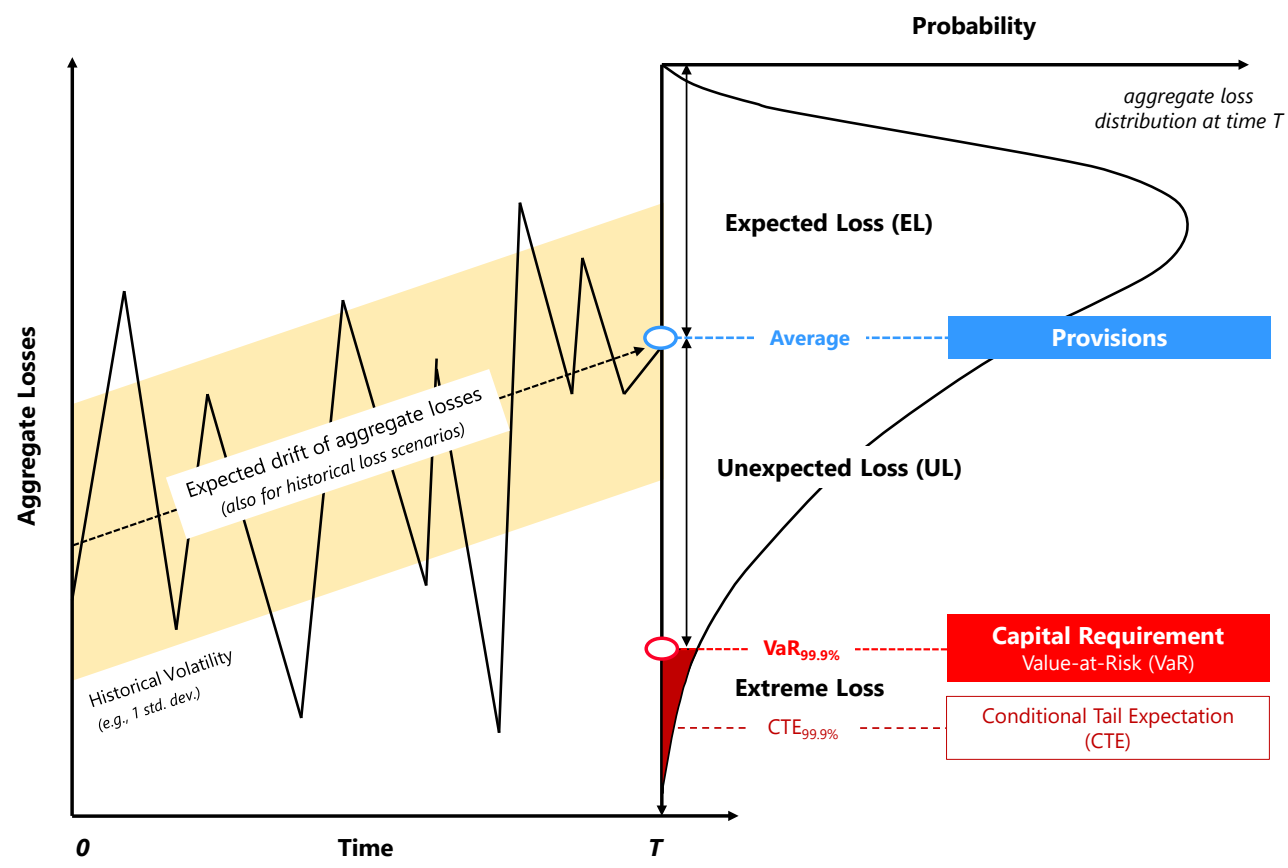

Source: adapted from Jobst, Ong, and Schmieder (2013).

$1 /$ For loan exposures, Basel require banks to set aside loan-loss provisions equivalent to expected losses. Additional provisions (i.e., credit cost) in a given year will reduce bank profit and therefore the numerator of the solvency ratio. 
Table 3. Asset Valuation Rules and Regulatory Capital Impact*

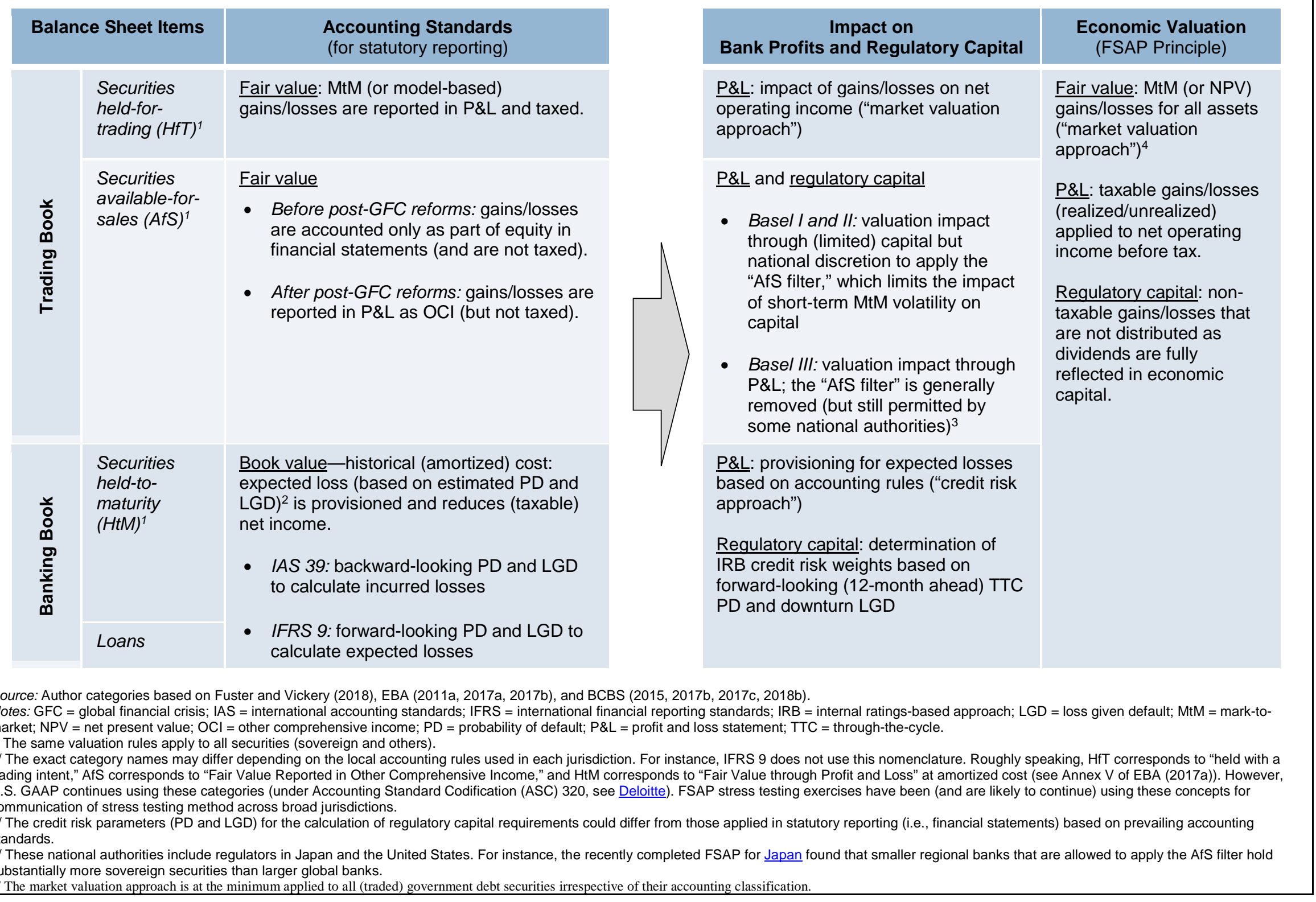


18. Generally, the methods to estimate expected loss differ depending on whether the exposures are in the banking book or trading book (see Table 3):

- Trading book exposures are mostly bonds and other market instruments; their expected losses stem from the securities' market valuation changes.

- Banking book exposures are mostly loans (see Appendix II). Therefore, their expected losses are estimated with credit risk approach that includes an empirical satellite model that forecasts credit risk parameters with macro-financial covariates. If banks use internal ratingbased (IRB) approaches, expected losses are estimated as the product of the probability of default (PD) and loss given default (LGD). Under the standardized approach, the losses are estimated using loan classification (or non-performing loan information) or credit rating, assuming a certain level of required provision rate for each category/rating of loans.

19. Stress tests broadly follow the Basel regulatory capital rules to estimate expected losses but tend to widen the application of market-consistent valuation. The objective of capital rules is to provide a fair and timely measure of bank solvency without introducing shortterm volatility. For instance, if banks hold substantial amounts of traded securities, mark-tomarket (MtM) valuation changes could lead to frequent changes in regulatory capital, which complicates both lending and investment activities. Therefore, the regulatory framework (and underlying accounting standards) includes features to smooth out excessive volatility and cyclical effects. In contrast, the main objective of macroprudential stress tests is to examine banks' resilience to tail events rather than normal cyclical downturns. For this purpose, it is critical to reflect all potential losses immediately and transparently using MtM valuation (i.e., the economic valuation approach). ${ }^{5}$

\section{In doing so, all traded exposures are ideally valued using a market-consistent} approach to make stress test results more comparable across banks. The same sovereign securities could be valued differently depending on their accounting treatment (and the way this informs the calculation of the CAR, see Table 3). If the market value of sovereign securities declines sharply, it is fully reflected in the valuation of HfT and AfS securities but not necessarily HtM securities, which are valued at amortized cost using historical estimates of credit risk parameters. Some jurisdictions, including Japan and the United States, allow some banks to continue applying the "AfS filter" that limits the impact of short-term volatility of the value of AfS securities on solvency ratio, though many (European) jurisdictions entirely removed the filter in the mid-2010s. ${ }^{6}$ Thus, banks with precisely the same portfolio and balance sheet may have different CARs depending on the share of AfS and HtM securities.

\footnotetext{
${ }^{5}$ Similarly, for banking book exposures, the Basel rules apply cyclically smoothed credit risk parameters called through-the-cycle (TTC) PDs and LGD; however, stress tests usually apply point-in-time (PiT) PDs and downturn LGD as "raw parameters."

${ }^{6}$ In the United States, the Federal Deposit Insurance Corporation allowed banks regulated with standardized approach and savings and loan holding companies to elect a one-time, permanent opt-out from the recognition of unrealized accumulated other comprehensive income (AOCI, see this Letter). In Japan, regional banks can continue using the AfS filter.
} 
21. The market-consistent approach is also useful for determining expected losses from banking book exposures when a country's history does not include any sovereign distress episode(s). No empirical satellite model can capture sovereign distress well without historical precedents. Market valuation, in contrast, is more sensitive to investors’ perception about the likelihood of sovereign distress.

\section{The market-consistent approach is critical when potential regulatory arbitrage or}

forbearance is a concern. During the European sovereign debt crisis, banks received a one-time supervisory approval to re-classify sovereign HfT and AfS securities as HtM (Acharya 2018). While such a measure is vital as a crisis management measure that limits the undesirable amplification effects from the banking sector, it reduces transparency for stress testing. Moreover, there is evidence that banks optimize the accounting treatment of government debt securities to reduce their capital impact. ${ }^{7}$

\section{This approach also helps assess the impact of sovereign-bank linkages on bank} funding costs. As discussed in Section II, one of the sovereign-bank linkage channels is through bank (wholesale) funding costs. ${ }^{8}$ Investors are likely to pay attention to bank solvency based on a full market valuation in addition to regulatory ratios. Therefore, one approach is to use a sensitivity test that estimates the impact of sovereign distress on market-value based solvency ratio and then estimate its impact on bank funding. The resulting reduction of net interest income could be part of the broader scenario tests where valuation losses from HtM securities are excluded.

\section{However, for unexpected losses from sovereign exposures, stress tests usually follow} the regulatory practice, even though it is considered problematic in the financial stability community. Under Basel regulations, local currency-denominated sovereign debt preserves their nominal value during times of stress, and, thus, could be considered "safe assets.” In many cases, these sovereign exposures are assigned a zero percent credit risk weight $(\mathrm{RW})$ under the standardized approach (SA) and very low RWs under the IRB approach if banks estimate PDs and LGDs for sovereigns with no (or limited) distress episodes in the past. While these practices underestimate sovereign risk (Hannoun 2011), recent BCBS regulatory reform efforts to change them have not concluded (BCBS 2017a). The challenge is that there are multiple reform approaches and different options, ranging from concentration-based measures to credit riskbased capital charges, but is not straightforward to see which one works the best. In the absence of any clear direction regarding potential changes in the regulatory treatment of sovereign risk, most FSAPs, for example, have not changed this practice. Introducing case-by-case adjustments would also reduce the comparability across different exercises.

\footnotetext{
${ }^{7}$ For instance, Fuster and Vickery (2018) found that U.S. banks responded to the removal of the AfS filter by reclassifying securities to HtM accounts instead of reducing the portfolio risk of the trading book.

${ }^{8}$ Wong and Hui (2009) examine the feedback effects between liquidity and solvency risks. Schmitz, Sigmund, and Valderrama (2017) examine the empirical validity of this feedback effects.
} 


\section{B. FSAP Practice}

25. Most FSAPs follow the above benchmark approach, with varying degree of valuation practices (see Tables 1 and 2). Many exercises during the European sovereign debt crisis for the EU Member States applied market-consistent valuations to all sovereign securities including $\mathrm{AfS}^{9}$ and HtM securities (except for France and Spain). For HtM securities, this meant applying valuation losses instead of provisions according to their credit risks. In the 2012 Italy FSAP, the valuation losses from HtM securities were excluded from a macro scenario test but included in a sensitivity test. For these cases, transparency was deemed most important, especially under various crisis management measures that mitigated valuation changes (e.g., the ECB's quantitative easing) and the forbearance. More recent FSAPs have applied the market valuation approach to HtM securities less frequently unless banks reported a high share of HtM securities or the share rose noticeably. Most FSAPs applied the credit risk approach for assessing sovereign risks with loans and receivables using historical credit risk parameters. Some FSAP are attempting to incorporate the indirect effects through funding cost as a part of broader efforts to incorporate solvency-liquidity interactions.

26. For countries with elevated sovereign risk, FSAP exercises have also included valuation losses that were not fully reflected in prudential reporting. Since CARs do not fully reflect the short-term cyclical changes in asset valuation, there could be a gap between the current market valuation of sovereign debt securities and their valuation in the last reported statutory accounts. Thus, a test would overestimate CAR without adjusting for the valuation gap. Similar adjustments are critical when there is forbearance to manage a crisis or due to the general weakness of the supervisory framework to handle problem assets. However, if sovereign securities are already priced at historically low levels, it may make sense to apply a smaller-thanotherwise shock (in line with adjusting the adversity of macroeconomic scenarios for stress tests that occur when banks already experience some distress).

\section{Calibrating Shocks}

\section{Sovereign risk shocks are difficult to calibrate with standard macroeconomic}

models. The baseline scenario usually includes the entire yield curve of (own) government securities, with which the forward yield curve can be estimated. For adverse scenarios, the size of shocks may not be sufficiently severe in macroeconomic models, which tend to be focused on changes in the short-term (policy) rate (and a projected long-term yield if available). Standard empirical and dynamic stochastic general equilibrium models do not endogenously model shocks to financial risk. Also, most of these models do not integrate essential non-linear effects of financial risks.

\section{Therefore, stress testers often use the market-implied valuation approach as an} alternative, statistical method to calibrate sovereign shocks to sovereign securities. Many FSAPs have used the approach since the European sovereign debt crisis to estimate the haircut to sovereign securities (see Tables 1 and 2). The next section describes a specific modeling technique, which is well-suited for the estimation of valuation haircuts that capture the tail risk of

\footnotetext{
${ }^{9}$ The AfS filter still existed during this time period (early 2010s).
} 
sovereign exposures under this approach. The haircuts can be derived from the expected change in the price of government bonds in response to changes in default risk. The price of government bonds broadly reflects two components - the risk-free interest rate and the credit risk premium. ${ }^{10}$ The risk-free rate represents the intertemporal cost of money in line with expected inflation expectations and the real interest rate. The credit risk component signifies sovereign default risk. In the absence of sovereign distress, government bonds are considered safe and yield a risk-free rate of return whose volatility determines any valuation changes. However, when investors recognize higher potential sovereign default risk (or their risk aversion increases), ${ }^{11}$ they demand a (higher) credit risk premium, which reduces the price of government bonds. Thus, haircuts reflect the differential price impact of higher sovereign risk, with general macro models providing the risk-free component. ${ }^{12}$ These valuation haircuts are applied to all sovereign exposures for a fully market-consistent capital assessment of sovereign risk; however, empirical constraints might preclude reasonable estimates for the valuation changes for all types of credit exposures under stress, limiting the market valuation approach to capital market instruments (in the trading book) only.

\section{For sovereign exposures in the banking book, especially non-capital market instruments, the credit risk approach may substitute for the market valuation approach to determine sovereign default risk, particularly in absence of reliable market prices. All} banks set aside reserves for expected losses from sovereign exposures in the same manner as commercial and consumer loans, consistent with applicable accounting standards. For creditsensitive exposures, such as loans and receivables, these reserves are called loan loss provisions (LLP) and typically cover the non-accrual amount of outstanding balances (which can be proxied via changes in non-performing loans and write-downs). If banks use IRB approaches to determine their capital requirement for credit risk, provisions for expected losses are based on estimated through-the-cycle PDs (or better, point-in-time) and downturn LGDs (see Table 3). ${ }^{13}$ Since PDs (and non-accruals) of sovereign exposures might change in ways that are quite different from that of commercial and retail exposures, a separate provisioning model for sovereign risk might be warranted. ${ }^{14}$ Otherwise, the sovereign risk shock is modelled as a

\footnotetext{
${ }^{10}$ More specifically, government debt yields are determined by (i) macroeconomic factors reflecting the evolving monetary policy stance and inflation credibility (which is reflected in the policy rate and inflation expectations), (ii) market factors (such as liquidity risk), and (iii) fiscal constraints and borrowing capacity (which determine actual and perceived default risk).

11 The market price of risk (based on the relation between asset returns and volatility) is a frequently used metric of risk aversion.

12 The risk-free interest rate term structure is assumed to be independent of credit risk in traditional sovereign bond pricing models.

13 The downturn LGD reflects the losses occurring during a downturn in a business cycle, which can be interpreted in many ways (Altman, Resti, and Sironi 2004). One definition of “downturn conditions" is consistent with that of a recession, i.e., at least two consecutive quarters of negative growth in real GDP. Often, negative growth is also accompanied by a negative output gap in an economy (where potential production exceeds actual demand).

${ }^{14}$ If only aggregate non-performing loan (NPL) data for all sectors are available (and if banks apply the standardized approach for unexpected credit risk losses), the sovereign risk shock is modelled as a NPL shock and should be calibrated separately for sovereign and other exposures.
} 
downgrade scenario, which implies a significant deterioration of PDs and LGDs, resulting in additional provisions to be held for banking book exposures.

\section{In some cases, sovereign risk shocks also include a "common” (global/regional)} interest rate component. For stress tests covering a region (such as the EU system-wide stress test) and smaller, open EMDEs, the change in sovereign bond yields comprises country-specific and common global/regional components. Each component covers adverse changes in the riskfree rate and the sovereign credit risk premium at different points of the interest rate term structure of government bonds (see Box 1).

- Common interest rate shock. The total change of sovereign yields reflects the changes of the regional risk-free rate and sovereign default risk across multiple countries if widespread concerns about public debt sustainability cause spillover effects within a region. For many smaller, open EMDEs, the interest rates in large advanced economies (especially the United States) have a substantial influence on domestic sovereign yields. If the common interest rate shock is uniform, ${ }^{15}$ and, thus, results in a parallel upward shift of the yield curve (i.e., it does not affect its curvature), the term structure remains unchanged. ${ }^{16}$

- Country-specific interest rate shock. The primary driver of the sovereign risk shock is the country-specific credit risk component. The sovereign credit shock can be calibrated based on the historical volatility of sovereign credit spreads, which can be derived explicitly (via sovereign CDS) or implicitly (via excess spreads over a benchmark government bond yield, such as the J.P. Morgan Emerging Markets Bond Index (EMBI) spreads). ${ }^{17}$ The data can then be parametrically modeled to generate point estimates of expected default risk at different maturities for each year of the stress test horizon (after controlling for contemporaneous changes in the general level of interest rates, which may influence the pricing of default risk). For an adverse scenario, high sovereign credit spreads away from their historical median could be applied (i.e., choosing the spreads at the tail of the historical distribution). ${ }^{18}$

\footnotetext{
${ }^{15}$ Common interest rate shocks might exacerbate sovereign risk in regionally-fragmented economies, which could be addressed by calibrating country-specific shocks based on weights dependent on the level of contagion risk between these economies.

${ }^{16}$ For example, the European system-wide stress testing exercise (see Table 4) took a similar approach until 2016. A 75-basis-point shock (40 percent increase compared to the latest actual yield) was applied to all euro area government bonds and CDS spreads with 10-year maturities. Then, CDS spreads with all other maturities were assumed to increase by 40 percent.

${ }^{17}$ CDS spreads represent a "purer" measure of credit risk than government bond yields. In the event of a default, the CDS contract payout recovers the par value, which means there is no need to determine the implied default probability (since the recovery rate is endogenized in the observed bond price). Moreover, CDS spreads may represent sovereign risk more accurately than sovereign bond yields when yields are kept artificially low by central bank bond purchase programs (see Box 2).

${ }^{18}$ The accurate expectation of default risk (and its price impact) would ideally be estimated using forward rates on CDS contracts to account for the variability of expected changes in credit spreads over different risk horizons. In contrast, the European system-wide stress testing exercise calibrates default risk based on the historical volatility of
} 
31. For loans and other non-capital market exposures in the banking book, the credit risk approach could be more suitable, particularly in the absence of reliable market prices. For loans, these reserves are called loan loss provisions and typically cover the potential losses from NPLs (that are not receiving interest payments). If banks use IRB approaches to determine their capital requirement for credit risk, provisions for expected losses are based on estimated through-the-cycle PDs (or better, point-in-time) and downturn LGDs (see Table 3). Since credit risk parameters for sovereign exposures are likely to behave distinctively from private loans, a separate credit risk model for sovereign risk, which predicts PDs and LGDs or NPLs of sovereign loans as a function of various macro-financial variables, might be warranted. However, when the country's history does not include any sovereign distress episode, such a model may not pick a meaningful level of default risk. Under the credit risk approach, the sovereign risk shock is modelled as a downgrade scenario, which implies a significant and sudden jump of PDs and LGDs.

\section{The sovereign risk shock would be less severe if countries were already in distress.}

During times of stress, the current sovereign yield curve already includes a level of default risk, which might already be high by historical standards. Further raising the default risk could lead to implausibly severe stress, especially compared to countries with stable interest rates.

\section{CALCUlating THE CAPITAL IMPACT}

\section{The accounting classification of sovereign exposures determines how their expected} losses impact bank' capital adequacy under stress. As Table 3 shows, security exposures in HfT, AfS, HtM, and loan exposures affect bank capital differently. Trading losses from HfT securities are considered realized losses, become a part of net income and are subject to taxation and dividend payout. Assuming all the AfS filters are removed, ${ }^{19}$ all unrealized gains and losses from AfS securities also become part of net income. However, the unrealized valuation changes are not subject to taxation (and do are usually not included in dividend payments). ${ }^{20}$ Therefore, all the valuation changes will reduce capital one-to-one. Expected credit loss from loan exposures will require additional loan loss reserves (LLRs), which are a part of the (taxable) net income. Banks usually pay tax and dividend only when taxable net income is positive.

country-specific spreads over the interest rate term structure of German government debt (EBA 2018a; see Table 5); This approach has evolved over time from the initial methodology (EBA 2011a), which centered on country-specific credit spreads being set to "common” (global/regional) interest rates and then scaled by the volatility of each country’s spot CDS spread; this introduced a potentially distorting common spread component into country-specific shocks.

${ }^{19}$ If the AfS filter continues to exist, as in some jurisdictions, then AfS securities will also have a valuation gap similar to HtM securities (but the size of the gap is different because the two types of securities are valued differently, see Table 3). However, unlike HtM securities, there is no LLR earmarked for the existing valuation gap for AfS securities.

${ }^{20}$ The accounting rule was changed to reflect all the valuation changes for AfS securities for transparency purposes. All AfS securities are valued at market prices of the reporting date. However, the rule continues to recognize that these are unrealized losses and gains, in contrast to realized trading gains and losses. Therefore, the valuation change from AfS securities is taken out from taxable net income. 
34. If the market valuation approach is used to value securities in HtM, the capital ratio under stress is calculated as follows.

$$
\begin{aligned}
& \mathrm{CET}_{\mathrm{t}}+\underbrace{\left(\begin{array}{c}
\text { Net income before sovereign losses } \\
-\Delta \mathbf{M t M} \times \mathbf{H f T} \\
-\Delta \text { LLR for sovereign loans }
\end{array}\right)(1-\mathrm{d})(1-\tau)}_{\text {via profit and loss }}
\end{aligned}
$$

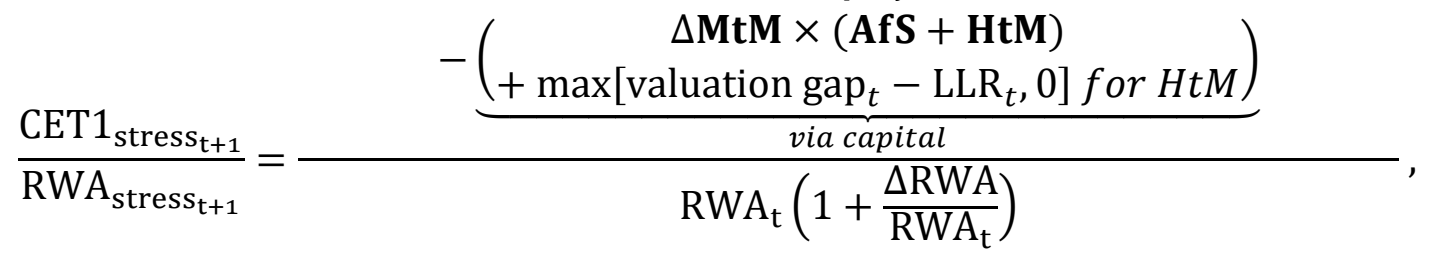

where $d$ is the dividend payout ratio, $\tau$ is the applicable tax rate, LLR denotes the amount of loan loss reserves, $\Delta M t M$ is mark-to-market valuation loss of securities (losses carry a positive sign), and $\Delta R W A$ defines the possible change in unexpected losses. Time $t$ is the latest actual value before adding stress, and $t+1$ means after stress. Expected losses from HtM securities affects the capital ratio similarly as the AfS securities. One difference is that HtM securities are likely to have a valuation gap at time $t$, which represents the difference between the amortized cost applied to value HtM securities and their market values. The LLR earmarked for HtM securities can cover a part of the gap, but a positive gap is likely to remain. Then, the stressed capital ratio represents both existing and additional losses from stress by including the remaining gap to the equation.

35. Alternatively, if the credit risk approach is applied to HtM, their expected losses are treated in the same way as those from loans. Banks need to set aside additional loan loss provisions to cover the deterioration of credit quality in the HtM securities in the stress scenario.

$$
\begin{aligned}
& \mathrm{CET}_{\mathrm{t}}+\underbrace{\left(\begin{array}{c}
\text { Net income before sovereign losses } \\
-\Delta \mathbf{M t M} \times \mathbf{H f T} \\
-\Delta \text { LLR for sovereign loans and HtM }
\end{array}\right)(1-\mathrm{d})(1-\tau)}_{\text {via profit and loss }} \\
& \frac{\mathrm{CET1}_{\text {stress }_{\mathrm{t}+1}}}{\mathrm{RWA}_{\text {stress }_{\mathrm{t}+1}}}=\frac{-\underbrace{\Delta \mathbf{M t M} \times \mathbf{A f S}}_{\text {via capital }}}{\mathrm{RWA}_{\mathrm{t}}\left(1+\frac{\Delta \mathrm{RWA}}{\mathrm{RWA}_{\mathrm{t}}}\right)}
\end{aligned}
$$




\section{EMPIRICAL APPLICATION: EXAMPLES FROM STRESS TESTS IN FSAPS FOR SELECTED EUROPEAN COUNTRIES}

36. This section illustrates the empirical application of the market-consistent valuation approach for assessing sovereign risk consistent with current FSAP practices in macroprudential solvency stress tests. We present a flexible, closed-form approach to calibrating market-implied haircuts using extreme value theory (EVT) to capture the impact of significant shocks to sovereign risk on bank solvency.

\section{A. Data Collection and Haircut Estimation}

\section{For estimating haircuts, we model the valuation change of government bonds using} the credit risk premium implied in the cost of protecting against sovereign default risksovereign CDS spreads (see Appendix II). Since sovereign credit distress is a rare event, the historical CDS spread dynamics are fitted to a generalized extreme value (GEV) distribution to derive the density forecast of a large, non-linear change in default risk (see Box 2). ${ }^{21}$ The density forecast is then incorporated into the relevant bond pricing formula or proxies of price-yield sensitivity, such as duration and convexity of the bonds. The bond pricing formula combines the default risk premium at different maturities of selected government debt securities ("benchmark bonds") with the applicable risk-free rate at the beginning of the estimation period. ${ }^{22}$ The haircuts for the market-consistent valuation of government bonds differ by the severity of sovereign risk shocks at different maturity tenors and macroeconomic scenarios. This approach was appliedwith a full parametric modeling of the CDS spread dynamics - in the FSAPs for Belgium (2013), Germany (2011), Spain (2012), and the United Kingdom (2011). ${ }^{23}$ Other FSAPs followed similar approaches using either the historical volatility of CDS or bond yields.

38. This approach generalizes the treatment of sovereign risk when the system-wide stress test of the EU banking sector was introduced (EBA 2010, 2011a; see Table 4). ${ }^{24,25}$ We use the daily data from January 2009 to December 2010 for the empirical application of the model, so that we can easily compare our results to those used in the two European exercises.

\footnotetext{
${ }^{21}$ The likelihood of the relevant macroeconomic scenario of the stress test could inform the adequate level of statistical significance of the sovereign risk shock.

${ }^{22}$ For each sample country, a selection of the most liquid (benchmark) bonds is grouped in maturity buckets of one, three, five, seven, and ten years, with a discretionary margin of +/- 0.5 years. When bond-by-bond data are available, a standard bond valuation formula (available in MS Excel ${ }^{\circledR}$ file “IMF Sovereign Risk Stress Testing Tool.xls” (available for download at https://www.imf.org/ /media/Files/Publications/WP/2019/datasets/wp19266.ashx) can be used to calculate bond values as discounted future coupon and principal repayments) and approximate the valuation haircut.

${ }^{23}$ The approach was also applied in FSAPs for several non-European countries, such as Hong Kong SAR (2014).

24 The valuation haircuts were derived based on the market-based approach suggested in this paper as part of the reference risk parameters for the market risk parameter component of the stress test.

25 The 2011 EU-wide stress test exercise (EBA 2011a, ECB 2011) involved shocks to sovereign spreads through a mixture of an across-the-board increase in yields of 75 basis points, plus a country-specific effect based on bond price movements preceding the forecasting period.
} 
This cross-validation helps assess whether our methodology can be a viable alternative to those used by European authorities using greater model flexibility.

\section{More specifically, we followed four steps for deriving the valuation haircuts: ${ }^{26}$}

- Selecting liquid government bonds at different maturities. For each country, we selected the most liquid fixed-rate local-currency-denominated government debt securities ("benchmark bonds” ${ }^{27}$ and create groups of bonds maturing within one year around the desired maturity tenor ("maturity buckets"). The sample of bonds was assumed to be representative of typical maturities of bank sovereign exposures (without knowing actual maturity information).

- Estimating the sovereign credit risk shock. For each of the identified maturity, we obtained daily time series data of the spot and forward sovereign CDS spreads ${ }^{28}$ to estimate the historical spread dynamics and determine the market-implied default rate. ${ }^{29}$ The recovery rate is endogenized in the default rate implied by the observable spread. We then calibrated the variation of spread changes over a sufficiently long estimation period ${ }^{30}$ using the GEV distribution. The distribution is suited for modeling tail events and provides a closed-form expression of their asymptotic tail behavior. ${ }^{31}$ We then obtained point estimates of expected PD at certain levels of severity (i.e., percentiles) for each year of the five-year test horizon. For the baseline scenario, we chose the last observable current or forward CDS spread (whichever is larger) to reflect current market expectations. For adverse scenarios, we applied higher country-specific credit shocks at the $75^{\text {th }}$ percentile (and higher) of the forecasted distribution. ${ }^{32}$ In all scenarios, we estimated the sovereign credit spread shock with and without a common interest rate shock of 50 basis points. ${ }^{33}$

\footnotetext{
${ }^{26}$ The template files for (i) the conversion of government bond data for the estimation of the valuation haircut ("IMF Sovereign Risk Stress Testing Tool.xls") and (ii) the download of historical CDS spread data ("Data_Input.xlsx") can be obtained at https://www.imf.org/ /media/Files/Publications/WP/2019/datasets/wp19266.ashx .

${ }^{27}$ Since the credit and interest rate assumptions refer to domestic currency yield curves it is necessary to choose local currency debt only.

${ }^{28}$ The CDS spreads were calculated consistent with the standard pricing formula using the "fair value model" of the International Swaps and Derivative Association (see Appendix II, Box A2) at quarterly payment frequencies. For euro area countries, only euro-denominated bonds were considered.

${ }^{29}$ The reference assets for the forward CDS spreads are the selected sample bonds.

${ }^{30}$ In our example, the estimation period is limited to two years (January 1, 2009 through December 30, 2010) since reliable sovereign CDS spreads for advanced economies were available only from January 1, 2009 (see Table 4).

${ }^{31}$ The cumulative GEV distribution function is calibrated under the upper bound assumption of both mean and variance being defined (see Appendices II and III).

${ }^{32}$ The selection of the $75^{\text {th }}$ percentile is consistent with the guidance on reference parameters for market risk in the EU-wide stress test in 2011. In the adverse scenario, they were set to the $25^{\text {th }}$ percentile of the empirical distribution.

${ }^{33}$ The importance of separately modeling the country-specific sovereign spread shock is consistent with recent evidence in Crump, Eusepi, and Moench (2018), who found that term premiums account for the bulk of the crosssectional and time series variation in yields and largely explain the yield curve's reaction to structural economic shocks.
} 
- Calculating individual valuation haircuts. The haircuts were set as the expected change in the prices of selected benchmark bonds vis-à-vis their market value as of the data cut-off date. The price change corresponds to the total yield changes, including the effects of the expected PDs and the risk-free rate, which varies across maturity tenors. Within each maturity group, individual bonds were priced over a five-year stress test horizon using both the adjusted zero-coupon bond and discounted cash flow methods, and considering the specific maturity dates, coupons, and coupon frequencies. ${ }^{34}$

- Determining the aggregate valuation haircut. The haircuts for the individual bonds were then aggregated to country-specific haircuts for each maturity group by taking weighted averages using the outstanding amount of these bonds as weights. ${ }^{35}$ Since the valuation haircut is specific to each benchmark bond, the aggregate valuation haircut for each country represents the weighted-average change in market valuation over the relevant stress test horizon. This implies that banks hold portfolios of sovereign debt securities similar to the portfolio of benchmark bonds used for deriving the aggregate valuation haircut when accurate portfolio data are not available (or cannot be accessed for estimation of the valuation haircuts). ${ }^{36}$ However, if complete portfolio data is indeed available, the valuation haircut can be more nuanced within each maturity bucket based on the term structure of credit risk premiums. ${ }^{37}$

\footnotetext{
${ }^{34}$ Since the CDS spread curve flattens significantly beyond the five-year maturity, we focused on a five-year maturity tenor of credit spreads and selected benchmark bonds.

35 The valuation of government bonds and the capital impact of market-implied sovereign haircuts (using historical data) might differ from that in the past due to changes in structural and macroeconomic conditions. For instance, IRB banks might need to increase risk weights for certain government bonds to better reflect their true riskiness. Also, monetary normalization will raise the "market price of risk," which may also affect investor risk appetite to take on sovereign risk. While these changes can make government bond prices more risk-sensitive, they are likely to be immaterial relative to the extreme increase of default risk under stress.

${ }^{36}$ Alternatively, one may pick a representative maturity as a general assumption of the interest rate elasticity of traded sovereign exposures.

${ }^{37}$ If the size-weighted maturity profile of sovereign portfolios is significantly different from the maturity terms at which valuation haircuts have been estimated, these haircuts may be adjusted to match the actual key rate durations.
} 


\section{Table 4. Comparison of Sovereign Valuation Haircut Methods in IMF FSAP and EU System-wide Stress Tests}

\begin{tabular}{|c|c|c|c|}
\hline & \multirow{2}{*}{$\frac{\text { IMF FSAP }^{1}}{\text { since } 2010}$} & \multicolumn{2}{|c|}{ EBA-ECB } \\
\hline & & 2011 & 2014,2016 and 2018 \\
\hline & \multicolumn{3}{|c|}{ Calculation of Sovereign Risk Shock ${ }^{2}$} \\
\hline $\begin{array}{l}\text { Common shock } \\
\text { (general yield curve) }\end{array}$ & $\begin{array}{l}\text { upward shift in the yield curve via constant or } \\
\text { maturity-dependent increase of risk-free rate (for } \\
\text { the zero-coupon bond pricing formula) or a } \\
\text { marginal change in the yield-to-maturity (for the } \\
\text { discounted cash flow formula) }\end{array}$ & $\begin{array}{l}\text { upward shift of the weighted average of national } \\
\text { sovereign CDS curves - spread shock consistent } \\
\text { with general macro scenario of a } 75 \text { basis points } \\
\text { spread increase on ten-year euro area } \\
\text { bonds and application of the relative average } \\
\text { increase (i.e., } 40 \text { percent) proportionately to all } \\
\text { other maturities of the CDS curve without altering } \\
\text { its shape }\end{array}$ & $\begin{array}{l}\text { upward shift in the yield curve as general interest rate } \\
\text { impact via maturity-specific marginal change in the } \\
\text { yield-to-maturity using changes of swap rates } \\
\text { (discounted cash flow formula) }\end{array}$ \\
\hline Data source & market-based; spot and forward CDS spreads & market-based; spot CDS spread & $\begin{array}{c}\text { market-based; government bond yields and } \\
\text { dependence structure between U.S. and German bond } \\
\text { yields }\end{array}$ \\
\hline $\begin{array}{l}\text { Idiosyncratic shock } \\
\text { (country-specific default risk) }\end{array}$ & $\begin{array}{l}\text { added to spread increase under common shock } \\
\text { (if any) }\end{array}$ & added to spread increase under common shock & $\begin{array}{l}\text { added to spread increase under common shock } \\
\text { implicit in general interest rate increase }\end{array}$ \\
\hline Measure & $\begin{array}{l}\text { based on past spread changes of forward CDS } \\
\text { spreads (for each country), estimated separately } \\
\text { for each maturity of benchmark bonds and each } \\
\text { period of the forecast horizon }\end{array}$ & $\begin{array}{c}\text { based on past spot CDS spread changes (for } \\
\text { each country), estimated separately for each } \\
\text { period of the forecast horizon }\end{array}$ & $\begin{array}{l}\text { implicit in the country-specific interest rate changes } \\
\text { ("yield shock") of government bonds via credit spread } \\
\text { impact (sovereign spread over swap) for each period } \\
\text { of the forecast horizon }\end{array}$ \\
\hline Statistical support & $\begin{array}{l}\text { current expectations from latest forward CDS } \\
\text { spread as well as different percentiles of the } \\
\text { parametrically estimated density forecast for } \\
\text { adverse scenarios }\end{array}$ & $\begin{array}{l}\text { historical (daily) volatility over the last month } \\
\text { preceding the forecast horizon }\end{array}$ & $\begin{array}{l}\text { historical volatility of CDS spreads; country-specific } \\
\text { shocks to EU long-term interest rates capture the } \\
\text { spillover impact from the initial U.S. bond yield shock } \\
\text { to German long-term yields and the widening of credit } \\
\text { spreads implied by change in sovereign bond yields of } \\
\text { EU countries }{ }^{4}\end{array}$ \\
\hline Maturity tenor ${ }^{3}$ & $\begin{array}{l}\text { large part of term structure } \\
(1,3,5,7, \text { and } 10 \text { years })\end{array}$ & $\begin{array}{l}\text { almost entire term structure } \\
\text { (3 months as well as } 1,2,3,5,10 \text {, and } 15 \text { years) }\end{array}$ & $\begin{array}{l}\text { almost entire term structure } \\
\text { (3 months as well as } 1,2,3,5,10 \text {, and }>10 \text { years) }\end{array}$ \\
\hline Estimation time period & $\begin{array}{l}\text { flexible, limited by data availability only (e.g., } \\
\text { Jan. } 1,2009 \text { to Oct. } 30,2013 \text { ( }>4.5 \text { years) in } \\
\text { the case of the FSAP for Hong Kong SAR) }\end{array}$ & between Oct. 31 and Dec. 1, 2010 ( $\approx$ one month) & $\begin{array}{l}\text { between Aug. 3, } 2012 \text { and Dec. 31, } 2013 \text { ( } \approx 1.5 \text { years) } \\
\text { for } 2014 \text { stress test; n.a. for exercises in } 2016 \text { and } \\
2018\end{array}$ \\
\hline \multirow[t]{2}{*}{ Forecast (stress) time horizon } & multiple periods ( 5 years) & front-loaded shock, single period (1 year) & $\begin{array}{l}\text { multiple periods ( } 3 \text { years) in 2014; front-loaded shock, } \\
\text { single period ( } 1 \text { year) for stress tests in } 2016 \text { and } 2018\end{array}$ \\
\hline & \multicolumn{3}{|c|}{ Calculation of Valuation Haircut $^{5}$} \\
\hline Valuation method & $\begin{array}{l}\text { zero-coupon bond pricing and discounted cash } \\
\text { flow method }\end{array}$ & \multicolumn{2}{|c|}{ discounted cash flow method } \\
\hline Bond selection & \multicolumn{3}{|c|}{$\begin{array}{l}\text { representative selection of outstanding local currency-denominated sovereign debt in each sample country ("benchmark bonds"); creation of maturity group } \\
\text { of bonds maturing within a short time window around the desired maturity tenor }\end{array}$} \\
\hline Maturity group & $\begin{array}{c}5 \text { years } \\
\text { (extendible to any selection of maturity group) }\end{array}$ & 3 months as well as $1,2,3,5,10$ and 15 years & 3 months as well as $1,2,3,5,10$ and $>10$ years \\
\hline $\begin{array}{l}\text { Length of window around } \\
\text { maturity groups ("maturity }\end{array}$ & \pm 6 months & \pm 2 months (3-month maturity grou & up) to \pm 3 years (10-year maturity group) \\
\hline Yield adjustment & \multicolumn{3}{|c|}{ adjustment of yields to take into account the change of yields between the end-point of the estimation window and starting point of the stress period } \\
\hline Applicable scenarios & baseline and adverse scenarios & adverse & scenario only \\
\hline $\begin{array}{l}\text { Scope of application } \\
\text { (expected losses) }^{7}\end{array}$ & $\begin{array}{c}\text { sovereign exposures (direct and indirect) in both } \\
\text { trading and banking books assessed under } \\
\text { market valuation approach; possible exception } \\
\text { of loans and receivables under credit risk } \\
\text { approach }^{8}\end{array}$ & $\begin{array}{r}\text { sovereign exposures (direct and indirect }{ }^{9} \text { ), ass } \\
\text { available for sale (AfS)) under market valuation al } \\
\text { loans and receivables in the banking }\end{array}$ & $\begin{array}{l}\text { ssessed at fair value (available-for-trading (AfT) and } \\
\text { approach: } ;^{10} \text { held-to-maturity }(\mathrm{HtM} \text { ) securities as well as } \\
\text { book assessed under credit risk approach }\end{array}$ \\
\hline Published information & $\begin{array}{l}\text { valuation haircuts for all relevant countries, } \\
\text { normally published in a "Technical Note on } \\
\text { Stress Testing" together with the "Financial } \\
\text { System Stability Assessment" report }\end{array}$ & valuation haircuts, by country & valuation haircuts, by country \\
\hline \multicolumn{4}{|c|}{ 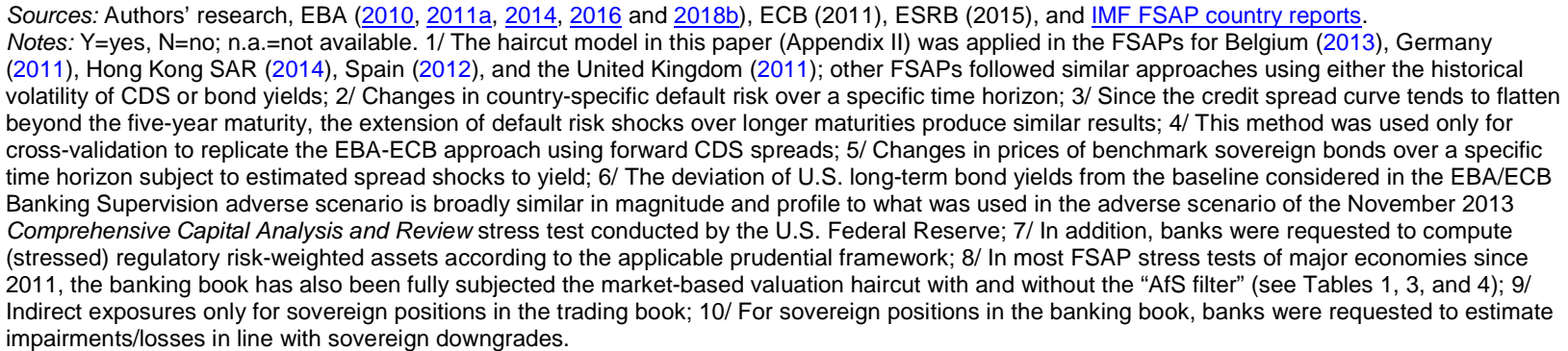 } \\
\hline
\end{tabular}

Calculation of Valuation Haircut $^{5}$

\begin{tabular}{|c|c|c|}
\hline $\begin{array}{l}\text { Common shock } \\
\text { (general yield curve) }\end{array}$ & $\begin{array}{l}\text { upward shift in the yield curve via constant or } \\
\text { maturity-dependent increase of risk-free rate (for } \\
\text { the zero-coupon bond pricing formula) or a } \\
\text { marginal change in the yield-to-maturity (for the } \\
\text { discounted cash flow formula) }\end{array}$ & 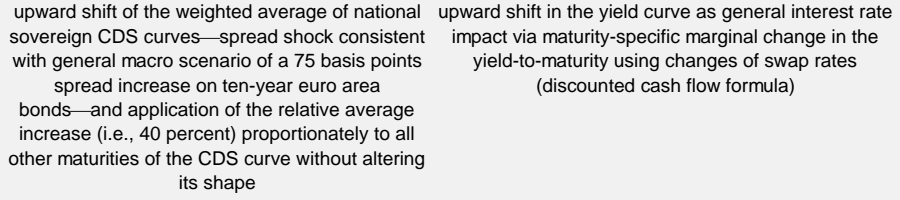 \\
\hline Data source & market-based; spot and forward CDS spreads & $\begin{array}{l}\text { market-based; government bond yields and } \\
\text { dependence structure between U.S. and German bond } \\
\text { yields }\end{array}$ \\
\hline $\begin{array}{l}\text { Idiosyncratic shock } \\
\text { (country-specific default risk) }\end{array}$ & $\begin{array}{l}\text { added to spread increase under common shock } \\
\qquad \text { (if any) }\end{array}$ & $\begin{array}{l}\text { added to spread increase under common shock } \\
\text { implicit in general interest rate increase }\end{array}$ \\
\hline Measure & $\begin{array}{l}\text { based on past spread changes of forward CDS } \\
\text { spreads (for each country), estimated separately } \\
\text { for each maturity of benchmark bonds and each } \\
\text { period of the forecast horizon }\end{array}$ & $\begin{array}{l}\text { implicit in the country-specific interest rate changes } \\
\text { ("yield shock") of government bonds via credit spread } \\
\text { impact (sovereign spread over swap) for each period } \\
\text { of the forecast horizon }\end{array}$ \\
\hline Statistical support & $\begin{array}{l}\text { current expectations from latest forward CDS } \\
\text { spread as well as different percentiles of the } \\
\text { parametrically estimated density forecast for } \\
\text { adverse scenarios }\end{array}$ & $\begin{array}{l}\text { historical volatility of CDS spreads; country-specific } \\
\text { shocks to EU long-term interest rates capture the } \\
\text { spillover impact from the initial U.S. bond yield shock } \\
\text { to German long-term yields and the widening of credit } \\
\text { spreads implied by change in sovereign bond yields of } \\
\text { EU countries }{ }^{4}\end{array}$ \\
\hline Maturity tenor ${ }^{3}$ & $\begin{array}{l}\text { large part of term structure } \\
(1,3,5,7, \text { and } 10 \text { years })\end{array}$ & $\begin{array}{cc}\text { almost entire term structure } & \text { almost entire term structure } \\
\text { ( } 3 \text { months as well as } 1,2,3,5,10 \text {, and } 15 \text { years }) & \text { (3 months as well as } 1,2,3,5,10 \text {, and }>10 \text { years) }\end{array}$ \\
\hline Estimation time period & $\begin{array}{l}\text { flexible, limited by data availability only (e.g., } \\
\text { Jan. } 1,2009 \text { to Oct. } 30,2013 \text { ( }>4.5 \text { years) in } \\
\text { the case of the FSAP for Hong Kong SAR) }\end{array}$ & $\begin{array}{l}\text { between Oct. } 31 \text { and Dec. 1, } 2010 \text { ( } \approx \text { one month) between Aug. 3, } 2012 \text { and Dec. 31, } 2013(\approx 1.5 \text { years) } \\
\text { for } 2014 \text { stress test; n.a. for exercises in } 2016 \text { and } \\
2018\end{array}$ \\
\hline \multirow[t]{2}{*}{ Forecast (stress) time horizon } & multiple periods (5 years) & $\begin{array}{l}\text { multiple periods ( } 3 \text { years) in 2014; front-loaded shock, } \\
\text { single period ( } 1 \text { year) for stress tests in } 2016 \text { and } 2018\end{array}$ \\
\hline & \multicolumn{2}{|r|}{ Calculation of Valuation Haircut ${ }^{5}$} \\
\hline Valuation method & $\begin{array}{l}\text { zero-coupon bond pricing and discounted cash } \\
\qquad \text { flow method }{ }^{6}\end{array}$ & discounted cash flow method \\
\hline Bond selection & \multicolumn{2}{|c|}{$\begin{array}{l}\text { representative selection of outstanding local currency-denominated sovereign debt in each sample country ("benchmark bonds"); creation of maturity group } \\
\text { of bonds maturing within a short time window around the desired maturity tenor }\end{array}$} \\
\hline Maturity group & $\begin{array}{c}5 \text { years } \\
\text { (extendible to any selection of maturity group) }\end{array}$ & 3 months as well as $1,2,3,5,10$ and $>10$ years \\
\hline $\begin{array}{l}\text { Length of window around } \\
\text { maturity groups ("maturity }\end{array}$ & \pm 6 months & \pm 2 months (3-month maturity group) to \pm 3 years (10-year maturity group) \\
\hline Yield adjustment & \multicolumn{2}{|c|}{ adjustment of yields to take into account the change of yields between the end-point of the estimation window and starting point of the stress period } \\
\hline Applicable scenarios & baseline and adverse scenarios & adverse scenario only \\
\hline $\begin{array}{l}\text { Scope of application } \\
\text { (expected losses) }^{7}\end{array}$ & $\begin{array}{c}\text { sovereign exposures (direct and indirect) in both } \\
\text { trading and banking books assessed under } \\
\text { market valuation approach; possible exception } \\
\text { of loans and receivables under credit risk } \\
\text { approach }^{8}\end{array}$ & $\begin{array}{l}\text { sovereign exposures (direct and indirect }{ }^{9} \text { ), assessed at fair value (available-for-trading (AfT) and } \\
\text { available for sale (AfS)) under market valuation approach; }{ }^{10} \text { held-to-maturity }(\mathrm{HtM}) \text { securities as well as } \\
\text { loans and receivables in the banking book assessed under credit risk approach }\end{array}$ \\
\hline Published information & $\begin{array}{l}\text { valuation haircuts for all relevant countries, } \\
\text { normally published in a "Technical Note on } \\
\text { Stress Testing" together with the "Financial } \\
\text { System Stability Assessment" report }\end{array}$ & valuation haircuts, by country \\
\hline \multicolumn{3}{|c|}{ 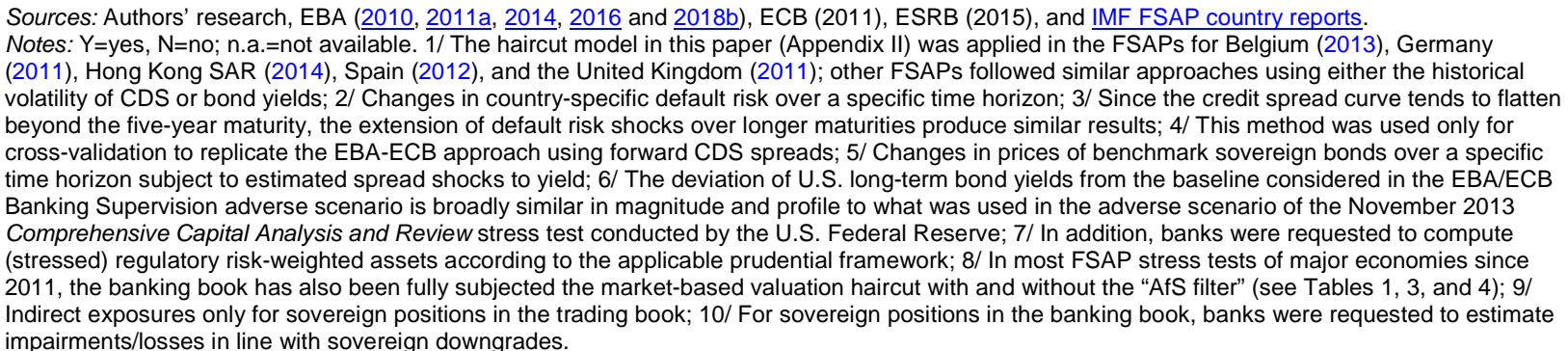 } \\
\hline
\end{tabular}




\title{
Box 2. Reasons for Choosing CDS Spread Dynamics for Estimating Valuation Haircuts
}

\author{
A closed-form pricing approach for estimating market-implied sovereign risk using CDS spread dynamics seems to be \\ preferable to other methods that calibrate sovereign valuation haircuts based on the price volatility of government \\ bonds:
}

- $\quad$ Risk measurement - CDS spreads are relatively “pure” measures of default risk (IMF 2013), which might otherwise be "contaminated" by the price impact of security characteristics (such as coupon frequency, creditor rights, and redemption features) as well as inflation and term premia (and their volatility) if it were extracted from government bond prices. Using CDS spreads also avoids potential basis risk from the choice of the appropriate risk-free rate and its term structure impacting the extraction of the credit spread component of government bond yields. In the event of a default, the CDS contract payout usually recovers the par value, which means there is no need to determine the implied default probability (since the recovery rate is endogenized in the observed bond price). Moreover, CDS spreads represent sovereign risk more accurately than sovereign bond yields when yields are kept artificially low by central bank bond purchase programs. However, sovereign CDS spreads could also be influenced by price distortions. Since sovereign CDS contracts for most countries tend to be denominated in U.S. dollars, FX rate changes (which are often positively correlated with shocks to sovereign risk) could amplify the CDS spread dynamics and lead to a potential overestimation of sovereign risk during times of stress (relative to the dynamics of credit spreads implied by price changes of local currency-denominated government bonds). In addition, CDS contracts provide protection sellers with a “delivery option” (i.e., the cheapest-todeliver government bond), which might raise the credit spread if it implies a relative reduction of the expected recovery rate (relative to that of cash instruments). ${ }^{1}$

- $\quad$ Market expectations - In addition, our model specification incorporates market expectations of future changes in sovereign risk (as reflected in forward CDS contracts), and, therefore, ensures time-consistency between the marketbased valuation haircut and the actual valuation change in each year of the stress test horizon. We can also examine the performance of using forward CDS contracts. Figure A2.2 (in Appendix II) shows the empirical distribution of spot and forward sovereign CDS spreads (with different starting times) for major AE and EMDE countries as of end-2010 (fitted to the GEV distribution specified in equation (8) in Appendix II). These data were used for the estimation of marketbased valuation haircuts in Appendix V, Tables A5.1 and A5.2. We find that forward CDS contracts overstated sovereign default risk in the wake of the European sovereign debt crisis but adequately projected the potential escalation of sovereign risk in vulnerable countries. ${ }^{2}$

- $\quad$ Model flexibility and price consistency of shocks - The functional form supports a more nuanced assessment of sovereign risk over the projection horizon and generates tractable estimates of tail events (outside the historical experience, which can be reconciled to the probabilistic severity of the overall scenario). This also offers the opportunity to cross-validate other approaches. Moreover, the estimated default risk is integrated into an asset pricing model, and, thus, controls for the marginal effect of changes in default risk on the convexity of government bond prices.

Note: 1/ All CDS spreads are derived from over-the-counter (OTC) markets and tend to be liquid only for a few maturities (compared to government bonds, which, at least in advanced economies, are traded in very liquid markets with a wide investor participation). The methodology in this paper is focused on 5-year sovereign CDS contracts, which is the most liquid maturity term (see Tables 4 and 5 ). 2 / For most countries, the estimated CDS spread under the two adverse scenarios (defined as the historical density forecast at the $75^{\text {th }}$ and $90^{\text {th }}$ percentiles) exceeded the realized CDS spread-measured at the end of each year (shown as grey dots in the boxplots on the left side of each country chart) and during each year (shown as boxplots on the right side of each country chart), except for the first year of the stress test horizon. Germany, Japan, and the United States notably benefitted from safe haven flows during the European sovereign debt crisis, which resulted in a gradual decline of sovereign CDS spreads. In contrast, for Italy and France, the actual sovereign CDS spreads during the first year of the risk horizon were higher than projected in the mild adverse scenario $\left(75^{\text {th }}\right.$ percentile) - at the $86^{\text {th }}$ and $81^{\text {th }}$ percentiles of the empirical distribution of one-year forward CDS and the $89^{\text {th }}$ and $87^{\text {th }}$ percentiles of the empirical distribution of spot CDS. 


\section{B. Findings}

40. Our estimated haircuts are broadly consistent with those in the European stress testing exercise but provide a more comprehensive and nuanced assessment. Table 5 provides the estimated valuation haircuts for sovereign exposures with an average maturity of five years in the baseline scenario and two adverse scenarios at end-2010 (see also Appendix V, Tables A5.1 and A5.2 for detailed results, including for non-European countries). The haircuts are broadly comparable to those used in the first European system-wide stress testing exercises (EBA 2010, 2011a; ECB 2011). ${ }^{38}$ However, the severity of haircuts seemed more plausible and differentiated across countries due to greater model flexibility regarding statistical confidence and configuration of interest rate shocks (see Box 2). ${ }^{39}$ Our distribution-based model specification also considers the market-implied assessment of future changes in sovereign risk, and, therefore, enhances the analysis of sovereign risk by anchoring the calibration of shocks in market expectations.

\section{Under a severe adverse scenario, sovereign haircuts on stressed European countries} average 15 percent during the first year of the stress test horizon. As of end-2010, forward CDS spreads indicate elevated expected default risk relative to the historical experience. Actual CDS-implied default risk of stressed European economies was already much higher than their historical average (and higher than the 75th percentile of the density distribution) at that time. In the case of Greece, forward prices on CDS imply near-default, which pushes the haircuts based on actual end-2010 data beyond the $99^{\text {th }}$ percentile (not reported). The results for other European countries are relatively benign at an average haircut of about five percent during the first year of the test horizon. There are little (if any) additional haircuts beyond 2011, given the flattening of the CDS curve at longer maturities and heavy discounting of bonds issued by stressed countries during 2011.

\footnotetext{
${ }^{38}$ In the case of Greece, our estimated haircuts are close to those used in the European system-wide stress testing exercise (EBA, 2011a), and in line with the average 21 percent mark-down of private creditors (Boone and Ardanga 2011).

${ }^{39}$ Our approach does not seem to be influenced by liquidity concerns in the sovereign CDS market. Historical data (since January 2011) suggest the pricing and trading volume of sovereign CDS spreads in the most significant sample countries are only weakly correlated.
} 
Table 5. Comparison of Sovereign Valuation Haircuts in European Stress Tests (2010-2011) and Results in IMF Stress Testing (Percent)

\begin{tabular}{|c|c|c|c|c|c|c|c|c|c|c|c|}
\hline & \multicolumn{4}{|c|}{ CEBS $^{1}$} & \multirow{4}{*}{$\begin{array}{c}\text { EBA }^{2} \\
\text { Adverse } \\
\end{array}$} & \multicolumn{6}{|c|}{ IMF $^{3}$} \\
\hline & \multirow{2}{*}{\multicolumn{2}{|c|}{ Baseline }} & & & & \multicolumn{3}{|c|}{ without common shock } & \multicolumn{3}{|c|}{ with common shock } \\
\hline & & & \multicolumn{2}{|c|}{ Adverse } & & \multirow[t]{2}{*}{ Baseline } & \multicolumn{2}{|c|}{ Adverse } & \multirow[t]{2}{*}{ Baseline } & \multicolumn{2}{|c|}{ Adverse } \\
\hline & & & & & & & at $75^{\text {th }}$ pct. & at $90^{\text {th }}$ pct. & & at $75^{\text {th }}$ pct. & at $90^{\text {th }}$ pct \\
\hline & 2010 & 2011 & 2010 & 2011 & 2011 & 2011 & 2011 & 2011 & 2011 & 2011 & 2011 \\
\hline \multicolumn{12}{|l|}{ Euro area } \\
\hline Austria & 1.0 & 2.8 & 3.1 & 5.6 & 3.4 & 2.1 & 1.3 & 2.2 & 4.3 & 3.5 & 4.5 \\
\hline Belgium & 1.4 & 3.1 & 4.3 & 6.9 & 5.9 & 7.2 & 3.9 & 7.8 & 9.5 & 6.3 & 10.0 \\
\hline Finland & 0.0 & 3.3 & 1.9 & 6.1 & 2.7 & 0.9 & 0.5 & 0.8 & 3.2 & 2.8 & 3.0 \\
\hline France & 1.5 & 3.0 & 3.7 & 6.0 & 4.1 & 3.5 & 2.0 & 3.7 & 5.8 & 4.4 & 6.1 \\
\hline Germany & 0.1 & 2.5 & 2.3 & 4.7 & 2.1 & 2.1 & 0.8 & 1.4 & 4.4 & 3.2 & 3.8 \\
\hline Netherlands & 1.1 & 2.5 & 3.0 & 5.2 & 3.2 & 1.8 & 0.9 & 1.5 & 4.0 & 3.1 & 3.8 \\
\hline \multicolumn{12}{|l|}{ Stressed } \\
\hline Greece & 3.9 & 4.3 & 20.1 & 23.1 & 12.6 & 3.7 & 11.9 & 27.0 & 5.9 & 13.9 & 28.7 \\
\hline Italy & 1.2 & 2.9 & 4.9 & 7.4 & 8.4 & 5.5 & 4.0 & 8.0 & 7.7 & 6.2 & 10.1 \\
\hline Ireland & 1.6 & 4.2 & 8.6 & 12.8 & 12.6 & 12.0 & 10.9 & 22.4 & 14.3 & 13.3 & 24.4 \\
\hline Portugal & 2.3 & 3.7 & 11.1 & 14.1 & 11.6 & 10.4 & 8.4 & 17.5 & 12.5 & 10.6 & 19.4 \\
\hline Spain & 1.3 & 4.1 & 6.7 & 12.0 & 9.0 & 8.7 & 5.5 & 11.3 & 11.1 & 8.0 & 13.6 \\
\hline \multicolumn{12}{|l|}{ Non-euro area } \\
\hline Czech Republic & 0.0 & 2.7 & 4.6 & 11.4 & 3.2 & 0.8 & 1.3 & 2.2 & 3.2 & 3.6 & 4.5 \\
\hline Denmark & 0.0 & 1.4 & 2.1 & 5.2 & 2.6 & 1.2 & 0.6 & 1.0 & 3.6 & 3.0 & 3.4 \\
\hline Norway 4/ & n.a. & n.a. & n.a. & n.a. & 1.5 & n.a. & n.a. & n.a. & n.a. & n.a. & n.a. \\
\hline Poland & 2.6 & 6.1 & 6.4 & 12.3 & 2.8 & 2.3 & 2.3 & 4.0 & 4.7 & 4.8 & 6.5 \\
\hline Sweden & 1.3 & 2.3 & 5.0 & 6.7 & 1.9 & 1.1 & 0.9 & 1.6 & 3.4 & 3.2 & 3.8 \\
\hline United Kingdom & 5.0 & 6.9 & 7.7 & 10.2 & 4.7 & 1.0 & 1.2 & 2.2 & 3.4 & 3.6 & 4.6 \\
\hline
\end{tabular}

Sources: Authors' research, EBA, and ECB.

Notes: Estimation based on the valuation haircuts of benchmark bonds at 5-year maturity. 1/ Valuation haircuts under both baseline and adverse scenarios (EBA 2010); 2/ Valuation haircuts under the adverse scenario (ECB 2011); 3/ FSAP haircuts using the zero-coupon pricing approach (as specified in Appendix II) based on current market expectations using end-year forward CDS prices

(baseline scenario) as well as the $75^{\text {th }}$ and the $90^{\text {th }}$ percentiles of the empirically fitted density distribution of a country-specific credit spread shock (adverse scenario), with and without a common interest rate shock of 50 basis points for all countries; 4/ No availability of liquid benchmark bonds/CDS swaps for Norway. 


\section{CONCLUSION}

42. In this paper, we presented how to stress test for sovereign risk, largely based on FSAP experiences, with a particular focus on a novel approach for calibrating marketconsistent valuation haircuts. Macroprudential solvency stress tests, such as those in FSAPs, share the following common characteristics in assessing the capital impact of sovereign distress:

- Comprehensive scope - It is ideal for covering all sovereign exposures in both the trading and banking books, for instance, by following the BCBS's semi-annual Basel III monitoring exercises (BCBS 2018a and 2018b), including indirect exposures that are either government-guaranteed or collateralized by instruments issued by sovereign entities.

Nonetheless, the structure of sovereign exposures (and their materiality) or data constraints varying across countries and may require narrowing the scope to (i) market valuation losses from government securities (mostly for banks in AEs) and (ii) higher provisions for loan exposures to general government and SOEs, which often dominate sovereign exposures of banks in EMDEs.

- Market-consistent valuation-The market valuation approach provides a transparent capital assessment of sovereign risk. Applying this approach to all securities, including HtM securities, allows the most transparent and comparable assessment across banks and jurisdictions. The treatment of HtM securities varied across FSAPs. In most cases, the credit risk approach was applied to loans and receivables (to capture the impact of impairments and downgrade risk); however, this approach might underestimate potential losses if there is no major distress event in the historical data. In these cases, using credit risk parameters consistent with the market valuation approach can generate sufficiently severe shocks.

- Unchanged risk weights-Capital requirements for unexpected losses from local sovereign exposures are very low due to their status as "safe assets." Stress tests typically maintain the prevailing capital intensity since the capital impact of revising the risk weights for sovereign exposures is likely to be very large, and policy discussions on reforming the current regulatory treatment are evolving.

- Adjusting for existing losses for sovereigns with ongoing distress-When stress is already ongoing, the latest market valuation could be even lower than the value reflected in solvency ratio for some exposures. Then, it is more transparent to separate deterioration of solvency ratio due to already materialized stress from additional stress in the adverse scenario.

- Integrating sovereign risk into the macroeconomic scenario-Where there are higher chances of outright sovereign default in economies where a large part of sovereign exposures are loans and guarantees (including state-owned enterprises), a more extensive range of macro-financial spillover effects become more important. Then, focusing on the valuation changes with sovereign securities may become too narrow. A more comprehensive approach, including an effort to embed them in a macro scenario- - the 
monetization of fiscal deficits (or large fiscal deficits with loose monetary policy) and resulting hyperinflation and currency crises with capital outflows-is likely to be essential.

\section{When calibrating the valuation haircuts for sovereign securities, our approach} underscores the importance of accounting for the tail-risk nature of sovereign risk. The potential losses from sovereign risk are likely to have a long tail: there is a very small chance that could cause extreme losses. Without using an adequate method, a stress test is likely to underestimate the potential impact. The paper presented the method that fits a GEV distribution to the historical spread dynamics of spot and forward sovereign CDS. This approach allows us to derive the density forecast of severe, non-linear changes in the credit risk premium consistent with the tail risk nature of sovereign distress within a flexible functional form. CDS spreads, when available, tend to provide a "pure” measure of maturity-consistent default risk than bond yields.

\section{An integrated sovereign risk assessment for macroprudential surveillance and} financial stability analysis will require additional work. The market valuation approach focuses on the direct impact of sovereign distress on bank solvency but does not consider other transmission channels across sectors and countries. Such feedback effects can be assessed more comprehensively by either (i) interacting sovereign debt sustainability analysis and bank stress tests or (ii) estimating the effects in empirical multi-sector models (such as Global Vector Autoregressive (GVAR) approaches), co-dependence models for both banks and sovereigns, or general equilibrium models with bank and sovereign distress. In addition, the interaction between solvency and liquidity conditions under stress could be explicitly addressed as part of integrated stress testing frameworks that model dynamic and systemic effects from credit, market and liquidity risks. For example, the implications of higher sovereign risk on bank profitability and liquidity risk due to higher funding costs could be explored, as well as the implications of setting higher haircuts on government debt as a key component of bank liquidity buffers. ${ }^{40}$ While these models are being developed, it is still hard to assess their performance.

\footnotetext{
${ }^{40}$ In principle, the same haircut estimation approach could be used for gauging haircuts to liquid assets in liquidity stress tests. The haircut for a liquidity stress test should be higher than those used for a solvency test (e.g., by taking the shock from tails of the distribution). The time horizon for a liquidity stress test is much shorter than that of a solvency test, and the distribution of yield changes within a month is much wider than the distribution of annual yield changes.
} 


\section{REFERENCES}

Acharya, Viral. 2018. “Understanding and Managing Interest Rate Risk at Banks.” Speech at the Fixed Income Money Markets and Derivatives Association (FIIMDA) Annual Dinner, January 15, Mumbai.

Altavilla, Carlo, Marco Pagano, and Saverio Simonelli. 2017. "Bank Exposures and Sovereign Stress Transmission.” Review of Finance 21 (6): 2103-39.

Altman, Edward, Andrea Resti, and Andrea Sironi. 2004."Default Recovery Rates in Credit Risk Modelling: A Review of the Literature and Empirical Evidence.” Economic Notes 3 (2): 183-208.

Ams, Julianne, Reza Baqir, Anna Gelpern, and Christoph Trebesch. 2018. "Sovereign Default.” In Sovereign Debt: A Guide for Economists and Practitioners, edited by S. Ali Abbas, Alex Pienkowski, and Kenneth Rogoff. Chapter 7. Oxford: Oxford University Press.

Ari, Anil. 2017. “Sovereign Risk and Bank Risk-Taking.” IMF Working Paper 17/280, International Monetary Fund, Washington, DC.

Artzner, Philippe, Freddy Delbaen, Jean-Marc Eber, and David Heath. 1999. "Coherent Measures of Risk.” Mathematical Finance 9 (3): 203-28.

BCBS (Basel Committee on Banking Supervision). 2016. “Standards: Minimum Capital Requirements for Market Risk.” January, Bank for International Settlements, Basel. . 2017a. “The Regulatory Treatment of Sovereign Exposures.” December. Bank for International Settlements, Basel.

. 2017b. “Finalizing Post-Crisis Reforms.” December. Bank for International Settlements, Basel.

. 2017c. "Standards: Regulatory Treatment of Accounting Provisions-Interim Approach and Transitional Arrangements.” March. Bank for International Settlements, Basel.

. 2018a. “Basel III Monitoring Report.” October. Bank for International Settlements, Basel.

. 2018b. “Instructions for Basel III Monitoring.” February. Bank for International Settlements, Basel.

Black, Fischer, and Myron Scholes. 1973. “The Pricing of Options and Corporate Liabilities.” Journal of Political Economy 81 (3): 637-54.

Boone, Laurence, and Silvia Ardagna. 2011. "Economics Eurozone-Euro Rendezvous: Big Bang?” July 21. Economic Analysis, Bank of America-Merrill Lynch, London. 
Borwein, Jonathan M., David M. Bradley, and Richard E. Crandall. 2000. “Computational Strategies for the Riemann Zeta Function.” Journal of Computational and Applied Mathematics 121 (11): 247-96.

Brigo, Damiano. 2004. “Constant Maturity Credit Default Swap Pricing with Market Models.” December. Working Paper, Department of Mathematics, King’s College London.

Brigo, Damiano, and Fabio Mercurio. 2006. Interest Rate Models: Theory and Practice, $2^{\text {nd }}$ edition. (Heidelberg: Springer Finance).

Brigo, Damiano, and Massimo Morini. 2005. “CDS Market Formulas and Models.” Mimeo.

Chatterjee, Somnath and Andreas A. Jobst. 2019. "Market-implied Systemic Risk and Shadow Capital Adequacy.” Staff Working Paper No. 823, September. Bank of England, London.

Coles, Stuart. 2001. An Introduction to Statistical Modelling of Extreme Values. Heidelberg: Springer Verlag.

Crump, Richard K., Stefano Eusepi, and Emanuel Moench. 2018. "The Term Structure of Expectations and Bond Yield.” April. Staff Reports No. 775, Federal Reserve Bank of New York.

De Marco, Filippo, and Marco Macchiavelli. 2016. “The Political Origin of Home Bias: The Case of Europe.” Finance and Economics Discussion Series 2016-060, Board of Governors of the Federal Reserve System, Washington, DC.

Dell’Ariccia, Giovanni, Caio Ferreira, Nigel Jenkinson, Luc Laeven, Alberto Martin, Camelia Minoiu, and Alex Popov. 2018. "Managing the Sovereign-Bank Nexus.” September. IMF Departmental Paper 18/16, International Monetary Fund, Washington, DC.

Embrechts, Paul, Claudia Klüppelberg, and Thomas Mikosch. 1997. Modeling Extremal Events for Insurance and Finance. Heidelberg: Springer Verlag.

Enria, Andreas, Adam Farkas and Lars J. Overby. 2016. "Sovereign Risk: Black Swans and White Elephants.” European Economy 1: 51-71.

EBA (European Banking Authority). 2010. “Aggregate Outcome of the 2010 EU-wide Stress Test Exercise Coordinated by CEBS in Cooperation with the ECB.” July. European Banking Authority, London. . 2011a. “2011 EU-wide Stress Test: Methodological Note.” March. European Banking Authority, London. . 2011b. “Capital Buffers for Addressing Market Concerns over Sovereign ExposuresMethodological Note.” October. European Banking Authority, London. 
. 2012. "Final Report on the Implementation of Capital Plans Following the EBA's 2011 Recommendation on the Creation of Temporary Capital Buffers to Restore Market Confidence.” October. European Banking Authority, London.

. 2014. “2014 EU-wide Stress Test: Aggregate Results.” October. European Banking Authority, London.

. 2016. “2016 EU-wide Stress Test: Results.” July. European Banking Authority, London. . 2017a. “Annex V. Reporting on Financial Information.” April. European Banking Authority, London.

. 2017b. "Final Report: Draft Implementing Standards Amending Implementing Regulation (EU) No 680/2014.” April. European Banking Authority, London. . 2018a. “2018 EU-wide Stress Test: Methodological Note.” January. European Banking Authority, London.

. 2018b. “2018 EU-wide Stress Test: Results.” November. European Banking Authority, London.

ECB (European Central Bank). 2011. "Appendix 4-Guidance for Calculations of Losses Due to Application of Market Risk Parameters and Sovereign Haircuts.” March (Frankfurt am Main: European Central Bank).

ESRB (European Systemic Risk Board). 2015. "Report on the Regulatory Treatment of Sovereign Exposures.” March. European Central Bank, Frankfurt am Main.

Fisher, Ronald A., and Leonard H. C. Tippett. 1928. "Limiting Forms of the Frequency Distribution of the Largest or Smallest Member of a Sample.” Proceedings of the Cambridge Philosophical Society 24 (2): 180-90.

Fuster, Andreas, and James Vickery. 2018. "Regulation and Risk Shuffling in Bank Securities Portfolios.” June. Staff Reports No. 851, Federal Reserve Bank of New York.

Gnedenko, Boris V. 1943. “Sur la Distribution Limite du Terme Maximum d’Une Série Aléatoire.” Annals of Mathematics 44 (3): 423-53.

Grandia, Roel, Petra Hänling, Michelina Lo Russo, and Pontus Åberg. 2019. “Availability of High-quality Liquid Assets and Monetary Policy Operations: An Analysis for the Euro Area.” February. Occasional Paper Series No. 218, European Central Bank, Frankfurt am Main.

Gray, Dale F., and Andreas A. Jobst. 2010a. "New Directions in Financial Sector and Sovereign Risk Management.” Journal of Investment Management 8 (1): 23-38. 
. 2010b. “Risk Transmission Between Sovereigns and Banks in Europe.” In IMF Global Financial Stability Report. October. Chapter 1. Washington, DC: International Monetary Fund.

. 2011a. “Modeling Systemic and Sovereign Risk.” In Lessons from the Financial Crisis, edited by Arthur Berd. London: RISK Books.

. 2011b. “Modelling Systemic Financial Sector and Sovereign Risk.” Sveriges Riksbank Economic Review 2: 68-106.

Hannoun, Hervé. 2011. "Sovereign Risk in Bank Regulation and Supervision: Where Do We Stand?” Paper presented at the High-Level Meeting for the Middle East and North Africa Region, Financial Stability Institute and Arab Monetary Fund, Abu Dhabi, UAE, October 21.

IMF (International Monetary Fund). 2013. “A New Look at the Role of Sovereign Credit Default Swaps.” In IMF Global Financial Stability Report. April. Chapter 2. Washington, DC: International Monetary Fund.

. 2014a. "How Do Changes in the Investor Base, and Financial Deepening Affect Emerging Market Economies?” In IMF Global Financial Stability Report. April. Chapter 2. Washington, DC: International Monetary Fund.

. 2014b. "IMF Executive Board Reviews Mandatory Financial Stability Assessments Under the Financial Sector Assessment Program.” Press Release 14/08, January 13, International Monetary Fund, Washington, DC.

. 2015. “From Banking to Sovereign Stress: Implications for Public Debt.” IMF Policy Paper, International Monetary Fund, Washington, DC.

Jeanblanc, Monique, and Marek Rutkowski. 2000. “Default Risk and Hazard Process.” In Mathematical Finance-Bachelier Congress 2000, edited by Helyette Geman, Dilip Madan, Stanley R. Pliska, and Ton Vorst. Heidelberg: Springer Finance.

Jenkins, Patrick. 2019. "EU’s Wilful Blindness to Sovereign Risk Adds to Eurozone Danger.” Opinion. Financial Times. January. https://www.ft.com/content/c83f64c2-103a-11e9a3aa-118c761d2745 (subscription required).

Jobst, Andreas A. 2007. "Operational Risk-The Sting is Still in the Tail But the Poison Depends on the Dose.” Journal of Operational Risk 2 (2): 1-56.

Jobst, Andreas A., Li Lian Ong, and Christian Schmieder. 2013. “An IMF Framework for Macroprudential Bank Solvency Stress Testing: Application to S-25 and Other G-20 Country FSAPs.” IMF Working Paper 13/68, International Monetary Fund, Washington, DC. 
. 2017. "Macroprudential Liquidity Stress Testing in FSAPs for Systemically Important Financial Systems.” IMF Working Paper 17/102, International Monetary Fund, Washington, DC.

Longstaff, Francis A., Jun Pan, Lasse H. Pedersen, and Kenneth J. Singleton. 2011. "How Sovereign is Sovereign Credit Risk?” American Economic Journal: Macroeconomics 3 (2): 75-103.

Merton, Robert C. 1973. “Theory of Rational Option Pricing.” Bell Journal of Economics and Management Science 4 (Spring): 141-83.

. 1974. “On the Pricing of Corporate Debt: The Risk Structure of Interest Rates.” Journal of Finance 29 (May): 449-70.

Schmitz, W. Stefan, Michael Sigmund, and Laura Valderrama. 2017. “Bank Solvency and Funding Cost: New Data and New Results.” IMF Working Paper 17/116, International Monetary Fund, Washington, DC.

Segoviano, Miguel. 2006. "Portfolio Credit Risk and Macroeconomic Shocks: Applications to Stress Testing under Data Restricted Environments.” IMF Working Paper 06/283, International Monetary Fund, Washington, DC.

Sondow, Jonathan. 1998. “An Antisymmetric Formula for Euler’s Constant.” Mathematics Magazine 71 (3): 219-220.

Thérond, Pierre and Pierre Ribereau. 2012. “Théorie des Valeurs Extrêmes.” L'actuariel 5 (June): 52-54.

Vandewalle, Börn, Jan Beirlant, and Mia Hubert. 2004. “A Robust Estimator of the Tail Index Based on an Exponential Regression Model.” In Theory and Applications of Recent Robust Methods (Statistics for Industry and Technology series), edited by Mia Hubert, Greet Pison, Anja Struyf, and Stefan Van Aelst. Basel: Birkhäuser.

Wong, Eric, and Cho-Hoi Hui. 2009. “A Liquidity Risk Stress-Testing Framework with Interaction between Market and Credit Risks.” Working Paper 06/2009, Hong Kong Monetary Authority.

World Bank. 2016. “Doing Business 2017-Equal Opportunity for All.” Washington, DC: World Bank. 


\section{APPENDIX I. INTERACTION AND FEEDBACK BETWEEN THE SOVEREIGN AND FINANCIAL Sector Balance Sheets Using Contingent Claims Analysis (CCA)}

We can use contingent claims analysis (CCA) ${ }^{41}$ to illustrate the interaction between the sovereign and financial sector balance sheets and the potential rise of their respective credit spreads during stress episodes (Gray and Jobst 2010a, 2010b; Chatterjee and Jobst, 2019). In the following analysis, we assume that banks are the only relevant financial institutions for the assessment contingent liabilities from this interaction.

The expected losses from total sovereign debt of a country can be expressed as a European put option, where the underlying asset is government asset $A$, the strike price is debt amount $D$, and maturity is sovereign debt maturity $T$, so that

$$
\mathbb{E}_{t}\left(L_{t+\tau}\right)=\mathcal{P}_{\text {sov }}(A, D, t, T)=\mathcal{N}\left(-x_{-}\right) D_{\text {sov }_{t, T}} e^{-r(T-t)}-\mathcal{N}\left(-x_{+}\right) \tilde{A}_{\text {sov }}
$$

where $\mathcal{N}(\cdot)$ is the cumulative distribution function of the standard normal distribution, with

$$
x_{ \pm}=\frac{1}{\sigma_{A_{S o v}} \sqrt{T-t}}\left[\ln \frac{\tilde{A}_{\text {sov }_{t}}}{D_{t, T}}+\left(r \pm \frac{\sigma_{A_{S o v}}^{2}}{2}\right)(T-t)\right]
$$

The term structure of the corresponding sovereign credit spread $s_{\text {sov }}$ can be used to (i) estimate the implied value of sovereign assets $\tilde{A}_{\text {sov }_{t}}$ and asset volatility $\sigma_{A_{s o v}}^{2}$ and (ii) calibrate a riskadjusted measure of market-implied sovereign risk (using the sovereign balance sheet) in the absence of measurable equity and equity volatility for sovereign debtors. Sovereign spreads (in basis points) are defined as

$$
S_{\text {sov }_{t}}=-\frac{1}{T-t} \ln \left(1-\frac{\mathcal{P}_{\text {Sov }}(A, D, t, T)}{D_{\text {sov }_{t, T}} e^{-r(T-t)}}\right) \times 10,000
$$

with sovereign default barrier, $D_{\text {sov }}$ (or threshold that debt restructuring is triggered), over time horizon $T-t$ at risk-free discount rate $r$, subject to the duration of debt claims, the leverage of the firm, and asset volatility. Rearranging the first equation above for the implicit sovereign put option gives

$$
\frac{\mathcal{P}_{\text {sov }}(A, D, t, T)}{D_{\text {sov }_{t, T}} e^{-r(T-t)}}=\mathcal{N}\left(-x_{-}\right)-\frac{\tilde{A}_{\text {sov }_{t}}}{D_{\text {sov }_{t, T}} e^{-r(T-t)}} \mathcal{N}\left(-x_{+}\right)
$$

so that

$$
S_{\text {Sov }_{t}}=-\frac{1}{T-t} \ln \left(1-\mathcal{N}\left(-x_{-}\right)-\frac{\tilde{A}_{\text {sov }_{t}}}{D_{\text {sov }_{t, T}} e^{-r(T-t)}} \mathcal{N}\left(-x_{+}\right)\right) \times 10,000
$$

\footnotetext{
41 The CCA is a generalization of option pricing theory pioneered by Black and Scholes (1973) and Merton (1973, 1974), which stipulates that equity can be modeled as an implicit call option, while risky debt can be modeled as the default-free value of debt less an implicit put option that captures expected losses.
} 
The sovereign default barrier (based on available information on the periodic debt service) and the observed sovereign credit spread at the weighted average maturity of the debt repayment schedule can be used to estimate the implied sovereign asset value, which is defined as

$$
A_{\text {sov }_{t}}=R_{t}+P V P S_{t}+\alpha \mathcal{P}_{\text {bank }}(A, D, t, T)+\text { Other }
$$

comprising (i) foreign currency reserves, $R$, (ii) the present value of the primary fiscal surplus (or net fiscal assets), $P V P S$, (iii) the implicit and explicit contingent liabilities from the aggregate banking sector risk, $\alpha \mathcal{P}_{\text {bank }}(A, D, t, T)$, and (iv) remainder items (“Other”). The contingent liabilities are defined as the share $\alpha$ of expected losses in the banking sector, which are defined — analogous to expected losses from sovereign risk — as put option

$$
\mathcal{P}_{\text {bank }}(A, D, t, T)=\mathcal{N}\left(-x_{-}\right) D_{\text {bank }_{t, T}} e^{-r(T-t)}-\mathcal{N}\left(-x_{+}\right) \tilde{A}_{\text {bank }_{t}}
$$

Since the contingent liabilities can be estimated using the Systemic CCA framework (Gray and Jobst 2011a, 2011b), ${ }^{42}$ and value of reserves and the primary fiscal balance are observable, we solve the above equation for the residual (“Other”). "Other” includes a number of public sector assets and various unrealized liabilities, such as pension and healthcare obligations as well as contingent financial support to non-bank financial institutions, guarantees from other governments or multilaterals, or backstop assets (e.g., land or other public sector assets). Thus, this valuation approach helps assess the effect of changes in any constituent component of sovereign default risk - reserves, the primary fiscal balance, and the implicit banking sector guarantee — on the sovereign asset value (and corresponding sovereign credit spreads) for sensitivity analysis and stress testing.

Conversely, the effect of contingent liabilities on the credit spreads of banks is a function of the implicit put option, $\alpha \mathcal{P}_{\text {bank }}(A, D, t, T)$ (derived from equity information), times the fraction of risk $1-\alpha$ retained by banks plus a premium $(\delta)$ if high sovereign spreads spill over to increase bank spreads such that

$$
s_{\text {bank }_{t}}=-\frac{1}{T-t} \ln \left(1-\frac{(1-\alpha) \mathcal{P}_{\text {bank }}(A, D, t, T)}{D_{\text {bank }_{t, T}} e^{-r(T-t)}}+\delta\right) \times 10,000
$$

This simple model shows how sovereign and bank credit spreads can interact and potentially lead to a destabilization process. Higher sovereign spreads can cause higher bank spreads as (i) the value of the implicit bank put option for sovereign guarantees decreases (i.e., $\alpha$ declines), (ii) the value of the bank's holdings of government debt decreases, and (iii) the bank default barrier may increase due to higher borrowing costs as the premium $(\delta)$ increases.

\footnotetext{
42 The Systemic CCA framework was applied in the macroprudential stress tests of banking sectors as part of the IMF FSAPs for Germany, Hong Kong SAR, Spain, Sweden, the United Kingdom, and the United States.
} 


\section{APPENDIX II. ESTIMATING VALUATION HAIRCUTS FOR SOVEREIGN RISK}

Sovereign valuation haircuts can be derived from the expected change in the price of government bonds consistent with the estimated change in market-implied sovereign default risk. The haircuts differ by the severity of shocks to sovereign risk at different maturity tenors and macroeconomic scenarios. We model the sovereign risk shock using forward-looking information from past changes in the cost of sovereign default risk protection.

The estimation draws on different data sources (see Figure A2.1). For each country, we select the most liquid fixed-rate local-currency-denominated government debt securities ("benchmark bonds”) ${ }^{43}$ with residual maturity up to 10 years and create groups of bonds maturing within one year around the desired maturity tenor ("maturity buckets"). The valuation change of these bonds under a particular scenario is calculated by combining the default risk premium at different maturities with the applicable risk-free rate at the beginning of the estimation period (which is equivalent to the valuation haircut relative to the prevailing market value of each bond). ${ }^{44}$ The default risk premium compensates for the expected default risk implied by the historical spread volatility of sovereign credit default swaps (CDS). The spread dynamics inform the density distribution of expected default risk over the stress test horizon. ${ }^{45}$ This approach generalizes the treatment of sovereign risk in the EU-wide stress testing for banks in an integrated asset pricing framework using the price dynamics of CDS rather than government bonds to calibrate a marketconsistent sovereign risk shock (see Table 5). ${ }^{46,47}$

Since the valuation haircut is specific to each benchmark bond, the aggregate valuation haircut for each country represents the weighted-average change in market valuation over the relevant stress test horizon. In the application of these haircuts to sovereign exposures, banks are assumed to hold portfolios of sovereign debt securities similar to their supply when accurate portfolio data are not available. ${ }^{48}$

\footnotetext{
43 Since the credit and interest rate assumptions refer to domestic currency yield curves it is necessary to choose local currency debt only.

${ }^{44}$ For each sample country, a selection of the most liquid (benchmark) bonds is grouped in maturity buckets of one, three, five, seven, and ten years, with a discretionary margin of +/- 0.5 years. When bond-by-bond data are available, a standard bond valuation formula (available in MS Excel ${ }^{\circledR}$ file "IMF Sovereign Risk Stress Testing Tool.xls" (available for download at https://www.imf.org/ /media/Files/Publications/WP/2019/datasets/wp19266.ashx) can be used to calculate bond values as discounted future coupon and principal repayments) and approximate the valuation haircut.

45 The assumption is based on the empirically derived probability function of forward rates of sovereign CDS contracts.

46 The valuation haircuts were derived based on the market-based approach suggested in this paper as part of the reference risk parameters for the market risk parameter component of the stress test.

47 The 2011 EU-wide stress test exercise (EBA 2011a, ECB 2011) involved shocks to sovereign spreads through a mixture of an across-the-board increase in yields of 75 basis points, plus a country-specific effect based on bond price movements preceding the forecasting period.

${ }^{48}$ Alternatively, one may pick a representative maturity as a general assumption of the interest rate elasticity of traded sovereign exposures.
} 
Figure A2.1. Overview of Haircut Valuation Methodology for Sovereign Exposures (five-year stress testing horizon)

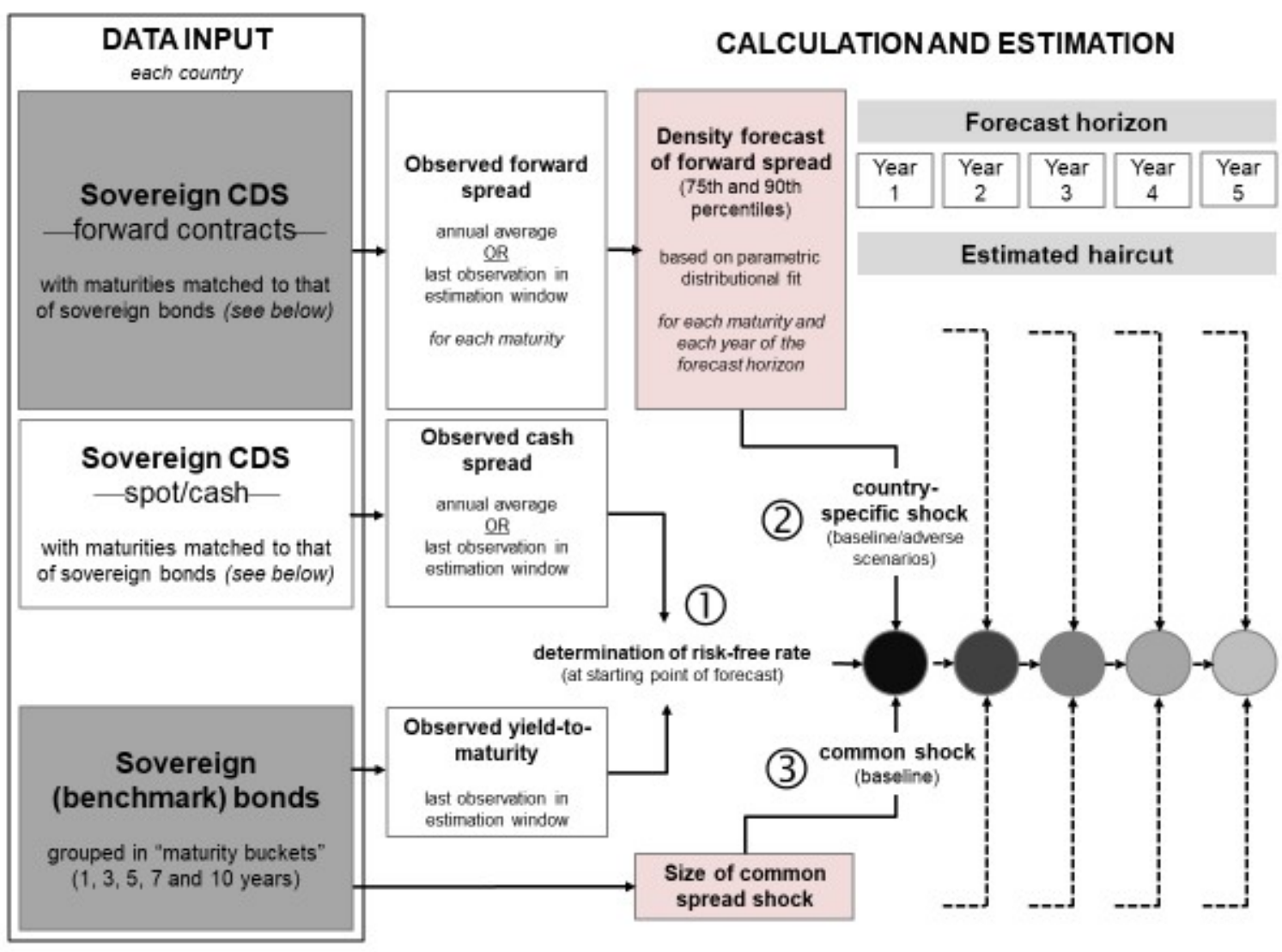

Source: authors.

Specification of the risk-free rate and the credit risk premium

First, we determine the prevailing risk-free rate and specify the credit risk premium under baseline conditions. We reconcile the standard pricing formula for a coupon-bearing bond with the zero-coupon bond pricing formula (assuming equivalence of economic value) to project future bond prices contingent on changes in idiosyncratic risk (with the possibility of considering a general shock to interest rates). This is done for selected outstanding (fixed rate) bonds $\left(b_{1}\right)$ of each sample country $j \epsilon J$, which are grouped by residual maturities $y \epsilon[k-0.5, k+0.5]$ in predefined "maturity term buckets" of $k \in K=\{1,3,5,7,10\}$ years.

Since each sample bond carries regular coupon payments, $c$, with a payout frequency $m$ in each year $n$, the observed market price $P_{b_{1}, j[k], t}$ conforms to the discounted cash flow (DCF) pricing formula: 


$$
P_{b_{1}, j[k], t}=\prod_{n=1}^{T-t} \frac{c_{n}}{\left(1+r_{b_{1}, j[k], t}\right)^{n / m}}+\frac{p}{\left(1+r_{b_{1}, j[k], t}\right)^{T-t}} \geq P_{b_{2}, j[k], t}
$$

with yield-to-maturity (YTM) $r_{b_{1}, j[k], t}$ at time $t$ (which determines the "data cut-off" for the estimation window over the remaining life of the bond $T-t$ ), the notional amount (or principal) $p$, and exceeds the zero coupon bond price $P_{b_{2}, j[k], t}$ by construction since $\lim _{c \rightarrow 0} r_{b_{2}, j[k], t}=$ $r_{b_{1}, j[k], t}$.

We can transform $P_{b_{1}, j[k], t}$ into the (non-observable) equivalent of a zero-coupon bond price (“zero coupon equivalent” or ZCE)

$$
P_{b_{1}, j[k], t}^{Z C E}=P_{b_{1}, j[k], t}-\prod_{n=1}^{T-t} \frac{c_{n}}{\left(1+r_{b_{1}, j[k], t}\right)^{n / m}}+\varphi_{t}=\frac{p}{\left(1+r_{b_{1}, j[k], t}\right)^{T-t}}+\varphi_{t}=P_{b_{2}, j[k], t}
$$

by stripping away all coupon payments $c$ (with payout frequency $m$ in each year $n)^{49}$ and adjusting for the first and second order pricing effects of the missing coupon payments (i.e., the positive impact of removing coupon payments on the price sensitivity of the bond relative to a lengthening of the duration), with adjustment factor

$$
\varphi_{t}=P_{b_{1}, j[k], t}\left(D_{b_{1}, j[k], t}^{\text {coupon }}\left(r_{b_{2}, j[k], t}-r_{b_{1}, j[k], t}\right)+\frac{1}{2} C_{b_{1}, j[k], t}^{\text {coupon }}\left(r_{b_{2}, j[k], t}-r_{b_{1}, j[k], t}\right)^{2}\right),
$$

where the marginal duration and convexity ${ }^{50}$ attributable to the coupon payment are

and

$$
D_{b_{1}, j[k], t}^{\text {coupon }}=\frac{1}{\left(1+r_{b_{1}, j[k], t}\right)} \prod_{n=1}^{T-t} \frac{n c_{n}}{m\left(1+r_{b_{1}, j[k], t}\right)^{n / m}}
$$

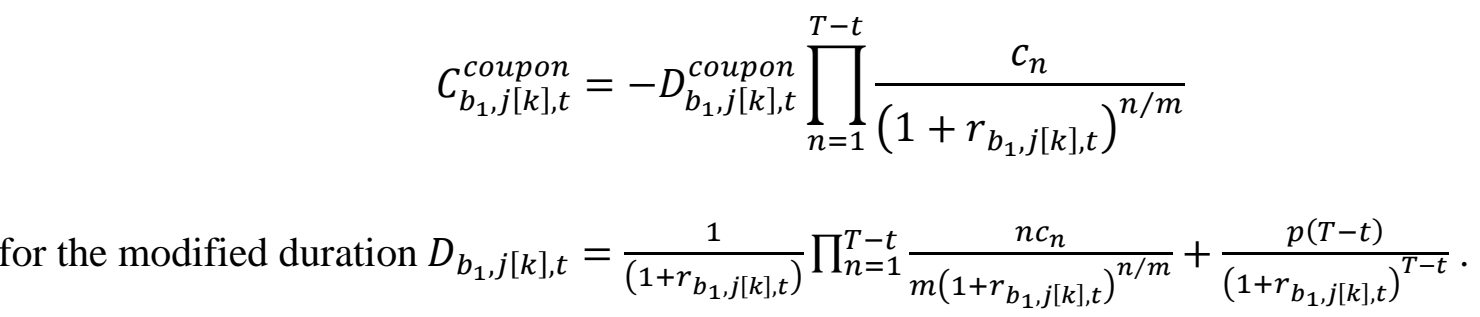

Given the zero-coupon bond pricing formula

$$
P_{b_{2}, j[k], t}=\exp \left(-r_{j[k], t}\right)\left(1-L G D_{j[k]} P D_{j[k], T-t}\right)
$$

\footnotetext{
${ }^{49}$ This step ignores the second order effect of interest rate changes on the future bond price (convexity) in the determination of haircuts.

${ }^{50}$ Duration is a first-order approximation of the true change in the value of a fixed income security and is only applicable for small changes in yields (less than 100 bps), which may underestimate the impact of large shocks. A second order approximation (or "convexity adjustment”) could be added for larger shocks. The convexity is a measure of how the duration of a bond changes as the interest rate changes. Specifically, one assumes that the interest rate is constant across the life of the bond and that changes in interest rates occur evenly.
} 
with a cumulative probability of default (PD)

$$
P D_{j[k], T-t}=\left(1-\left(1-P D_{j[k], t}\right)^{T-t}\right)
$$

at the last observable sample date $t$ until maturity date $T$, and given constant loss-given-default (LGD) and the unknown country-specific risk-free rate $r_{f_{j[k], t}}$, we can re-write the ZCE to

$$
P_{b_{1}, j[k], t}^{Z C E}=\frac{p}{\left(1+r_{b_{1}, j[k], t}\right)^{T-t}}+\varphi_{t}=\exp \left(-\hat{r}_{f_{j[k], t}}\right)\left(1-L G D_{j[k]} P D_{j[k], T-t}\right)
$$

assuming a constant hazard rate in continuous time. Using the sovereign CDS as a measure of country-specific default risk, the equation above can be re-written as

$$
P_{b_{1}, j[k], t}^{Z C E}=\frac{p}{\left(1+r_{b_{1}, j[k], t}\right)^{T-t}}+\varphi_{t}=\exp \left(-\left(\hat{r}_{f_{j[k], t}}+\frac{s_{C D S_{j[k], t}}}{10,000}\right)(T-t)\right)
$$

where

$$
S_{C D S_{j[k], t}}=-\frac{1}{T-t} \ln \left(1-P D_{j[k], T-t} L G D_{j[k]}\right) \times 10,000
$$

is the cash $k$-year sovereign CDS spread (in basis points) of country $j$ at time $t$, which represents idiosyncratic credit risk.

Equation (2) above can now be solved for the time-varying risk-free rate

$$
\hat{r}_{f_{j[k], t}}=\frac{1}{T-t} \ln \left(\frac{p}{\left(1+r_{b_{1}, j[k], t}\right)^{T-t}}+\varphi_{t}\right)-\frac{\min \left(\bar{s}_{C D S_{j[k], t}} s_{C D S_{j[k], t}}\right)}{10,000}
$$

after we smooth the market-implied credit risk. The default risk is defined as the minimum of the last observable cash CDS spread with a maturity of $k$ years, $s_{C D S_{j[k], t}}$, and the average cash CDS spread over the last 12 months of the estimation period, $\bar{s}_{C D S_{j[k], t}}$.

We also introduce some flexibility in the selection of time $t$, which might occur before the yearend (a commonly used reference date for stress test scenarios). Thus, we decrease the yield by $\Delta r_{b_{2}, j[k]}=r_{b_{2}, j[k], t+\tau}-r_{b_{2}, j[k], t}$ as a market value adjustment to reflect the pricing effect of shortening the residual maturity to $T-t-\tau$ caused by fraction of up to one year $\tau \epsilon] 0,1[$ until time $t+\tau$. So equation (3) can be generalized to

$$
\hat{r}_{f_{j[k], t+\tau}}=\frac{1}{T-t-\tau} \ln \left(\frac{p}{\left(1+r_{b_{1}, j[k], t+\tau}\right)^{T-t-\tau}}+\varphi_{t+\tau}\right)-\Delta r_{b_{2}, j[k]}-\frac{\min \left(\bar{s}_{C D S_{j[k], t},{ } C D S_{j[k], t}}\right)}{10,000}
$$

with

$$
\varphi_{t+\tau}=P_{b_{1}, j[k], t+\tau}\left(\begin{array}{c}
D_{b_{1}, j[k], t+\tau}^{\text {coupon }}\left(r_{b_{2}, j[k], t+\tau}-r_{b_{1}, j[k], t+\tau}\right) \\
+\frac{1}{2} C_{b_{1}, j[k], t+\tau}^{\text {coupon }}\left(r_{b_{2}, j[k], t+\tau}-r_{b_{1}, j[k], t+\tau}\right)^{2}
\end{array}\right)
$$


where $r_{b_{1}, j[k], t+\tau}$ and $r_{b_{2}, j[k], t+\tau}$ are the updated yields reflecting the valuation effect (caused by the mismatch of the desired starting point and the timing of the last observable bond price), and $P_{b_{1}, j[k], t+\tau}$ is the updated market price of the coupon bond (without coupon payments). Given $\tau \geq 0$, equation (4) above can then be solved for the time-varying risk-free rate.

\section{Calculation of the credit risk premium under baseline conditions}

For the determination of the future bond price under baseline conditions, we incorporate observable market expectations about changes in country-specific default risk. The future price $P_{b_{2}, j[k], i}$ of each outstanding bond of country $j$ at time $t+\tau+i$ is calculated over stress test horizon of $T-t-\tau-i$ years, where $i \in I$. It is derived from using the estimated risk-free rate $\hat{r}_{f_{j[k], t+\tau}}$ and applying the ith-period maturity-matched market-implied default risk $P D_{j[k], i}$ to the standard zero-coupon pricing formula so that

$$
P_{b_{2}, j[k], i}=\exp \left(-\left(\begin{array}{c}
\hat{r}_{f_{j[k], t+\tau}}+\Delta \hat{r}_{f_{j[k], t}} \\
\max \left(\begin{array}{l}
\min \left(\bar{s}_{C D S_{j[k], t}} s_{C D S_{j[k], t}}\right), \\
\min \left(\bar{f}_{C D S_{j[k], i}} f_{C D S_{j[k], i}}\right)
\end{array}\right) \\
10,000
\end{array}\right)(T-t-\tau)\right.
$$

where $P_{b_{2}, j[k], i}-P_{b_{2}, j[k], t+\tau}$ informs the haircut relative to the current valuation. The implied default risk $P D_{j[k], i}$ for each period of the test horizon is given by the continuous time expression of default

$$
P D_{j[k], i}=\left(\exp \left(-\frac{\max \left(\begin{array}{c}
\min \left(\bar{s}_{C D S_{j[k], t}}, s_{C D S_{j[k], t}}\right), \\
\min \left(\bar{f}_{C D S_{j[k], i},} f_{C D S_{j[k], i}}\right)
\end{array}\right)}{10,000}(T-t-\tau)-1\right) \frac{1}{L G D_{j[k]}}\right.
$$

based on the hazard rate $P D_{j[k], i} \times L G D_{j[k]}$, where the $k$-year sovereign CDS spread at the ithperiod is defined as the greater of (i) the minimum of the last observable cash CDS spread, $s_{C D S_{j[k], t}}$ (with a maturity of $k$ years prior to the starting point of the forecasting period) and the average cash CDS spread, $\bar{s}_{C D S_{j[k], t}}$ (over the last 12 months of the estimation period) and (ii) the minimum of the last observable forward CDS spread, $f_{C D S_{j[k], i}}$ (with a maturity of $k$ years prior to the starting point of the forecasting period), and the average forward CDS spread, $\bar{f}_{C D S_{j[k], i}}$ (over the last 12 months of the estimation period) (see Box A2). ${ }^{51,52}$ The forward CDS spread can be interpreted as the price effect of uncertainty around the expected default risk expressed in the

\footnotetext{
${ }^{51}$ Using the current CDS spread as the lower bound in this specification assumes away valuation gain.

52 Because of certain simplifying assumptions, especially regarding the pricing of the forward CDS term structure, the estimates of each country’s haircuts in outer years are biased downward.
} 
cash CDS spread of the same maturity. ${ }^{53}$ The term $\Delta \hat{r}_{f_{j[k], t}}>0$ denotes the possibility of incorporating a positive (common) shock to the risk-free rate during all (or selected) periods during the test horizon. This interest rate shock is kept maturity-specific to account for either an upward (parallel) shift or a change in the slope of the interest rate term structure. In the case of the former, it would simplify to $\Delta \hat{r}_{f_{j, t}}>0$.

For comparative purposes, the same approach is applied to the DCF pricing formula, which is used for the estimation of market risk parameters in EU system-wide stress tests. Based on equation (1), we obtain

$$
P_{b_{1}, j[k], i}=\prod_{n=1}^{T-t-\tau} \frac{c_{n}}{\left(1+r_{b_{1}, j[k], t}+\theta_{j[k], t}\right)^{n / m}}+\frac{p}{\left(1+r_{b_{1}, j[k], t}+\theta_{j[k], t}\right)^{T-t-\tau}} \geq P_{b_{2}, j[k], i}
$$

where

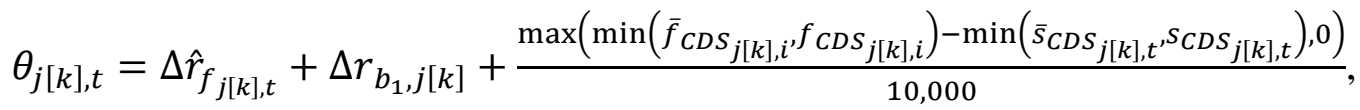

which comprises the same components as equation (5) by defining the common interest shock, $\Delta \hat{r}_{f_{j[k], t}}$ (in addition to the risk-free rate included in $r_{b_{1}, j[k], t}$ ), the market value adjustment, $\Delta r_{b_{1}, j[k]}=r_{b_{1}, j[k], t+\tau}-r_{b_{1}, j[k], t}$ (if we move the starting time of the test horizon beyond the empirical cut-off date), and the expected increase of sovereign risk implied by the forward CDS spread. In contrast to equation (5), however, this specification includes only the marginal increase of country-specific risk (as specified in equation (7)) since the uncertainty associated with the expected default risk at time $t, \min \left(\bar{s}_{C D S_{j[k], t}}, s_{C D S_{j[k], t}}\right)$ is already reflected in the observable bond price $P_{b_{1}, j[k], i} \cdot{ }^{54}$

\footnotetext{
${ }^{53}$ For instance, the forward matrix for the sovereign CDS spread at the test horizon of $i \in I=\{0.5,1,3,5,7,10\}$ years can be obtained from Bloomberg L.P. via the command "BDS( " [add ticker of CDS], "

"FORWARD_CDS_MATRIX", "SW_CURVE_DT=20161231", "startrow="\&2, "endrow="\&2, "cols=10; rows=1 ")" on December 31, 2016, where "[add ticker of CDS]" would need to be replaced with "GERMAN CDS USD SR 5Y Corp" to generate the information for senior CDS on German government bonds at a maturity of five years.

${ }^{54}$ When individual bond data is not available, the average duration of a given sovereign bond portfolio could be used as an approximation. Then bond valuation changes would be defined by $-d P_{b_{1}, j, t} / P_{b_{1}, j, t}=$ $\bar{D}_{b_{1}, j, t}^{\text {coupon }} /\left(1+\bar{r}_{b_{1}, j, t}\right) \times \Delta \bar{r}_{b_{1}, j, t}$, where $\Delta \bar{r}_{b_{1}, j, t}$ is the change in volume-weighted sovereign yield, and $\bar{D}_{b_{1}, j, t}^{\text {coupon }}$ is the average duration of the bond portfolio.
} 


\section{Box A2. Forward Credit Default Swap (CDS) Contracts and the Standard CDS Pricing Formula}

This Box derives a market model for forward rates on CDS contracts consistent with the general pricing model (such as the forward CDS matrix <FWCS in Bloomberg) to derive a forward-looking measure of market-implied default risk as specified in equation (5).

A CDS represents an agreement between two parties, which is typically designed to transfer to the "credit protection seller" the financial loss the "credit protection buyer" would incur if a designated third party (i.e., the reference entity) were to default (i.e., causing a so-called "credit event").

As a natural starting point for the conventional definition of a CDS, consider a contract valid during the time interval $\left[T_{a}, T_{b}\right]$, where the protection buyer pays the annual rate $S_{R C D S}(t)$ (in basis points) at times $t \in\left\{T_{a}, T_{a+1}, T_{i}, \ldots, T_{b}\right\}$ or until default time $\tau \in\left[T_{a}, T_{b}\right]$ of the reference entity (based on a pre-defined default event). The seller of the CDS contract then provides the deterministic protection payment $L G D=$ $(1-R)$ at the default time $\tau$. Formally, the discounted cash flows for the protection seller associated with the basic structure of this so-called "running CDS" (RCDS) with unit notional at time $t \leq T_{a}$ can be written as the net payoff

$$
\begin{gathered}
\prod_{R C D S}(t)=\underbrace{\sum_{i=a+1}^{b} D\left(t, T_{i}\right) \alpha_{i} S_{R C D S}(t) \mathbf{1}_{\left\{\tau \geq T_{i}\right\}}}_{\text {premium leg }} \\
+\underbrace{D(t, \tau)\left(T_{\tau+1}-\tau\right) s_{R C D S}(t) \mathbf{1}_{\left\{T_{t-1}<\tau<T_{t}\right\}}}_{\text {accrual leg }}-\underbrace{D(t, \tau) L G D \mathbf{1}_{\left\{T_{t-1}<\tau \leq T_{t}\right\}}}_{\text {protection leg }}=0
\end{gathered}
$$

where $\alpha_{i}$ denotes the fraction of one year between $T_{i}$ and $T_{i-1}, T_{\tau+1}$ is the first date after $\tau$ within the time grid $T_{i}, r_{f}(t)$ is the prevailing risk-free rate, and $D(t)$ is the discount factor. The general market model underpins the standard pricing methodology accepted by the market (and used in Bloomberg L.P.), which applies a (time-changed) Poisson process for the expected default probability while treating the recovery rate on default as constant and exogenous. Equation (A3.1) above can be re-written to the no-arbitrage pricing condition for the closed-form valuation of a CDS contract over a maturity tenor of $n$ days as

$$
\begin{aligned}
& P V_{R C D S}(t)= \underbrace{6 \sum_{i=1}^{n} \frac{t_{i}-t_{i-1}}{360} s_{R C D S}(t) S(t) D(t)}_{\text {remium leg }}+\underbrace{\int_{t_{i-1}}^{t_{i}} \sum_{i=1}^{n} \frac{t_{i}-t_{i-1}}{360} s_{R C D S}(t) D(x) h(x) d x}_{\text {protection leg }} \\
&-\underbrace{\exp \left(-\int_{t_{i}}^{t} h(x) d x\right) L G D \int_{t_{i}}^{t} D(x) h(x) d x}_{\text {accrual leg }}=0
\end{aligned}
$$

so that the present value of payoffs to the buyer and seller of credit protection cancel out, where $h(t)$ is the constant "hazard rate" (or default probability), and the survival rate is defined as

$$
S(t)=\exp \left(-\int_{0}^{t} h(x) d x\right)=\exp (-h t) .{ }^{55}
$$

\footnotetext{
${ }^{55}$ The input data required are the effective date, maturity date, premium payment dates, the risk-free interest rate term structure (derived from Libor/Euribor and swap rates), the survival probability curve obtained from the hazard rate, and the recovery rate for a credit event.
} 


\section{Box A2. Forward Credit Default Swap (CDS) Contracts and the Standard CDS Pricing Formula} (continued)

Thus, the premium payment of spread $s_{R C D S}(t)$ to offset the cumulative probability of default (PD) at the last observable sample date until maturity for constant LGD is defined as

$$
S_{R C D S}(t)=\frac{\exp \left(-\int_{t_{i}}^{t} h(x) d x\right) L G D \int_{t_{i}}^{t} D(x) h(x) d x}{\sum_{i=1}^{n} \frac{t_{i}-t_{i-1}}{360} S(t) D(t)+\int_{t_{i-1}}^{t_{i}} \sum_{i=1}^{n} \frac{t_{i^{-}}-t_{i-1}}{360} D(x) h(x) d x} \approx-\ln (1-(1-R) P D(t)) / t .
$$

The first term ("premium leg") of equation (A3.2) quantifies the quarterly premium amount (in basis points) to be paid to the credit protection seller as the difference in days between payment dates divided by 360 and multiplied by the CDS spread $s_{R C D S}(t)$ (or "premium coupon"), then multiplied by the probability that the reference entity survives up to the premium payment date, and discounted to the present. $^{56}$

The second term in the formula ("accrual leg”) defines the value of any accrued premium payment on a credit event that occurs between payment periods as the number of days since last coupon date divided by 360 , multiplied by the premium amount, multiplied by the conditional probability that a default occurs at time $t$, and discounted to the present. Any accrued but unpaid premium is paid upon the triggering of a contingent payment after a credit event has occurred.

The final term ("protection leg") above specifies the value of the payment to the credit protection buyer of LGD, which is the par value (set to unity) minus the recovery value of the reference entity at time $t$ between the effective and scheduled termination date. Such payment after recovery is assumed to occur with the conditional probability of a credit event, i.e., the probability that the reference entity survives up to time $t$ multiplied by the hazard rate, discounted to the present. ${ }^{57}$

The general CDS pricing formula above can be adapted to derive the forward rate on the CDS spread. We first simplify equation (A3.1) above by setting $T_{\tau+1}=\tau$, which eliminates the accrual leg so that

$$
\prod_{P R C D S}(t)=\underbrace{\sum_{i=a+1}^{b} D\left(t, T_{i}\right) \alpha_{i} S_{P R C D S}(t) \mathbf{1}_{\left\{\tau \geq T_{i}\right\}}}_{\text {premium leg }}-\underbrace{D\left(t, T_{i}\right) L G D \mathbf{1}_{\left\{T_{t-1}<\tau \leq T_{t}\right\}}}_{\text {protection leg }}=0
$$

denotes the valuation of the "postponed payoff RCDS" (PRCDS) (Brigo 2004), with $S_{P R C D S}(t)=$ $D\left(t, T_{i}\right) L G D \mathbf{1}_{\left\{T_{t-1}<\tau \leq T_{t}\right\}} / \sum_{i=a+1}^{b} D\left(t, T_{i}\right) \alpha_{i} \mathbf{1}_{\left\{\tau \geq T_{i}\right\}}$.

\footnotetext{
${ }^{56}$ Premium payments are calculated on an actual/360 day-count convention.

${ }^{57}$ In practice, a 30-day delay in the payment of the recovery amount is assumed in the context of this valuation approach. The fair market CDS spread is calculated with an effective date equal to the trade date plus one business day, and regular quarterly premium payments on March 20, June 20, September 20, and December 20.
} 


\section{Box A2. Forward Credit Default Swap (CDS) Contracts and the Standard CDS Pricing Formula (continued)}

Since $\prod_{P R C D S}(t)$ is not a real world payoff (but approximates a general CDS payoff), we can compute the CDS price according to risk-neutral valuation. Under no arbitrage, the discounted payoff of selling the CDS contract can be written as risk-neutral expectation

$$
\mathbf{E}_{t}^{\mathbb{Q}}\left(\prod_{P R C D S a}(t) \mid \mathcal{F}_{t}\right),
$$

which is conditional on the filtration $\mathcal{F}_{t}$ representing all available information up to time $t$, where $\mathbb{Q}$ is the risk-neutral equivalent martingale measure, and default is modeled as a $\mathcal{F}_{t}$-stopping time (Brigo and Morini 2005). It is convenient to express prices in credit risk valuation using a subfiltration structure, since a market operator might have information on the probability of default but cannot say exactly when, or even if, default has happened.

Following Jeanblanc and Rutkowski (2000), we can represent the flow of all information except the default itself ("default-free information") in subfiltration $\mathcal{H}_{t}$. Thus, it is then possible (and in many cases preferable) to define pricing formulas in terms of the conditional survival probability $\operatorname{Pr}\left(\tau>t \mid \mathcal{H}_{t}\right)$, which can be assumed to be strictly positive in any state of the world, with expectations conditional on the usual default-free filtration $\mathcal{H}_{t}$ (Brigo and Mercurio 2006) so that ${ }^{58}$

where

$$
P V_{P R C D S}(t, s(t), L G D)=0
$$

$$
\begin{aligned}
\prod_{P R C D S}(t)= & \frac{\mathbf{1}_{\{\tau>t\}}}{\operatorname{Pr}\left(\tau>t \mid \mathcal{H}_{t}\right)} \underbrace{\sum_{i=a+1}^{b} \alpha_{i} S_{P R C D S}(t) \mathbf{E}_{t}^{\mathbb{Q}}\left(D\left(t, T_{i}\right) \mathbf{1}_{\left\{\tau \geq T_{i}\right\}} \mid \mathcal{H}_{t}\right)}_{\text {premium leg }} \\
& -\underbrace{L G D \sum_{i=a+1}^{b} \mathbf{E}_{t}^{\mathbb{Q}}\left(D\left(t, T_{i}\right) \mathbf{1}_{\left\{T_{i-1}<\tau \leq T_{i}\right\}} \mid \mathcal{H}_{t}\right)}_{\text {protection leg }}
\end{aligned}
$$

If the CDS spread $s_{P R C D S}(t)$ is fixed at time $t$ such that the contract in equation (A3.3) above has a value of zero over time steps $i \in[a, b]$, we can write

$$
S_{P R C D S}(t)=\frac{L G D \sum_{i=a+1}^{b} \mathbf{E}_{t}^{\mathbb{Q}}\left(D\left(t, T_{i}\right) \mathbf{1}_{\left\{T_{i-1}<\tau \leq T_{i}\right\}} \mid \mathcal{H}_{t}\right)}{\alpha_{i} \sum_{i=a+1}^{b} \mathbf{E}_{t}^{\mathbb{Q}}\left(D\left(t, T_{i}\right) \mathbf{1}_{\left\{\tau \geq T_{i}\right\}} \mid \mathcal{H}_{t}\right)}
$$

\footnotetext{
${ }^{58}$ For the proof, see Brigo and Mercurio (2006).
} 


\section{Box A2. Forward Credit Default Swap (CDS) Contracts and the Standard CDS Pricing Formula (continued)}

Thus, the real world CDS represents a ratio of survival probabilities if the right probability measure and information flow (as reflected in the filtration choice) are selected in defining conditional default probabilities.

Given the dependence of one-period CDS spreads on the default probability in the context of real market discrete-tenor CDS spreads, one needs to consider a probability measure associated with discrete tenor interest rates, i.e., a forward rate measure. This would separate the risk-free interest rate from default probabilities. Thus, for the time interval $[m, b]$, the forward rate on the CDS contract under the general market model (see equation (A3.4) above) is defined as

$$
f_{P R C D S}(t)=\frac{L G D \sum_{i=m+1}^{b} \mathbf{E}_{t}^{\mathbb{Q}}\left(D\left(t, T_{i}\right) \mathbf{1}_{\left\{T_{i-1}<\tau\right\}} \mid \mathcal{H}_{t}\right)-\mathbf{E}_{t}^{\mathbb{Q}}\left(D\left(t, T_{i}\right) \mathbf{1}_{\left\{\tau \geq T_{i}\right\}} \mid \mathcal{H}_{t}\right)}{\alpha_{j} \sum_{j=m+1}^{b} \mathbf{E}_{t}^{\mathbb{Q}}\left(D\left(t, T_{j}\right) \mathbf{1}_{\left\{\tau \geq T_{j}\right\}} \mid \mathcal{H}_{t}\right)}
$$

where $\mathbf{E}_{t}^{\mathbb{Q}}\left(D\left(t, T_{m}\right) F\left(T_{m-1} ; T_{m-1}, T_{m}\right) \mid \mathcal{H}_{t}\right)$ with the forward measure $F(\cdot)$. In the main text, we denote the forward rate on sovereign CDS spreads $S_{C D S_{j[k], i}}$ with maturity of $k$ years for $i$-number of years as $f_{C D S_{j[k], i}{ }^{59}}$

\section{Estimation of the credit risk premium under adverse scenarios}

For the specification of valuation haircuts under adverse scenarios, changes in sovereign risk during times of stress are derived from the past dynamics of forward-looking estimates of market-implied assessment of default risk using forward CDS spreads. For this approach, extreme value theory (EVT) is applied as a general statistical concept to model the historical distribution of these spreads to account for large (non-linear) fluctuations in sovereign risk in the past and the possibility of such tail events affecting the valuation of sovereign bonds over a given test horizon.

More specifically, the historical distribution of spreads is assumed to fall within the domain of attraction of the generalized extreme value (GEV) distribution as a closed form solution to estimating their limiting (or asymptotic tail) behavior, i.e., the probability of large positive increases in both the level and volatility of spreads. Based on the parametric fit of the GEV to the historical observations of forward CDS spreads, we can use the density distribution at a high percentile level, such as the conditional tail expectation (CTE), as a stressed country-specific

\footnotetext{
${ }^{59}$ Parties to forward agreements need to have exactly opposite hedging interests that coincide in the timing and amount of the protection bought and sold against adverse price movements (“double coincidence”). Forward contracts have zero value at the time of inception (i.e., they coincide with the spot rate). They gain in value as changes to the parameters determining the price of the reference assets increase the future price above the expected price set at inception.
} 
risk component to replace $\min \left(\bar{f}_{C D S_{j[k], i}}, f_{C D S_{j[k], i}}\right)$ in the definition of future bond prices $P_{b_{1}, j[k], i}$ and $P_{b_{2}, j[k], i}$ under zero-coupon and DCF pricing, respectively, at time $T-t-\tau$ as specified in equations (5) and (6) above.

We use this parametric approach to model the adverse scenario of valuation haircuts. For each sample country, we specify the individual asymptotic tail behavior of a historical series of forward CDS spreads through parametrically fitting a sequence of normalized extremes (maxima or minima) drawn from a sample of independent and identically distributed (i.i.d.) random variables to a GEV distribution. This enables us to identify the possible limiting laws of asymptotic tail behavior (i.e., the likelihood of even larger extremes as the level of statistical confidence approaches certainty). The Fisher-Tippett-Gnedenko theorem (Fisher and Tippett 1928; Gnedenko 1943) defines the attribution of a given distribution of normalized maxima (or minima) to be of an extremal type.

Let the matrix

$$
\chi_{f_{C D S_{j[k], i}}}=f_{C D S_{j[k], i}}^{1}, \ldots, f_{C D S_{j[k], i}}^{Z}
$$

denote a vector-valued i.i.d. random series of forward CDS spreads $f_{C D S_{j[k], i}}$ with a maturity tenor of $k$ years for sample country $j$ at the ith period of the test horizon. $\mathcal{Y}_{f_{C D S}[k], i}=$ $\max \left(f_{C D S_{j[k], i}}^{1}, \ldots, f_{C D S_{j[k], i}}^{Z}\right)$ with the cumulative distribution function $\mathcal{F}(x)$ and $x \in \mathbb{R}$ defines the sample maxima with ascending order statistics $f_{C D S_{j[k], i}}^{z, 1} \leq \cdots \leq f_{C D S_{j[k], i}}^{z, z}$ over an estimation period of $z$-number of observations. The distribution of normalized extremes satisfies the conditions of GEV if there exists a choice of normalizing constants $\beta_{j[k], i}^{Z}>0$ and $\alpha_{j[k], i}^{Z}>0$, such that the probability of each ordered $z$-sequence of normalized sample maxima $\left(\mathcal{Y}_{f_{C D S_{j[k], i}}}-\alpha_{j[k], i}^{Z}\right) / \beta_{j[k], i}^{Z}>0$ converges to the non-degenerate limit distribution $G_{f_{C D S_{j[k], i}}}(\cdot)$ as $z \rightarrow \infty$ and $f_{C D S_{j[k], i}} \in \mathbb{R},{ }^{60}$ so that

$$
\lim _{z \rightarrow \infty} \operatorname{Pr}\left(\left(\mathcal{Y}_{f_{C D S_{j[k], i}}}-\alpha_{j[k], i}^{Z}\right) / \beta_{j[k], i}^{Z} \leq x\right) \rightarrow G_{f_{C D S_{j[k], i}}}(\cdot)
$$

If the normalized extremes only roughly follow GEV, they are considered to fall within the maximum domain of attraction (MDA) of $G_{f_{C D S}[k], i}(\cdot)$. In this case, their distribution conforms to one of three distinct types of extremal behavior as limiting distributions (which are expressed below in their general form without specific notation): ${ }^{61}$

\footnotetext{
60 The upper tails of most (conventional) limit distributions (weakly) converge to this parametric specification of asymptotic behavior, irrespective of the original distribution of observed maxima (unlike parametric VAR models).

${ }^{61}$ See Embrechts, Klüppelberg, and Mikosch (1997), Coles (2001), Vandewalle, Beirlant, and Hubert (2004), and Thérond and Ribereau (2012) for additional information on the definition of EVT.
} 


$$
\begin{gathered}
E V 0: G_{0}(x)=\exp (-\exp (-x)) \quad \text { if } x \geq 0, \xi=0 \\
E V 1: G_{1}(x)=\exp \left(-x^{-1 / \xi}\right) \quad \text { if } x \in[\mu-\sigma / \xi, \infty[, \xi>0 \\
\left.\left.E V 2: G_{2}(x)=\exp \left(-(-x)^{-1 / \xi}\right) \quad \text { if } x \in\right]-\infty, \mu-\sigma / \xi,\right], \xi<0 .
\end{gathered}
$$

If $\xi>0$, GEV falls within the class of Fréchet (EV1) distributions, which feature regularly varying tails, including fat-tailed distributions, such as Stable Paretian distributions. $\xi<$ 0 indicates (negative) Weibull (EV2)-type distributions, i.e., distributions without a tail but a finite end-point (e.g., uniform or beta distributions). In the case of $\xi \rightarrow \infty$, GEV approaches a Gumbel (EV0) distribution, which encapsulates thin-tailed distributions, ${ }^{62}$ for which all moments exist.

The cumulative distribution functions in the above equations are combined into a unified parametric specification of the general GEV cumulative distribution function, ${ }^{63}$ which for $x_{f_{C D S_{j[k], i}}}$ is defined as

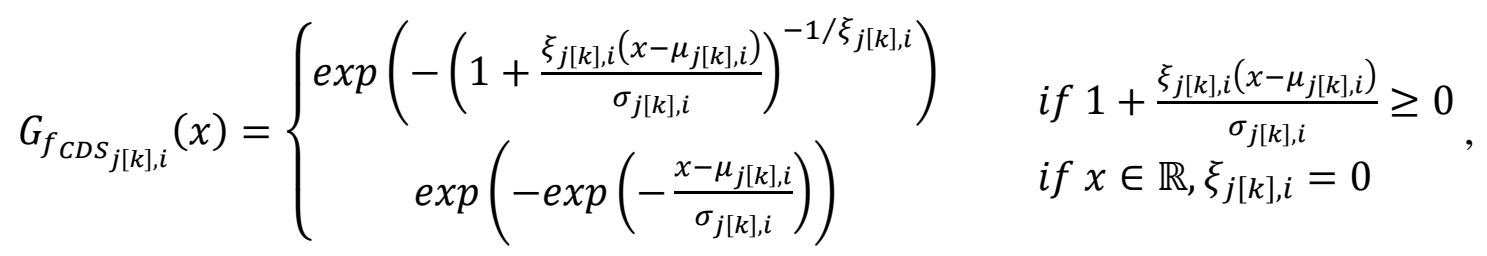

with the index for the test horizon dropped from this notation for simplicity. Differencing equation (8) above as $G_{f_{C D S}[k], i}^{\prime}(x)=\frac{d}{d x} G_{f_{C D S_{j[k], i}}}(x)$ yields the probability density function

$$
g_{f_{C D S_{j[k], i}}}(x)=\frac{1}{\sigma_{j[k], i}}\left(1+\frac{\xi_{j[k], i}\left(x-\mu_{j[k], i}\right)}{\sigma_{j[k], i}}\right)^{-1 / \xi_{j[k], i}-1} \exp \left(-\left(1+\frac{\xi_{j[k], i}\left(x-\mu_{j[k], i}\right)}{\sigma_{j[k], i}}\right)_{+}^{-1 / \xi_{j[k], i}}\right),
$$

where the scale, location, and shape parameters are estimated as $\hat{\mu}_{j[k], i}>0, \hat{\sigma}_{j[k], i}>0$, and $\hat{\xi}_{j[k], i}$, respectively. ${ }^{64}$ The scale parameter represents the annualized volatility of (at least)

\footnotetext{
${ }^{62}$ For instance, normal, log-normal, gamma, and exponential distributions.

${ }^{63}$ Standard pricing models of CDS spreads assume that the essential input variables (i.e., the likelihood of default and the recovery rate up to one year) provide sufficient statistical support to inform a multi-period estimate of expected loss as a monotonically increasing density function of continuously distributed default risk.

${ }^{64}$ The upper tails of most conventional limit distributions weakly converge to this parametric specification of asymptotic behavior, irrespective of the original distribution of observed maxima (unlike parametric VAR models). The higher the absolute value of the shape parameter, the larger the weight of the tail and the slower the speed at
} 
monthly observations of CDS spreads. The shape parameter is determined by the type of submodel (EV0, EV1, or EV2). The moments are estimated concurrently by means of the linear combinations of ratios of spacings (LRS) method, which determines how quickly the probability of extreme observations converges to zero, using the historical spread dynamics over a chosen estimation horizon (Coles 2001; Jobst 2007) (see Appendix IV). ${ }^{65}$ The associated maximum likelihood (ML) estimator is evaluated numerically by using an iteration procedure (e.g., over a rolling window of a constant number of observations with periodic updating) to maximize the likelihood $\prod_{i=1}^{z} g_{f_{C D S}[k], i}(x \mid \theta)$ over all three parameters $\theta=\left(\hat{\mu}_{j[k], i}, \hat{\sigma}_{j[k], i}, \hat{\xi}_{j[k], i}\right)$ simultaneously. ${ }^{66}$

Given the expectation

$$
\begin{gathered}
\int_{0}^{\infty} \frac{x}{\hat{\sigma}_{j[k], i}}\left(1+\frac{\hat{\xi}_{j[k], i}\left(x-\hat{\mu}_{j[k], i}\right)}{\hat{\sigma}_{j[k], i}}\right)^{-1 / \hat{\xi}_{j[k], i}-1} \exp \left(-\left(1+\frac{\hat{\xi}_{j[k], i}\left(x-\hat{\mu}_{j[k], i}\right)}{\hat{\sigma}_{j[k], i}}\right)^{-1 / \hat{\xi}_{j[k], i}}\right) d x= \\
\left(\hat{\mu}_{j[k], i}+\frac{\hat{\sigma}_{j[k], i}}{1-\hat{\xi}_{j[k], i}}\right)\left(-\left(1+\frac{\hat{\xi}_{j[k], i}\left(x-\hat{\mu}_{j[k], i}\right)}{\hat{\sigma}_{j[k], i}}\right)^{-1 / \hat{\xi}_{j[k], i}}\right)
\end{gathered}
$$

based on the cumulative distribution function in equation (8) above, we obtain the CTE (or conditional value-at-risk ( $\mathrm{VaR})$ ) as probability-weighted residual density beyond a pre-specified statistical confidence level ("severity threshold") over the certain estimation period. The corresponding density distribution at a certain statistical confidence level $a$ can be derived as

$$
C T E_{a, f_{C D S_{j[k], i}}}=\mathbb{E}\left(x \mid x \geq G_{f_{C D S_{j[k], i}}^{-1}}(a)=\operatorname{VaR}_{a, f_{C D S_{j[k], i}}}\right)
$$

with quantile function

which the tail approaches its limit. The shape parameter also indicates the number of moments of the distribution, e.g., if $\xi=1 / 2$, the first moment (mean) and the second moment (variance) exist, but higher moments have an infinite value. The moments of order $n \geq 1 / \xi$ are unbounded, i.e., $1 / \xi$ indicates the highest bounded moment for the distribution. This is of practical importance since many results for asset pricing in finance rely on the existence of several moments.

${ }^{65}$ A rough estimation for each sample country is provided in the data template for this method (available in MS Excel ${ }^{\circledR}$ file “Data_Input.xlsx” (https://www.imf.org/ /media/Files/Publications/WP/2019/datasets/wp19266.ashx), which allows the user to download the relevant CDS data from Bloomberg $L_{1} . P$. and calculate the respective point estimates of changes in CDS spreads according to the quantile function $G_{f_{C D S}[k], i}$ (a) in equation (10). We uniformly calibrate the shape parameter to $\xi=0.33$ in the application of this calibration approach in generating the results shown in "Appendix V. Detailed Estimation Results: Valuation Haircuts.”

66 The maximum likelihood estimator fails for $\xi \leq-1$ since the likelihood function does not have a global maximum in this case. However, a local maximum close to the initial value can be attained. 


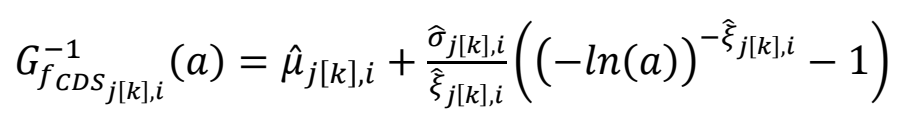

and

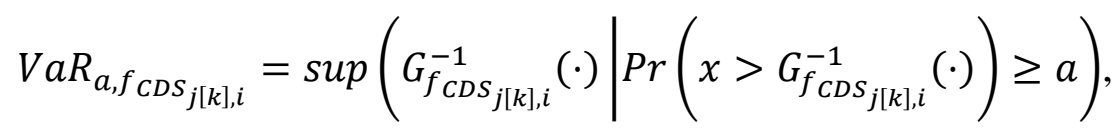

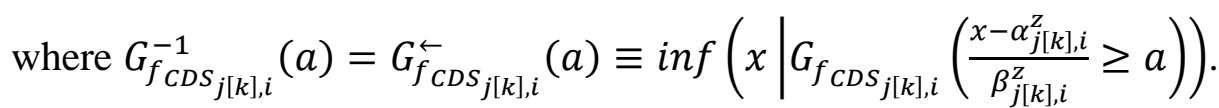

Equation (9) is specified by the general definition of CTE (Artzner and others 1999) as

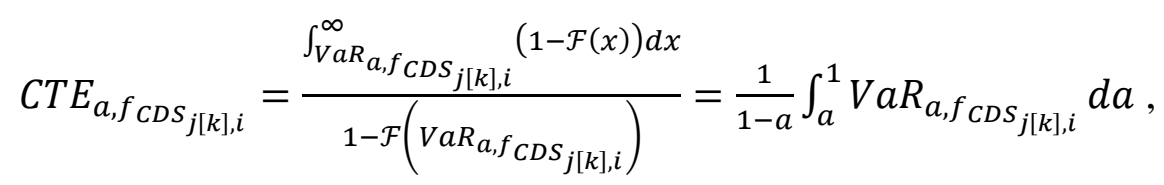

where $\operatorname{VaR}_{a, f_{C D S_{j[k], i}}} \equiv \inf (x \mid \mathcal{F}(x \geq a))$ is the quantile of order $0<a<1$ (say, $a=0.95$ ).

Thus, we can refine the specification of the future price of each outstanding bond of country $j$ (with a common shock to the interest rate term structure at period $i$ ) under both pricing approaches — equations (5) and (6) above—as

$$
\hat{P}(a)_{b_{2}, j[k], i}=\exp \left(-\left(\hat{r}_{f_{j[k], t+\tau}}+\Delta \hat{r}_{f_{j[k], t}}+\frac{C T E_{a, f_{C D} S_{j[k], i}}}{10,000}\right)(T-t-\tau)\right)
$$

and

$$
\hat{P}(a)_{b_{1}, j[k], i}=\prod_{n=1}^{T-t-\tau} \frac{c_{n}}{\left(1+r_{b_{1}, j[k], t}+\widehat{\theta}(a)_{j[k], i}\right)^{n / m}}+\frac{p}{\left(1+r_{b_{1}, j[k], t}+\widehat{\theta}_{j[k], i}\right)^{T-t-\tau}}
$$

where

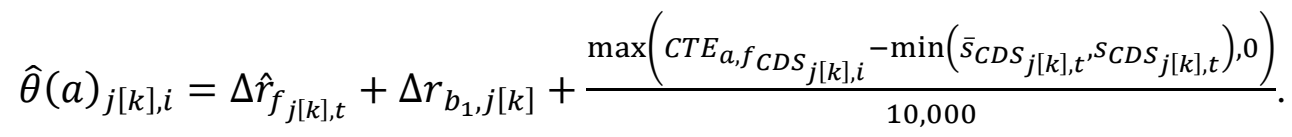

The valuation haircuts are then derived from bond price changes in response to expected changes in idiosyncratic (default) risk and common interest rate shocks. For different scenarios (affecting the severity of haircuts), we distinguish between (i) current market expectations (for the baseline scenario) based the prevailing level of forward sovereign CDS spreads, $f_{C D S_{j[k], i}}$, and (ii) the density forecasts of expected default risk (for the adverse scenarios), $G_{f_{C D}}^{-1}(a)$, based on the 
historical dynamics of forward sovereign CDS spreads, whose empirical distribution has an asymptotic tail behavior consistent with GEV as defined in equation (10) above: ${ }^{67}$

- For the baseline scenario, the spreads observed at the start of the stress test horizon imply the expected change of default risk affecting the future bond price over $i$-periods in the future based on the two different pricing formulas in equations (5) and (6) above.

- For the adverse scenarios, however, haircuts should reflect the volatility of market expectations of default risk; thus, point estimates are derived at high levels of statistical confidence to project the model-based impact of higher spreads during times of stress on bond prices. For instance, we can choose density forecasts at the $75^{\text {th }}$ percentile (for a mild adverse scenario (“adverse 1 ”)) and $90^{\text {th }}$ percentile (for a severe adverse scenario (“adverse 2")) of the quantile function (see equation (10)) as country-specific shocks. ${ }^{68}$ The percentile choice should be consistent with the probabilistic severity of the overall macroeconomic scenario of the stress test; however, the statistical significance of country-specific spread shocks cannot be directly compared to that of changes in the real GDP growth rate (or other, low-frequency macroeconomic variables), which often inform the severity of the macroeconomic scenarios. Given the shorter estimation horizon and higher frequency of CDS data, the percentile level of the density forecast tends to be lower than the one implied by the projected deterioration of macroeconomic conditions over the stress test horizon.

Thus, for each year over the test horizon of $i \in n$ years, we have a vector of three bond prices

$$
\mathbf{P}_{b_{1}, j[k], i}=\left\{P_{b_{1}, j[k], i} ; \hat{P}(a)_{b_{1}, j[k], i_{\text {adverse } 1}} ; \hat{P}(a)_{b_{1}, j[k], i_{\text {adverse } 2}}\right\}
$$

and

$$
\mathbf{P}_{b_{2}, j[k], i}=\left\{P_{b_{2}, j[k], i} ; \hat{P}(a)_{b_{2}, j[k], i_{\text {adverse } 1}} ; \hat{P}(a)_{b_{2}, j[k], i_{\text {adverse } 2}}\right\}
$$

for each pricing method, based on current market expectations and two different density forecasts of default risk at statistical confidence level $a \in\{0.75 ; 0.90\}$.

The corresponding haircuts are calculated for each bond from changes in bond prices in each year $i$ over the test horizon, relative to the base year $t$, using the following specification for the baseline scenario as

\footnotetext{
${ }^{67}$ We obtain confidence intervals, on which basis one can construct an adverse scenario (for example, one standard deviation worse than the baseline, or, preferably, at a very level of statistical significance).

68 The calibration of the country-specific spread shock is based on annualized volatility of (at least monthly) observations. This means that point estimates at a chosen percentile level imply a much higher degree of statistical confidence (and, thus, are more extreme) than growth shocks at the same percentile level (derived from historical distribution of annual growth rates). In practical terms, the country-specific sovereign risk shock at the 75th percentile is likely to be consistent with a decline of real GDP growth of at least twice its standard deviation (or 98th percentile) over a long-term estimation period (which is the statistical confidence underpinning most adverse scenarios in system-wide stress tests (Jobst, Ong, and Schmieder 2013).
} 


$$
\Delta P_{b_{1}, j[k], i}=\left(\frac{P_{b_{1}, j[k], i}}{P_{b_{1}, j[k], t}^{Z C E}}-1\right) \times 100
$$

and

$$
\Delta P_{b_{2}, j[k], i}=\left(\frac{P_{b_{2}, j[k], i}}{P_{b_{2}, j[k], t}}-1\right) \times 100
$$

where $P_{b_{1}, j[k], i}$ and $P_{b_{2}, j[k], i}$ are the bond prices under each pricing method, respectively. ${ }^{69}$ The general haircut $h$ for country $j$ is derived as an issuance size-weighted average of individual projected haircuts applied to a $q$-number of bonds outstanding, ${ }^{70}$ so that

$$
\left\{\begin{array}{l}
h_{b_{1}, j[k], i} \\
h_{b_{2}, j[k], i}
\end{array}\right\}=\max \left(\left\{\begin{array}{c}
\sum_{b=1}^{q} \Delta P_{b_{1}, j[k], i} \\
\sum_{b=1}^{q} \Delta P_{b_{2}, j[k], i}
\end{array}\right\} \times \frac{A m t_{b, j}}{\sum_{b=1}^{q} A m t_{b, j}}, 0\right)
$$

where $\Delta P_{b_{1}, j[k], i}$ and $\Delta P_{b_{2}, j[k], i}$ are the haircuts under each pricing method over test period $i$, and $A m t_{b, j}$ is the outstanding amount of bond $b$ issued by country $j$. As a final step, these haircuts would then be applied to the amount of sovereign bond exposures to countries $j \in J$ held in both the banking and trading books at time $t$. The sovereign bond losses or changes in valuation in each year $t$ over the test horizon are calculated as $\sum_{j}^{J}\left\{\begin{array}{l}h_{b_{1}, j[k], i} \\ h_{b_{2}, j[k], i}\end{array}\right\} \times$ exposure $_{i, j}$, based on a firm's total exposure to country $j$.

\footnotetext{
69 The haircut estimation is not fully accurate because the bond portfolio is assumed to be constant (i.e., without replacement of maturing bonds with newly issued securities). The assumption overstates the actual haircut, unlike in cases when the sample of bonds changes and the remaining maturity is kept constant.

${ }^{70}$ Haircuts are set to zero when bond price rise (e.g., for safe-haven sovereigns).
} 


\section{Figure A2.2. Sovereign Credit Default Swap Spreads, 5-year Maturity Term—Projected and Realized Spreads over Projection Horizon (2011-15) \\ (basis points)}
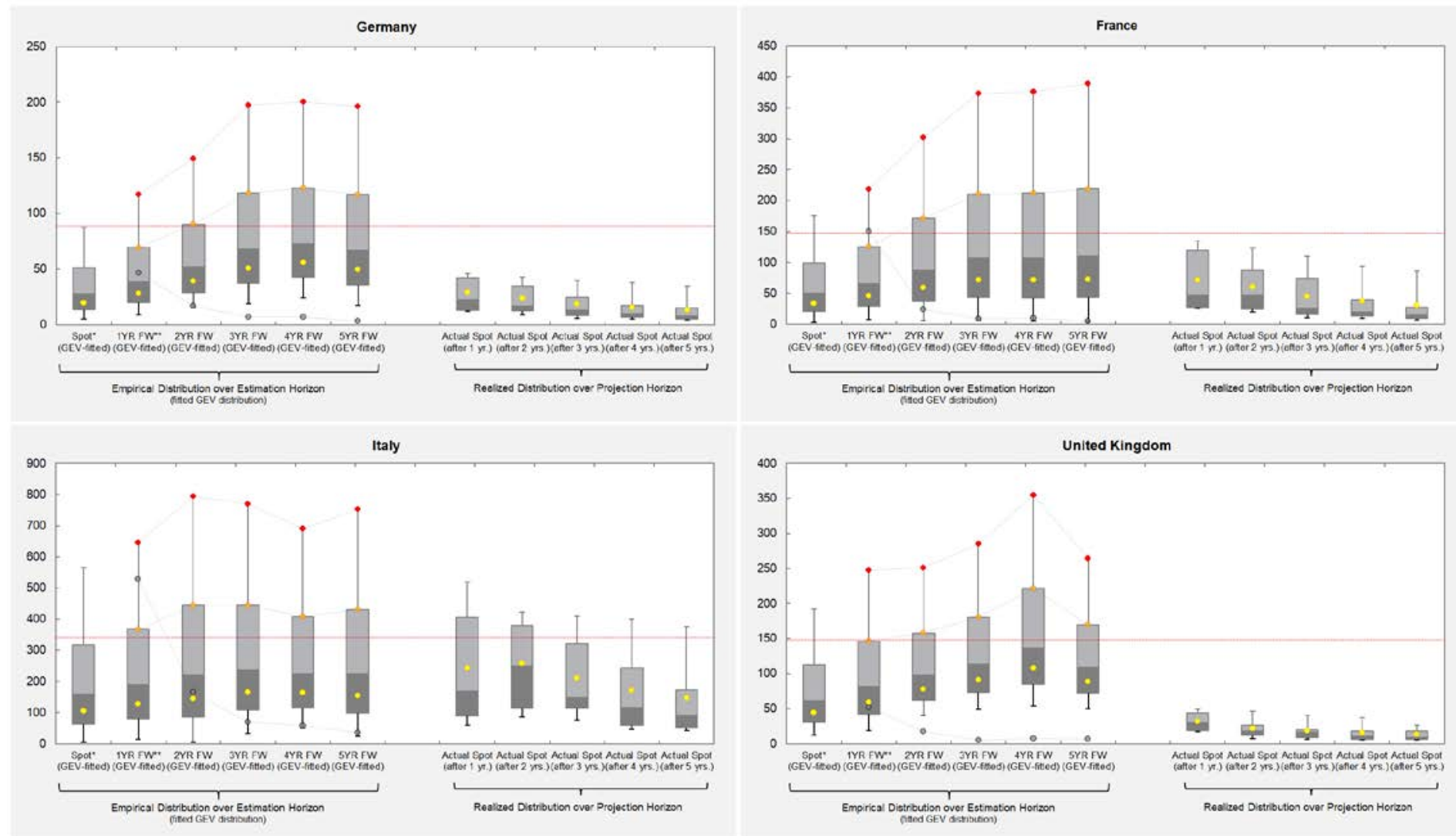

Sources: Bloomberg L.P. and author estimates.

Notes:

*/ historical density estimates based on generalized extreme value (GEV) distribution fitted to observed sovereign CDS spot spreads (with shape parameter = 0.33) according to Appendix II (with shape parameter $=0.33$ ) over the estimation horizon from March 2009 to Dec. 2010;

**/ historical density estimates based on GEV distribution fitted to observed forward sovereign CDS spreads (with starting times between one and five years) according to Appendix I (with shape parameter $=0.33$ ) over the estimation horizon from March 2009 to Dec. 2010.

Boxplots include the mean (yellow dot), the $25^{\text {th }}$ and $75^{\text {th }}$ percentiles (grey box, with the change of shade indicating the median), and the $10^{\text {th }}$ and $90^{\text {th }}$ percentiles (whiskers). The orange/red dots indicate the projected CDS spreads under the adverse scenarios (at the $75^{\text {th }}$ and $90^{\text {th }}$ historical density) while the grey dots show the actual CDS spreads at the end of each year during the projection horizon. The red line indicates the highest observed CDS spread observed during the estimation horizon. 


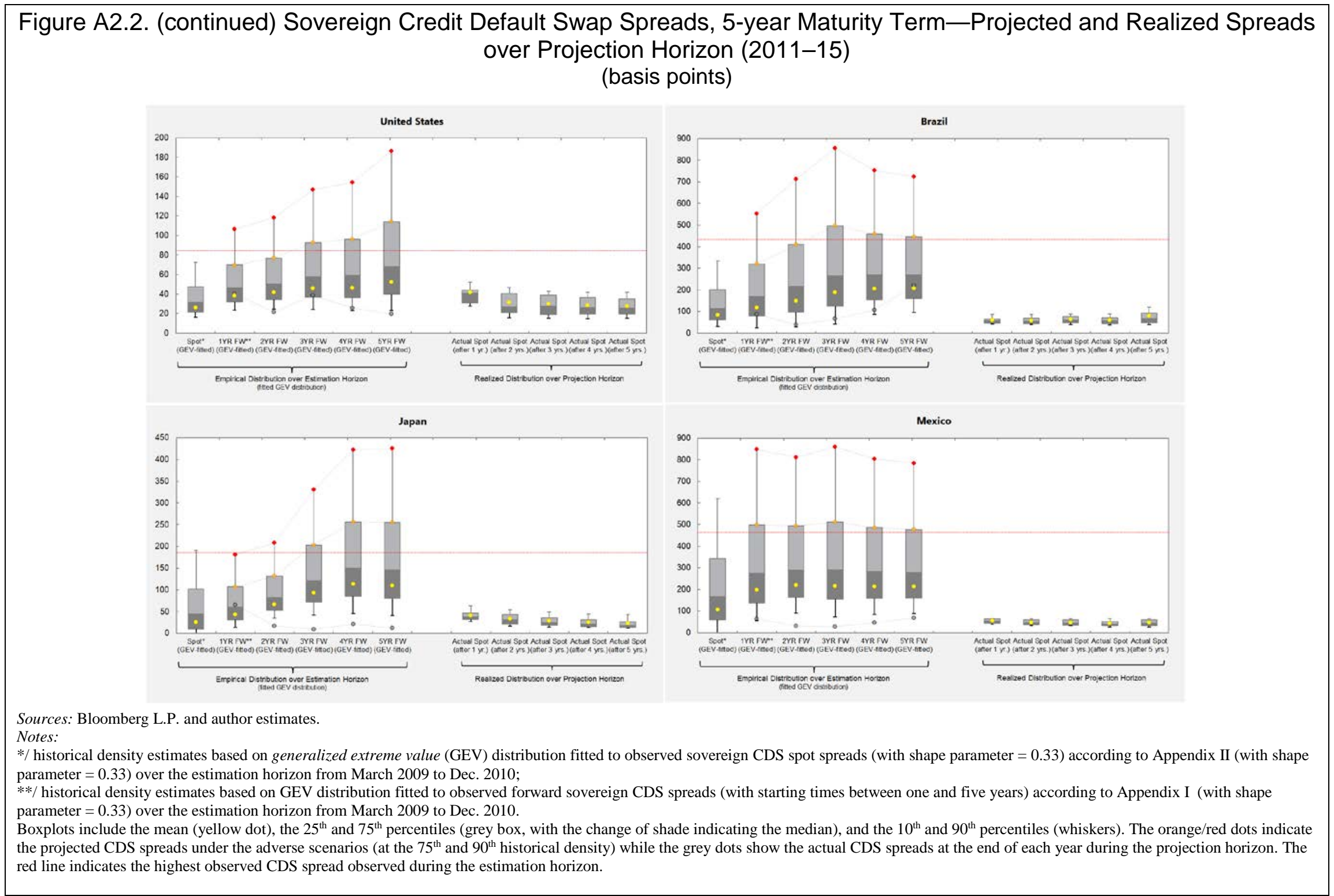




\section{APPENDIX III. MOMENTS OF THE GEV DisTRIBUTION AND ESTIMATION OF THE SHAPE PARAmeter Using the Linear Combination of Ratios of SPACings (LRS) Method}

Since all raw moments of $G(\cdot)$ are defined contingent on the tail shape, the natural estimator of $\hat{\xi}$ is derived by means of the Linear Combination of Ratios of Spacings (LRS) method using the linear combination

$$
\hat{\xi}=\left(\frac{n}{4}\right)^{-1} \sum_{i=1}^{n / 4} \frac{\ln \left(\hat{v}_{i}\right)}{-\ln (c)}
$$

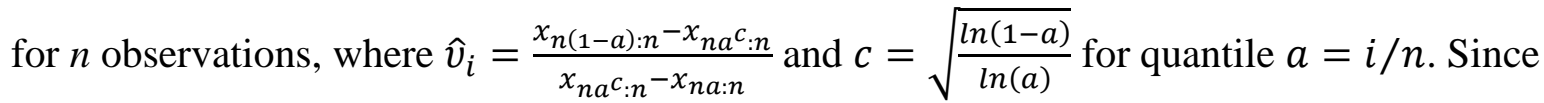
$x_{n a: n}=G^{-1}(a)$, the approximation $\hat{v}_{i} \approx \frac{G^{-1}(1-a)-G^{-1}\left(a^{c}\right)}{G^{-1}\left(a^{c}\right)-G^{-1}(a)}=c^{-1+\hat{\xi}}$ holds. The simple statistics are defined as

$$
\begin{gathered}
\text { mean: }\left\{\begin{array}{cc}
\mu+\frac{\sigma\left(g_{1}-1\right)}{\xi} & \text { if } \xi \neq 0, \xi<1 \\
\mu+\sigma \gamma & \text { if } \xi=0 \\
\infty & \text { if } \xi \geq 1
\end{array},\right. \\
\text { variance: }\left\{\begin{array}{cc}
\sigma^{2} \frac{\left(g_{2}-g_{1}^{2}\right)}{\xi^{2}} & \text { if } \xi \neq 0, \xi<\frac{1}{2} \\
\sigma^{2} \frac{\pi^{2}}{6} & \text { if } \xi=0 \\
\infty & \text { if } \xi \geq \frac{1}{2}
\end{array},\right. \\
\text { skewness: }\left\{\begin{array}{cc}
\frac{g_{3}-3 g_{1} g_{2}-2 g_{1}^{3}}{\left(g_{2}-g_{1}^{2}\right)^{\frac{3}{2}}} & \text { if } 0<\xi<\frac{1}{3} \\
-\frac{g_{3}-3 g_{1} g_{2}-2 g_{1}^{3}}{\left(g_{2}-g_{1}^{2}\right)^{\frac{3}{2}}} & \text { if } \xi<0 \\
\frac{12 \sqrt{6} \zeta(3)}{\pi^{3}} & \text { if } \xi=0 \\
\infty & \text { if } \xi \geq \frac{1}{3}
\end{array},\right. \text { and } \\
\text { kurtosis: }\left\{\begin{array}{c}
\frac{g_{4}-4 g_{1} g_{3}-3 g_{2}^{2}-12 g_{2} g_{1}^{2}-6 g_{1}^{4}}{\left(g_{2}-g_{1}^{2}\right)^{2}} \\
\frac{12}{5}
\end{array} \quad \text { if } \xi \neq 0, \xi<\frac{1}{4}\right. \\
\infty
\end{gathered}
$$

with $g_{p}=\Gamma(1-p \xi)$ for $p \in[1, \ldots, 4]$, Euler's constant $\gamma$ (Sondow 1998) and Riemann zeta function $\zeta(\cdot)$ (Borwein, Bradley, and Crandall 2000) and gamma probability density function $\Gamma(\cdot)$. 


\section{APPENDix IV. CREdit Risk-BASEd APPROACH TO EstimAting EXPECTED LOSSES OF HTM SOVEREIGN EXPOSURES IN THE BANKING BOOK}

Since held-to-maturity (HtM) securities in bank books are recorded at historical cost, changes in their market valuation do not impact net income; however, their expected loss should be covered by provisions based on estimated credit risk parameters, i.e., the probability of default (PD) and the loss-given-default (LGD).

The cross-sectional sensitivity of rating-implied PDs to macroeconomic conditions helps determine changes in sovereign default risk under stress (and the associated coverage rate of provisions). The prevailing credit risk assessment of sovereign issuers by one or more of the leading credit rating agencies (e.g., Moody's, S\&P, or Fitch) can be used to determine the corresponding PD. Mapping tables help convert ratings into PDs over different test horizons. The implied PD obtained this way represents the starting point of sovereign default risk $\left(\mathrm{PD}_{0}\right)$. For instance, based on a panel regression analysis, the elasticity can be estimated as

$$
\gamma=\Delta \operatorname{logit}\left(\mathrm{PD}_{\mathrm{t}}\right) / \Delta d r g d p_{t}
$$

where $\Delta \operatorname{logit}\left(P D_{t}\right)$ is the forecasted change in default risk $\operatorname{logit}\left(P D_{t}\right)-\operatorname{logit}\left(P D_{0}\right)$, with logistic transform (logit), and $d r g d p_{t}$ is the year-on-year growth rate of real GDP. This expression can be rearranged as:

$$
P D_{t}=\left(\frac{P D_{t-1}}{1-P D_{t-1}}\right) \times \exp \left(\gamma \Delta d r g d p_{t}\right) /\left(1+\left(\frac{P D_{t-1}}{1-P D_{t-1}}\right) \times \exp \left(\gamma \Delta d r g d p_{t}\right)\right) .
$$

Hence, based on the above elasticity and the changes in real GDP growth under each scenario, the implied sovereign PD can be calculated. If no historical evidence of technical default is available, the recovery rate, i.e., $1-L G D$, can be extracted from the World Bank's Doing Business Report (World Bank 2016) ${ }^{71}$ and used as a proxy for the loss-given-default (LGD). ${ }^{72}$

\footnotetext{
71 “Doing Business” measures regulations affecting 11 areas of the life of a business. Ten of these areas are included in the 2017 ranking on the ease of doing business: starting a business, dealing with construction permits, getting electricity, registering property, getting credit, protecting minority investors, paying taxes, trading across borders, enforcing contracts, and resolving insolvency.

${ }^{72}$ For a cross-country sample of 117 countries, we applied this approach to a total of 2,120 observations. Panel fixed effects were used for the estimation of $\gamma$. This elasticity $\gamma$ was estimated to be -0.09 .
} 
Appendix V. Detailed Estimation Results: VAluation Haircuts

Table A5.1. Sovereign Valuation Haircuts_Common and Country-specific Interest Rate Shocks (Zero-Coupon Pricing/Discounted Cash Flow Method)

\begin{tabular}{|c|c|c|c|c|c|c|c|c|c|c|c|c|c|c|c|}
\hline \multirow[b]{6}{*}{ Europe } & \multicolumn{15}{|c|}{ Sovereign Debt Valuation Haircut } \\
\hline & \multirow{2}{*}{\multicolumn{5}{|c|}{$\begin{array}{c}\text { Baseline Scenario } \\
\text { Current expectations based on } \\
\text { end-year forward prices }\end{array}$}} & \multicolumn{10}{|c|}{$\begin{array}{c}\text { Adverse Scenario } \\
\text { Forecast based on historical density function }\end{array}$} \\
\hline & & & & & & \multicolumn{5}{|c|}{$75^{\text {th }}$ percentile } & \multicolumn{5}{|c|}{$90^{\text {th }}$ percentile } \\
\hline & 2011 & 2012 & 2013 & 2014 & 2015 & 2011 & 2012 & 2013 & 2014 & 2015 & 2011 & 2012 & 2013 & 2014 & 2015 \\
\hline & \multicolumn{15}{|c|}{ 'IMF-FSAP Approach'-Zero Coupon Pricing Method with Forward CDS Spreads } \\
\hline & & & & & & & & & & & & & & & \\
\hline Austria & 4.3 & 4.5 & 4.3 & 4.0 & 3.9 & 3.5 & 3.9 & 4.0 & 3.9 & 3.6 & 4.5 & 5.0 & 5.1 & 4.9 & 4.7 \\
\hline Belgium & 9.5 & 9.0 & 8.2 & 7.8 & 7.3 & 6.3 & 6.7 & 6.5 & 6.1 & 5.8 & 10.0 & 10.6 & 10.1 & 9.5 & 9.3 \\
\hline Finland & 3.2 & 3.3 & 3.4 & 3.4 & 3.4 & 2.8 & 3.0 & 3.1 & 3.1 & 3.1 & 3.0 & 3.4 & 3.5 & 3.5 & 3.5 \\
\hline France & 5.8 & 5.9 & 5.6 & 5.6 & 5.2 & 4.4 & 4.9 & 4.9 & 4.7 & 4.5 & 6.1 & 6.7 & 6.7 & 6.6 & 6.4 \\
\hline Germany & 4.4 & 4.7 & 4.8 & 4.7 & 4.7 & 3.2 & 3.5 & 3.7 & 3.7 & 3.7 & 3.8 & 4.2 & 4.5 & 4.5 & 4.4 \\
\hline Netherlands & 4.0 & 4.3 & 4.4 & 4.4 & 4.4 & 3.1 & 3.5 & 3.5 & 3.5 & 3.5 & 3.8 & 4.2 & 4.2 & 4.2 & 4.3 \\
\hline Greece & 5.9 & 8.5 & 12.2 & 12.2 & 20.7 & 13.9 & 8.4 & 7.2 & 9.1 & 10.1 & 28.7 & 21.7 & 20.4 & 22.9 & 24.1 \\
\hline Italy & 7.7 & 7.2 & 6.8 & 6.6 & 6.5 & 6.2 & 6.6 & 6.4 & 6.1 & 5.8 & 10.1 & 10.7 & 10.3 & 9.9 & 9.4 \\
\hline Ireland & 14.3 & 10.9 & 9.7 & 10.0 & 10.0 & 13.3 & 12.1 & 10.9 & 10.7 & 10.6 & 24.4 & 22.5 & 20.7 & 20.4 & 20.2 \\
\hline Portugal & 12.5 & 9.9 & 8.1 & 6.8 & 5.7 & 10.6 & 9.8 & 8.4 & 7.5 & 7.5 & 19.4 & 18.1 & 15.9 & 14.7 & 14.5 \\
\hline Spain & 11.1 & 10.5 & 9.9 & 9.2 & 8.9 & 8.0 & 7.6 & 7.3 & 7.2 & 7.0 & 13.6 & 12.9 & 12.6 & 12.6 & 12.2 \\
\hline Czech Republic & 3.2 & 3.4 & 3.5 & 3.5 & 3.7 & 3.6 & 4.0 & 4.3 & 4.4 & 4.4 & 4.5 & 4.9 & 5.3 & 5.4 & 5.5 \\
\hline Denmark & 3.6 & 3.8 & 3.9 & 3.9 & 3.9 & 3.0 & 3.3 & 3.4 & 3.4 & 3.4 & 3.4 & 3.6 & 3.8 & 3.9 & 4.1 \\
\hline Poland & 4.7 & 5.2 & 5.5 & 5.7 & 5.8 & 4.8 & 5.3 & 5.6 & 6.0 & 6.0 & 6.5 & 7.0 & 7.4 & 7.9 & 8.1 \\
\hline Sweden & 3.4 & 3.6 & 3.6 & 3.6 & 3.7 & 3.2 & 3.5 & 3.6 & 3.6 & 3.6 & 3.8 & 4.1 & 4.3 & 4.3 & 4.2 \\
\hline United Kingdom & 3.4 & 3.6 & 3.6 & 3.5 & 3.4 & 3.6 & 4.1 & 4.2 & 4.0 & 3.6 & 4.6 & 5.1 & 5.1 & 4.8 & 4.2 \\
\hline \multicolumn{16}{|l|}{ Other Countries } \\
\hline Brazil & 3.7 & 4.5 & 5.1 & 5.6 & 5.8 & 4.4 & 5.3 & 5.9 & 6.3 & 6.4 & 5.6 & 6.5 & 7.1 & 7.4 & 7.4 \\
\hline Japan & 4.6 & 5.4 & 6.0 & 6.2 & 6.3 & 4.6 & 5.6 & 6.4 & 6.8 & 7.0 & 5.9 & 7.2 & 8.2 & 8.8 & 9.2 \\
\hline Mexico & 3.6 & 4.4 & 4.8 & 5.0 & 5.2 & 4.3 & 5.0 & 5.6 & 5.8 & 5.7 & 5.5 & 6.2 & 6.7 & 6.8 & 6.7 \\
\hline \multirow[t]{2}{*}{ United States } & 3.4 & 3.6 & 3.7 & 3.8 & 3.7 & 3.1 & 3.5 & 3.6 & 3.7 & 3.7 & 3.5 & 4.0 & 4.2 & 4.3 & 4.5 \\
\hline & \multicolumn{15}{|c|}{ Adapted 'EBA Approach'-Discounted Cash Flow Method with Forward CDS Spreads } \\
\hline Europe & & & & & & & & & & & & & & & \\
\hline Austria & 3.9 & 4.1 & 4.0 & 3.7 & 3.5 & 3.6 & 3.7 & 3.5 & 3.3 & 3.6 & 4.5 & 4.6 & 4.5 & 4.3 & 4.7 \\
\hline Belgium & 8.5 & 8.0 & 7.4 & 7.0 & 6.6 & 6.1 & 5.8 & 5.4 & 5.2 & 5.8 & 9.5 & 9.1 & 8.5 & 8.3 & 9.3 \\
\hline Finland & 2.9 & 3.0 & 3.1 & 3.1 & 3.1 & 2.7 & 2.8 & 2.8 & 2.8 & 3.1 & 3.1 & 3.2 & 3.2 & 3.2 & 3.5 \\
\hline France & 5.4 & 5.4 & 5.1 & 5.2 & 4.8 & 4.5 & 4.5 & 4.3 & 4.1 & 4.5 & 6.2 & 6.2 & 6.0 & 5.8 & 6.4 \\
\hline Germany & 4.0 & 4.3 & 4.3 & 4.3 & 4.2 & 3.2 & 3.4 & 3.4 & 3.4 & 3.7 & 3.8 & 4.1 & 4.1 & 4.0 & 4.4 \\
\hline Netherlands & 3.7 & 3.9 & 4.0 & 4.0 & 4.1 & 3.2 & 3.2 & 3.2 & 3.2 & 3.5 & 3.8 & 3.9 & 3.9 & 3.9 & 4.3 \\
\hline Greece & 4.7 & 6.7 & 9.7 & 9.6 & 16.3 & 6.6 & 5.7 & 7.2 & 8.0 & 10.1 & 17.1 & 16.2 & 18.1 & 19.1 & 24.1 \\
\hline Italy & 7.0 & 6.6 & 6.2 & 6.0 & 5.9 & 6.0 & 5.8 & 5.5 & 5.3 & 5.8 & 9.7 & 9.4 & 8.9 & 8.5 & 9.4 \\
\hline Ireland & 11.8 & 9.0 & 8.0 & 8.3 & 8.3 & 10.0 & 9.0 & 8.8 & 8.7 & 10.6 & 18.6 & 17.0 & 16.8 & 16.7 & 20.2 \\
\hline Portugal & 10.9 & 8.7 & 7.1 & 6.0 & 5.0 & 8.6 & 7.3 & 6.6 & 6.5 & 7.5 & 15.8 & 13.9 & 12.8 & 12.7 & 14.5 \\
\hline Spain & 9.8 & 9.3 & 8.7 & 8.1 & 7.8 & 6.7 & 6.5 & 6.4 & 6.2 & 7.0 & 11.4 & 11.1 & 11.1 & 10.7 & 12.2 \\
\hline Czech Republic & 2.8 & 3.0 & 3.1 & 3.1 & 3.2 & 3.5 & 3.8 & 3.8 & 3.9 & 4.4 & 4.4 & 4.6 & 4.7 & 4.8 & 5.5 \\
\hline Denmark & 3.3 & 3.4 & 3.5 & 3.5 & 3.5 & 2.9 & 3.0 & 3.1 & 3.1 & 3.4 & 3.3 & 3.4 & 3.5 & 3.7 & 4.1 \\
\hline Poland & 4.0 & 4.4 & 4.6 & 4.8 & 4.9 & 4.5 & 4.8 & 5.0 & 5.1 & 6.0 & 5.9 & 6.2 & 6.7 & 6.8 & 8.1 \\
\hline Sweden & 3.0 & 3.2 & 3.2 & 3.3 & 3.3 & 3.1 & 3.2 & 3.2 & 3.2 & 3.6 & 3.7 & 3.8 & 3.8 & 3.7 & 4.2 \\
\hline United Kingdom & 3.1 & 3.3 & 3.3 & 3.2 & 3.1 & 3.7 & 3.8 & 3.6 & 3.3 & 3.6 & 4.6 & 4.6 & 4.3 & 3.8 & 4.2 \\
\hline \multicolumn{16}{|l|}{ Other Countries } \\
\hline Brazil & 2.8 & 3.4 & 3.9 & 4.2 & 4.3 & 4.0 & 4.5 & 4.7 & 4.8 & 6.4 & 4.9 & 5.3 & 5.6 & 5.5 & 7.4 \\
\hline Japan & 4.4 & 5.2 & 5.7 & 5.9 & 6.0 & 5.4 & 6.1 & 6.5 & 6.7 & 7.0 & 6.9 & 7.8 & 8.5 & 8.8 & 9.2 \\
\hline Mexico & 3.0 & 3.6 & 3.9 & 4.1 & 4.2 & 4.1 & 4.6 & 4.7 & 4.7 & 5.7 & 5.0 & 5.5 & 5.5 & 5.5 & 6.7 \\
\hline United States & 3.1 & 3.3 & 3.4 & 3.5 & 3.4 & 3.2 & 3.3 & 3.4 & 3.4 & 3.7 & 3.7 & 3.9 & 4.0 & 4.1 & 4.5 \\
\hline
\end{tabular}

Sources: Bloomberg L.P. and authors' calculations.

Notes: The valuation haircuts show the expected cumulative weighted-average price decline of selected benchmark government bonds over a five-year test horizon (2011-15) relative to the observed market price on December 31, 2010, based on a common interest rate shock of 50 basis points and a proportionate country-specific credit spread shock according to the zero-coupon pricing formula ("IMF FSAP") and the discounted cash flow pricing formula used in the EU system-wide stress testing exercises ("EBA Approach") as specified in Appendix II. The countryspecific credit spread shock is derived from the historical changes of forward contracts on five-year sovereign credit default swaps (CDS) until end-2010 (i.e., cut-off date). The baseline is based on "current expectations" using the larger of the (i) last observed spot (forward) spread and (i) the average spot (forward) spread over the 12 months prior to the cut-off date. The two adverse scenarios reflect the density distribution (based on GEV-fitted asymptotic tail behavior) of historical spread dynamics at the $75^{\text {th }}$ and $90^{\text {th }}$ percentiles, respectively. The haircuts for European countries under the "IMF Approach" in 2011 [black box] correspond the values for the baseline and adverse scenarios in Table 5. The heavy discounting of bonds issued by vulnerable euro area economies during 2011 implies little (if any) additional haircuts based on market prices beyond the initial test period. 


\section{Table A5.2. Sovereign Valuation Haircuts — Country-specific Interest Rate Shock Only (Zero-Coupon Pricing /Discounted Cash Flow Method)}

\begin{tabular}{|c|c|c|c|c|c|c|c|c|c|c|c|c|c|c|c|}
\hline \multirow[b]{5}{*}{ Europe } & \multicolumn{15}{|c|}{ Sovereign Debt Valuation Haircut } \\
\hline & \multirow{2}{*}{\multicolumn{5}{|c|}{$\begin{array}{l}\text { Baseline Scenario } \\
\text { Current expectations based on } \\
\text { end-year forward prices }\end{array}$}} & \multicolumn{10}{|c|}{ Forecast bas } \\
\hline & & & & & & \multicolumn{5}{|c|}{$75^{\text {th }}$ percentile } & \multicolumn{5}{|c|}{$90^{\text {th }}$ percentile } \\
\hline & \multicolumn{15}{|c|}{ 'IMF-FSAP Approach'-Zero Coupon Pricing Method with Forward CDS Spreads } \\
\hline & & & & & & & & & & & & & & & \\
\hline Austria & 2.1 & 2.2 & 2.1 & 1.8 & 1.6 & 1.3 & 1.7 & 1.8 & 1.6 & 1.4 & 2.2 & 2.7 & 2.9 & 2.7 & 2.5 \\
\hline Belgium & 7.2 & 6.6 & 5.9 & 5.4 & 5.0 & 3.9 & 4.4 & 4.1 & 3.7 & 3.4 & 7.8 & 8.3 & 7.8 & 7.2 & 7.0 \\
\hline Finland & 0.9 & 1.1 & 1.2 & 1.2 & 1.2 & 0.5 & 0.8 & 0.9 & 0.9 & 0.9 & 0.8 & 1.2 & 1.3 & 1.3 & 1.3 \\
\hline France & 3.5 & 3.5 & 3.2 & 3.2 & 2.8 & 2.0 & 2.4 & 2.5 & 2.3 & 2.1 & 3.7 & 4.4 & 4.4 & 4.2 & 4.0 \\
\hline Germany & 2.1 & 2.4 & 2.4 & 2.3 & 2.3 & 0.8 & 1.2 & 1.4 & 1.4 & 1.3 & 1.4 & 1.9 & 2.1 & 2.1 & 2.0 \\
\hline Netherlands & 1.8 & 2.1 & 2.2 & 2.2 & 2.2 & 0.9 & 1.2 & 1.3 & 1.2 & 1.2 & 1.5 & 2.0 & 2.0 & 2.0 & 2.0 \\
\hline Greece & 3.7 & 6.4 & 10.2 & 10.1 & 18.8 & 11.9 & 6.2 & 5.1 & 7.0 & 8.0 & 27.0 & 19.8 & 18.6 & 21.1 & 22.3 \\
\hline Italy & 5.5 & 5.0 & 4.6 & 4.4 & 4.2 & 4.0 & 4.4 & 4.2 & 3.9 & 3.6 & 8.0 & 8.6 & 8.2 & 7.7 & 7.3 \\
\hline Ireland & 12.0 & 8.5 & 7.3 & 7.6 & 7.6 & 10.9 & 9.7 & 8.5 & 8.3 & 8.2 & 22.4 & 20.5 & 18.5 & 18.3 & 18.1 \\
\hline Portugal & 10.4 & 7.7 & 5.8 & 4.6 & 3.4 & 8.4 & 7.6 & 6.1 & 5.3 & 5.2 & 17.5 & 16.1 & 13.9 & 12.6 & 12.4 \\
\hline Spain & 8.7 & 8.2 & 7.5 & 6.8 & 6.5 & 5.5 & 5.1 & 4.9 & 4.8 & 4.5 & 11.3 & 10.6 & 10.3 & 10.2 & 9.8 \\
\hline Czech Republic & 0.8 & 1.0 & 1.1 & 1.2 & 1.3 & 1.3 & 1.7 & 1.9 & 2.0 & 2.1 & 2.2 & 2.6 & 2.9 & 3.0 & 3.1 \\
\hline Denmark & 1.2 & 1.4 & 1.5 & 1.5 & 1.5 & 0.6 & 0.8 & 0.9 & 1.0 & 1.0 & 1.0 & 1.2 & 1.4 & 1.5 & 1.7 \\
\hline Poland & 2.3 & 2.7 & 3.0 & 3.2 & 3.3 & 2.3 & 2.9 & 3.2 & 3.5 & 3.6 & 4.0 & 4.6 & 5.0 & 5.6 & 5.7 \\
\hline Sweden & 1.1 & 1.3 & 1.4 & 1.4 & 1.4 & 0.9 & 1.2 & 1.3 & 1.3 & 1.3 & 1.6 & 1.9 & 2.0 & 2.0 & 1.9 \\
\hline United Kingdom & 1.0 & 1.2 & 1.2 & 1.1 & 1.0 & 1.2 & 1.7 & 1.8 & 1.6 & 1.2 & 2.2 & 2.7 & 2.7 & 2.4 & 1.9 \\
\hline \multicolumn{16}{|l|}{ Other Countries } \\
\hline Brazil & 1.2 & 2.0 & 2.7 & 3.1 & 3.4 & 2.0 & 2.9 & 3.5 & 3.9 & 4.0 & 3.2 & 4.1 & 4.7 & 5.0 & 5.0 \\
\hline Japan & 2.2 & 3.0 & 3.6 & 3.8 & 3.9 & 2.1 & 3.2 & 4.0 & 4.5 & 4.6 & 3.5 & 4.8 & 5.8 & 6.5 & 6.9 \\
\hline Mexico & 1.2 & 1.9 & 2.4 & 2.6 & 2.8 & 1.9 & 2.6 & 3.2 & 3.4 & 3.4 & 3.1 & 3.8 & 4.3 & 4.4 & 4.4 \\
\hline \multirow[t]{2}{*}{ United States } & 0.9 & 1.2 & 1.3 & 1.3 & 1.3 & 0.6 & 1.0 & 1.1 & 1.2 & 1.3 & 1.1 & 1.6 & 1.8 & 1.9 & 2.0 \\
\hline & \multicolumn{15}{|c|}{ Adapted 'EBA Approach'-Discounted Cash Flow Method with Forward CDS Spreads } \\
\hline Europe & & & & & & & & & & & & & & & \\
\hline Austria & 1.9 & 2.1 & 1.9 & 1.7 & 1.5 & 1.2 & 1.5 & 1.6 & 1.5 & 1.3 & 2.1 & 2.5 & 2.6 & 2.5 & 2.3 \\
\hline Belgium & 6.4 & 6.0 & 5.3 & 4.9 & 4.5 & 3.5 & 3.9 & 3.7 & 3.3 & 3.1 & 7.0 & 7.5 & 7.0 & 6.5 & 6.3 \\
\hline Finland & 0.8 & 1.0 & 1.1 & 1.1 & 1.1 & 0.5 & 0.7 & 0.8 & 0.8 & 0.8 & 0.7 & 1.1 & 1.1 & 1.2 & 1.2 \\
\hline France & 3.2 & 3.2 & 2.9 & 3.0 & 2.6 & 1.8 & 2.2 & 2.3 & 2.1 & 1.9 & 3.4 & 4.0 & 4.0 & 3.8 & 3.7 \\
\hline Germany & 1.9 & 2.2 & 2.2 & 2.1 & 2.1 & 0.7 & 1.1 & 1.2 & 1.3 & 1.2 & 1.3 & 1.7 & 1.9 & 1.9 & 1.8 \\
\hline Netherlands & 1.7 & 1.9 & 2.0 & 2.0 & 2.0 & 0.8 & 1.1 & 1.2 & 1.1 & 1.1 & 1.4 & 1.8 & 1.9 & 1.8 & 1.9 \\
\hline Greece & 2.9 & 5.1 & 8.1 & 8.0 & 14.9 & 9.4 & 4.9 & 4.0 & 5.5 & 6.3 & 21.4 & 15.7 & 14.7 & 16.7 & 17.7 \\
\hline Italy & 5.0 & 4.6 & 4.1 & 4.0 & 3.8 & 3.6 & 4.0 & 3.8 & 3.5 & 3.2 & 7.2 & 7.7 & 7.4 & 7.0 & 6.6 \\
\hline Ireland & 9.9 & 7.0 & 6.0 & 6.2 & 6.3 & 9.0 & 8.0 & 7.0 & 6.8 & 6.7 & 18.4 & 16.9 & 15.3 & 15.1 & 14.9 \\
\hline Portugal & 9.1 & 6.8 & 5.1 & 4.0 & 3.0 & 7.4 & 6.6 & 5.4 & 4.6 & 4.6 & 15.2 & 14.0 & 12.1 & 11.0 & 10.9 \\
\hline Spain & 7.7 & 7.2 & 6.6 & 6.0 & 5.7 & 4.9 & 4.5 & 4.3 & 4.2 & 4.0 & 10.0 & 9.3 & 9.0 & 9.0 & 8.7 \\
\hline Czech Republic & 0.7 & 0.9 & 1.0 & 1.0 & 1.1 & 1.1 & 1.5 & 1.7 & 1.8 & 1.8 & 1.9 & 2.3 & 2.6 & 2.7 & 2.7 \\
\hline Denmark & 1.1 & 1.3 & 1.3 & 1.4 & 1.4 & 0.6 & 0.8 & 0.9 & 0.9 & 0.9 & 0.9 & 1.1 & 1.2 & 1.3 & 1.5 \\
\hline Poland & 1.9 & 2.3 & 2.6 & 2.7 & 2.8 & 2.0 & 2.4 & 2.7 & 3.0 & 3.0 & 3.4 & 3.9 & 4.2 & 4.7 & 4.8 \\
\hline Sweden & 1.0 & 1.1 & 1.2 & 1.2 & 1.3 & 0.8 & 1.1 & 1.2 & 1.2 & 1.2 & 1.4 & 1.7 & 1.8 & 1.8 & 1.7 \\
\hline United Kingdom & 0.9 & 1.1 & 1.1 & 1.0 & 0.9 & 1.1 & 1.5 & 1.6 & 1.5 & 1.1 & 2.0 & 2.5 & 2.5 & 2.2 & 1.7 \\
\hline \multicolumn{16}{|l|}{ Other Countries } \\
\hline Brazil & 0.9 & 1.5 & 2.0 & 2.4 & 2.5 & 1.5 & 2.1 & 2.6 & 2.9 & 3.0 & 2.4 & 3.1 & 3.5 & 3.8 & 3.8 \\
\hline Japan & 2.1 & 2.9 & 3.4 & 3.6 & 3.7 & 2.0 & 3.1 & 3.8 & 4.3 & 4.4 & 3.3 & 4.6 & 5.5 & 6.2 & 6.6 \\
\hline Mexico & 1.0 & 1.6 & 2.0 & 2.2 & 2.3 & 1.5 & 2.2 & 2.6 & 2.8 & 2.7 & 2.5 & 3.1 & 3.5 & 3.6 & 3.6 \\
\hline United States & 0.9 & 1.1 & 1.2 & 1.2 & 1.2 & 0.6 & 0.9 & 1.1 & 1.1 & 1.2 & 1.0 & 1.5 & 1.7 & 1.7 & 1.9 \\
\hline
\end{tabular}

Sources: Bloomberg L.P. and authors’ calculations.

Note: The valuation haircuts show the expected cumulative weighted-average price decline of selected benchmark government bonds over a fiveyear test horizon (2011-15) relative to the observed market price on December 31, 2010, based on a proportionate country-specific credit spread shock according to the zero-coupon pricing formula ("IMF FSAP") and the discounted cash flow pricing formula used in the EU system-wide stress testing exercises ("EBA Approach") as specified in Appendix II. The country-specific credit spread shock is derived from the historical changes of forward contracts on five-year sovereign credit default swaps (CDS) until end-2010 (i.e., cut-off date). The baseline is based on "current expectations" using the larger of the (i) last observed spot (forward) spread and (i) the average spot (forward) spread over the 12 months prior to the cut-off date. The two adverse scenarios reflect the density distribution (based on GEV-fitted asymptotic tail behavior) of historical spread dynamics at the $75^{\text {th }}$ and $90^{\text {th }}$ percentiles, respectively. The haircuts for European countries under the 'IMF Approach” in 2011 [black box] correspond the values for the baseline and adverse scenarios in Table 5. The heavy discounting of bonds issued by vulnerable euro area economies during 2011 implies little (if any) additional haircuts based on market prices beyond the initial test period. 


\section{APPENDiX VI. CAUSES FOR High SOVEREIGN EXPOSURES IN THE BANKING SECTOR}

Various factors could encourage banks to hold sovereign exposures that strengthen sovereignbank linkages (Dell'Ariccia and others 2018). The factors include: (i) the regulatory incentive hypothesis, (ii) the risk-taking hypothesis, and (iii) the financial repression and deficit absorption hypotheses.

- Regulatory incentive hypothesis - Current banking regulations favor investment in "home sovereigns," which intensifies bank-sovereign linkages within countries. Sovereign exposures are treated as safe assets, which encourages banks to hold more sovereign securities. Sovereign exposures often receive low risk weights—zero percent for local currency-denominated debt, ${ }^{73}$ which results in low capital coverage for unexpected losses. Sovereign exposures are also exempted from large exposure limits. ${ }^{74}$ Overall, the accounting-based valuation of banks is not fully sensitive to changes in market prices, because they reflect a diverse mix of market and book values of different types of bank sovereign exposures. This approach aims to avoid excessive balance sheet volatility and procyclicality of regulatory capital ratios due to full mark-to-market (MtM) valuation. ${ }^{75}$

- Risk-taking (or “carry trade”) hypothesis —-Banks may hold an excessive amount of "riskier" sovereign securities with higher yields to enhance profits. Doing so becomes more attractive when returns from loans and alternative assets are low ${ }^{76}$ and when short-term rates (the cost of carrying) are low. ${ }^{77}$ Moreover, banks may take an excessive carry trade risk when their capitalization is already low, and risk-shifting incentives encouraging "gambling for resurrection" (due to limited liability) are strong (Ari 2017). The expectation of bailout or forbearance in the event of a sovereign default could also encourage excessive carry trades.

\footnotetext{
${ }^{73}$ Usually, sovereign exposures that are either denominated in foreign currency or issued by a foreign entity that does not have the highest rating (“AAA”) receive non-zero risk weights. For IRB banks, the risk weights may not be zero depending on their internal ratings of sovereigns. However, the IRB approach is more prevalent in advanced economies where internal ratings tend generate very low capital charges.

${ }^{74}$ Furthermore, in the euro area, the preferential treatment extends to all euro-denominated sovereign securities issued by the EU Member States (compliant with the Basel framework).

${ }^{75}$ Moreover, the liquidity coverage ratio under the Basel framework requires banks to hold sufficient high-quality liquid assets (HQLA) against potential cash-flow shortfalls. Sovereign securities are considered safer and more liquid assets than private sector assets. See Grandia et al. (2019) for a current assessment of the availability of HQLA in the euro area.

76 The European Systemic Risk Board (2015) found evidence that some euro area banks in stressed countries increased their sovereign exposures when domestic macroeconomic conditions deteriorated.

77 This applies to banks that have a stable and low-cost deposit base or access to cheap central bank liquidity during times of monetary accommodation.
} 
- "Financial repression" and deficit absorption hypothesis ${ }^{78}$ _Banks may also hold sovereign debt due to cyclical reasons (deficit absorption) and public policies. In downturns, banks often act as ready buyers of sovereign debt as lending opportunities and private sector asset returns diminish. During times of stress, banks' capacity to take the role as “contrarian investors” can contribute to realigning market prices of sovereign exposures with fundamentals (especially if market disruptions are excessive or arbitrage opportunities are expensive or not available). From a structural perspective, classic financial repression refers to government policies that pressure banks to hold more government debt to secure fiscal deficit financing. Such measures are often observed in some EMDEs with fiscal, institutional, and governance challenges. ${ }^{79}$ Altavilla and others (2017) also find that public, bailed-out and poorly capitalized European banks responded to sovereign stress by purchasing domestic public debt more than other banks because of moral suasion. ${ }^{80}$

\footnotetext{
${ }^{78}$ De Marco and Macchiavelli (2016) discuss how the political economy has influenced the scope of government debt exposures in Europe.

${ }^{79}$ In some economies (e.g., India), regulations require banks to hold a minimum amount of sovereign securities, which creates captive demand for public debt. Directed lending — often to SOEs_-is another instrument. The government may also exercise moral suasion to amplify financial repression.

${ }^{80}$ More specifically, their empirical analysis of determinants of banks' sovereign exposures between 2007 and 2015 revealed that public banks’ purchases of sovereign debt significantly amplified the impact of sovereign stress on their domestic lending (and lending by their foreign subsidiaries in non-stressed countries).
} 